\title{
FINANCIAL FRICTIONS AND DURABLE GOODS IN DSGE MODELS WITH STICKY PRICES
}

\author{
by \\ Ugochi Emenogu \\ M.Sc. Applied Mathematics \\ Ryerson University, Toronto, Ontario, Canada, 2012 \\ A dissertation \\ presented to Ryerson University \\ in partial fulfilment of the \\ requirements for the degree of \\ Doctor of Philosophy \\ in the Program of \\ Economics
}

Toronto, Ontario, Canada, 2018

(C) Ugochi Emenogu, 2018 


\section{DECLARATION}

I hereby declare that I am the sole author of this dissertation. This is a true copy of the dissertation, including any required final revisions, as accepted by my examiners.

I authorize Ryerson University to lend this dissertation to other institutions or individuals for the purpose of scholarly research.

I further authorize Ryerson University to reproduce this dissertation by photocopying or by other means, in total or in part, at the request of other institutions or individuals for the purpose of scholarly research.

I understand that my dissertation may be made electronically available to the public. 


\title{
Financial frictions and durable goods in DSGE models with sticky prices Doctor of Philosophy, 2018 Ugochi Emenogu Economics Ryerson University
}

\begin{abstract}
The focus of this dissertation is to study the role of financial frictions in DSGE models with durable goods and sticky prices, and how key economic variables respond in such an environment to monetary policy shocks. The first chapter studies the empirical evidence regarding the response of durable and non-durable goods to monetary policy shocks. Using quarterly data from Canada and the United States, and a vector autoregressive (VAR) model, we trace out empirically the effects of monetary policy innovations on key macroeconomic variables. We find that in response to an increase in the interest rate, durable consumption, non-durable consumption, output, and household debt decrease, and the nominal interest rate rises. In the second chapter, we show that in the presence of agency costs and equity based borrowing, the twosector sticky price model with collateral frictions resolve the co-movement problem in a way which is consistent with the empirical evidence, even when durable prices are nearly flexible. In the third chapter, we examine the effect of financial frictions on the consumption of durables and non-durables in a two-sector DSGE model with sticky prices and heterogeneous agents. The financial frictions are a combination of loan-to-value (LTV) and payment-to-income (PTI) constraints faced by borrowers. In this setting a monetary contraction reduces the maximum amount that consumers can borrow in order to purchase durable goods. As a result, the model predicts that the consumption of durables falls, along with non-durables even when durable prices are fully flexible. Thus, the model matches better the predictions of the model with
\end{abstract}


the data, relative to the existing literature. The fourth chapter of the dissertation studies the effectiveness of macro-prudential policy measures in curbing house price inflation amid rising outward foreign direct investment from abroad. To assess the usefulness of these macro-prudential policy tools, we use database of housing prices, GDP, bank crises, policy rates, Chinese outward investment and macro-prudential policy measures covering advanced countries at quarterly frequency from 2003 to 2016. The results suggest that Macro-prudential policy measures help in reducing house prices and OFDI has a significant and positive correlation with house prices movements. 


\section{ACKNOWLEDGMENTS}

I owe an incredible debt to my supervisor, Prof. Leo Michelis, for his guidance and persistent support. His contributions, suggestions and constructive comments made completion of this project possible.

My special thanks also go to my committee members, Dr. Constantine Angyridis and Dr. Debapriya Sen, for their support, and to Dr. Kim Min Seong who provided useful feedback on the empirical component of this thesis. I was lucky to interact with an amazing group of faculty and Ph.D students at Ryerson and I am thankful to them for all the support and unique intellectual experience.

I would like to express my heartfelt gratitude to my family. None of this would have been possible without my husband, Peter, and children, Akachukwu, Ozioma and Uzonna, who made a lot of sacrifice, endured my long working hours and exercised a lot of patience through out my doctoral studies. I am also thankful to my brothers and sisters for their unwavering support throughout these years.

I acknowledge the financial support I received from Ryerson University and Ontario government through Ryerson graduate scholarship, Ontario graduate scholarship and Ontario graduate fellowship. 


\section{DEDICATION}

I dedicate this dissertation to the memories of my late parents, Justina and Hyacinth

Emenogu, who believed so much in me and would have supported me throughout this academic journey. 


\section{Table of Contents}

Abstract $\ldots \ldots \ldots \ldots \ldots \ldots \ldots \ldots \ldots \ldots \ldots \ldots \ldots \ldots$ ii

List of Tables ....................... . . xi

List of Figures $\ldots \ldots \ldots \ldots \ldots \ldots \ldots \ldots \ldots \ldots \ldots \ldots \ldots \ldots \ldots$

List of Appendices . . . . . . . . . . . . . . . xiv

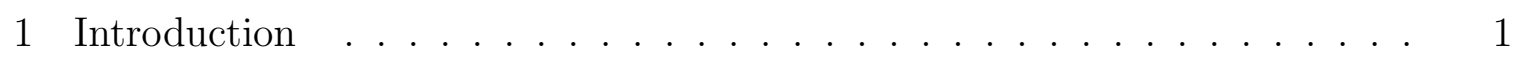

2 Empirical Evidence $\ldots \ldots \ldots \ldots \ldots$

2.1 Introduction . . . . . . . . . . . . . . . 6

2.2 Literature Review . . . . . . . . . . . . . . . 6

2.2.1 Empirical Method: Vector Auto-regression . . . . . . . . 7

2.2.2 Recursive Assumption in Identifying Monetary Policy Shocks . 8

3 Agency Costs, Consumption Loans and the Co-movement between Durable and Nondurable Consumption $\ldots \ldots \ldots \ldots$

3.1 Introduction . . . . . . . . . . . . . . . . . . . 12

3.2 Related Literature . . . . . . . . . . . . . . . . . . . 15

3.3 The Model . . . . . . . . . . . . . . . . . . . . . . . . . . . . . 18

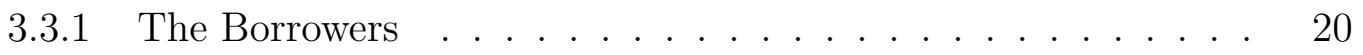

3.3.2 Analytical Expression for $G\left(\bar{\tau}_{t}\right)$ and $\Gamma\left(\bar{\tau}_{t}\right) \ldots \ldots 26$

3.3 .3 The Lenders/ Savers . . . . . . . . . . . . . . . . . . 27

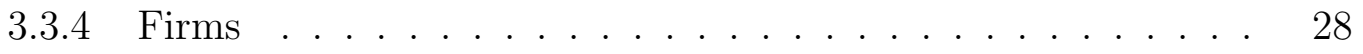


3.3.5 Market Clearing Conditions _. . . . . . . . . . . . 30

3.3 .6 Monetary Policy . . . . . . . . . . . . . . . . . . . . 31

3.3 .7 Nested Models . . . . . . . . . . . . . . . . . . . . . . . 31

3.4 Calibration . . . . . . . . . . . . . . . . . . . . 32

3.4.1 The Co-movement Problem and Related Predictions of Sticky Price Models . . . . . . . . . . . . . . . . . 33

3.4.2 Improving the Predictions of Sticky Price Models . . . . . . . 38

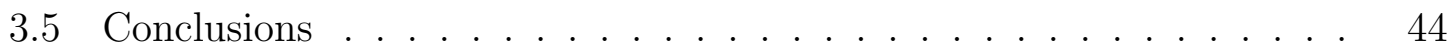

4 Financial Frictions, Durable Goods and Monetary Policy . . . . . . . . . 46

4.1 Introduction . . . . . . . . . . . . . . . . 46

4.2 Related Literature . . . . . . . . . . . . . . . . . . . 51

4.3 The Interaction of the PTI and LTV Constraints . . . . . . . 53

4.4 The model . . . . . . . . . . . . . . . . . . . . 56

4.4 .1 Households . . . . . . . . . . . . . . . . . . . . . 57

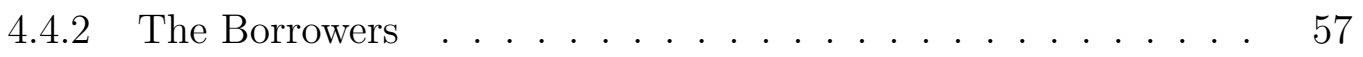

4.4 .3 The Savers . . . . . . . . . . . . . . . . . . . . 65

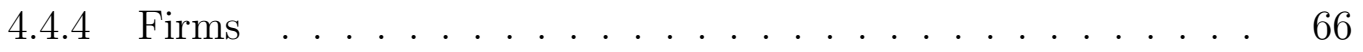

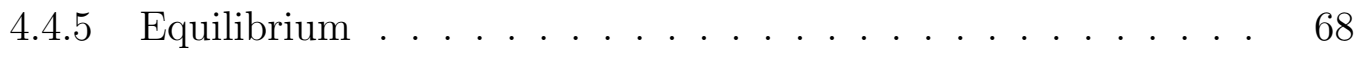

4.4 .6 Market Clearing Conditions . . . . . . . . . . . . . . 68

4.4 .7 Monetary Policy . . . . . . . . . . . . . . . . . . . 69

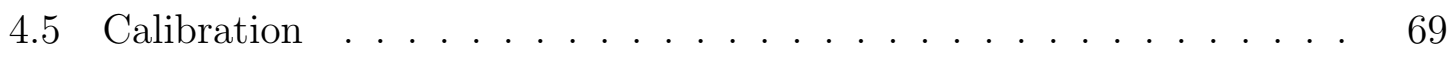

4.6 Results of Monetary Contraction _. . . . . . . . . . . 71

4.6 .1 Results . . . . . . . . . . . . . . . . 71

4.6.2 Resolving the Co-movement Problem . . . . . . . . . . . 74 
4.6.3 Adding Adjustment Costs to Durables . . . . . . . . . . . . . 77

4.7 Sensitivity analysis . . . . . . . . . . . . . . . . . . . . 78

4.7.1 Durable price rigidity . . . . . . . . . . . . . . 79

4.7.2 Alternative LTV and PTI ratios . . . . . . . . . . . . . 80

4.7.3 Changing the elasticity of labour supply . . . . . . . . . . 82

4.8 Conclusion . . . . . . . . . . . . . . . . . . . 83

5 House prices, financial frictions and rising Chinese outward direct investment 86

5.1 Literature Review . . . . . . . . . . . . . . . . . . . 89

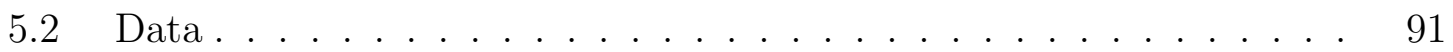

5.2.1 Housing Prices and Chinese OFDI . . . . . . . . . . . . . . . . 92

5.2.2 Macroprudential Measures ... . . . . . . . . . . . 96

5.3 Empirical framework . . . . . . . . . . . . . . . . . . 97

5.4 Panel unit root and co-integration test . . . . . . . . . . . 102

5.5 Estimation Results . . . . . . . . . . . . . . . . . . . . 104

5.6 Simulation Results . . . . . . . . . . . . . . . 106

5.7 Conclusions . . . . . . . . . . . . . . . . . . 109

6 Conclusion .............................. 110

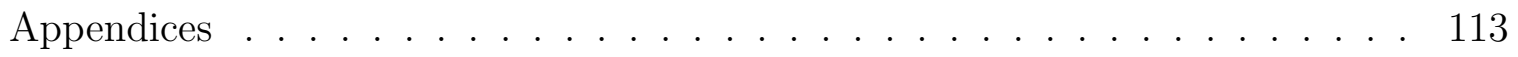

A Solving the model with adjustment costs to durables . . . . . . . . . 114

B Results from Monte-Carlo simulations . . . . . . . . . . . . . . 116

C Countries Considered . . . . . . . . . . . . . . 119 
D Data Sources for Chapter 4 . . . . . . . . . . . . . . 120

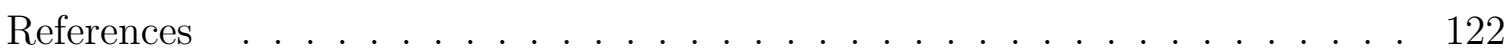




\section{LIST OF TABLES}

4.1 Maximum Loan due to the PTI limit . . . . . . . . . . . . . . 55

$4.2 \quad$ Parameter Values . . . . . . . . . . . . . . . . . . . . . . . . 71

5.1 Pesaran's Panel Unit Root Test Results (10 Countries) . . . . . . . . 103

5.2 Pesaran's Panel Unit Root Test Results (21 Countries) . . . . . . . . 103

5.3 Regression results for dynamic panel data model . . . . . . . . . . 105

5.4 Regression results for dynamic panel data model . . . . . . . . . 106

5.5 Bias corrected (LSBC2)least squares estimates for different sample sizes,$\rho=0.3 \ldots \ldots \ldots \ldots \ldots \ldots \ldots \ldots \ldots$ 


\section{LIST OF FIGURES}

2.1 Monetary Policy Shock US VAR . . . . . . . . . . . . . . . . 10

2.2 Monetary Policy Shock CAN VAR . . . . . . . . . . . . . . 11

3.1 Impulse responses to a monetary policy tightening without credit frictions 35

3.2 Impulse responses to a monetary contraction with and without credit

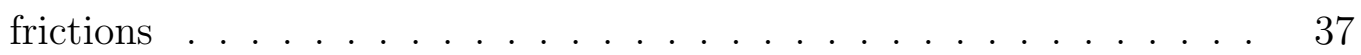

3.3 Comparing the three sticky price models at nearly flexible durable prices 39

4.1 Comparison of the models with two frictions and one friction . . . . . 72

4.2 Impulse response of durable purchases . . . . . . . . . . . . . . . . 75

4.3 Comparison of the models: two frictions, one friction, and no frictions. 76

4.4 Impulse responses with adjustment cost to durable . . . . . . . . . 78

4.5 Comparison of the models at different levels of durable price stickiness. 80

4.6 Impulse responses at different LTV ratios. . . . . . . . . . . . . . . 81

4.7 Impulse responses at different PTI ratios. . . . . . . . . . . . . . . 82

4.8 Impulse responses of employment at different degrees of price stickiness. 83

5.1 Total Chinese OFDI . . . . . . . . . . . . . . . . . . 93

5.2 House Prices Canada . . . . . . . . . . . . . . . . . . . . . . . . 93

5.3 House Prices USA . . . . . . . . . . . . . . . . . . . . . . 93

5.4 House Prices Australia . . . . . . . . . . . . . . . . . . . . . 93

5.5 Sector distribution of Chinese outward direct investment (2005-2017)

Source:Chinese Global Investment Tracker (CGIT) . . . . . . . . 94 
5.6 Chinese total real estate sector outward direct investment (2004-2015) in 10,000 USD Data Source:National Bureau of Statistics China . . 95

5.7 Chinese total outward direct investment (2004-2015) in 10,000 USD Data Source:National Bureau of Statistics China . . . . . . . . 96 


\section{LIST OF APPENDICES}

Appendix A: Solving the model with Adjustment cost . . . . . . . . . . . 114

Appendix B: Monte-Carlo Simulation _ . . . . . . . . . . . . 116

Appendix C: Countries Considered in Chapter 4 . . . . . . . . . . . . 119

Appendix D: Data Sources for Chapter 4 . . . . . . . . . . . . . . 120 


\section{Chapter 1}

\section{INTRODUCTION}

The focus of this dissertation is to study the role of financial frictions in DSGE models with durable goods and sticky prices, and how key economic variables respond in such an environment to monetary policy shocks. In particular, the main objective of my research is to develop two-sector general equilibrium models with sticky prices and imperfect financial markets, the predictions of which match the data in an empirically satisfactory way relative to the existing models, and to apply these models in order to study the behaviour of durable goods and the housing market in response to monetary policy changes.

The first chapter of the dissertation studies the empirical evidence regarding the response of durable and non-durable goods to monetary policy shocks. Using quarterly data from Canada and the United States, and a vector autoregressive (VAR)

model, we trace out empirically the effects of monetary contraction on some key macroeconomic variables. Specifically, we find that, in response to a monetary contraction, durable consumption, non-durable consumption, gross output, and household debt decrease, and the nominal interest rate rises. Contrary to this evidence, the baseline two-sector New Keynesian model with durable goods predicts a negative co-movement between durable and non-durable consumption: following a monetary tightening, durable consumption increases and non-durable consumption decreases. This is known as the "co-movement problem" in the literature. Monacelli (2009) intro-

duced financial frictions in the form of a collateral constraint with a fixed loan-to-value 
(LTV) ratio in the baseline model, and attempted to resolve the co-movement problem with limited success. Sterk (2010) reconsidered this model and concluded that collateral constraints make the co-movement problem more difficult to solve. The reason is that lenders now lend less to the borrowers and use their extra savings to increase the consumption of durables, thus exacerbating the co-movement problem.

The second chapter of the dissertation attempts to resolve the co-movement puzzle and some other countrerfactual predictions of sticky price models by incorporating asymmetric information between borrowers and lenders, and consumption loans into the baseline two-sector sticky price model with collateral constraints. Following Forlati and Lambertini (2011) borrowers use their durables as collateral when they borrow, and they also experience an idiosyncratic durable investment shock which is private information. They default on their loans if they experience low realizations of the idiosyncratic shock. Lenders must pay a monitoring cost to observe the quality of borrowers durable asset used as collateral. In addition, borrowers can borrow against their durable collateral to finance some real outlays, such as consumption or home improvements, which we call consumption loans. A key feature of this model is that agency costs and loan defaults make the LTV ratio endogenous, which declines after a monetary contraction and thus tightens credit conditions. As a result, durable and non-durable expenditures fall, gross output declines and the nominal interest rate increases at the empirically relevant 1.5-quarters durable price stickiness. Consumption loans reinforce the endogenous LTV effects, and help to align the predictions of the model with the empirical evidence by reducing the borrowers' effective real wage and thus their employment, consumption spending and output.

The third chapter attempts to resolve the co-movement puzzle, and also eliminate the counterfactual predictions of sticky price models with respect to the response of 
output and the nominal interest rate to a monetary contraction, even when durable prices are fully flexible. Full durable price flexibility has been assumed in many papers in this literature. In this case, models with credit frictions perform worse than models without frictions because not only they make the co-movement problem harder to resolve, but also because they predict an expansionary effect on output, despite the monetary tightening (Sterk, 2010). In this chapter, the set of financial frictions is extended to include not only a collateral constraint against the expected value of durables (LTV constraint), but also a payment-to-income constraint (PTI constraint) which makes the borrowers debt payments a fixed fraction of their random labour income. In the model, both constraints are satisfied in equilibrium but the maximum amount of collateralized loans is determined by the minimum amount implied by the two constraints. In this setting, a monetary contraction causes the PTI constraint to bind more often, resulting in a drastic reduction of loans issued to borrowers in order to spend on durable purchases, which decline along with expenditures on the more expensive non-durables goods. This resolves the co-movement problem even at fully flexible durable prices, which is not possible in existing sticky price models with only collateral frictions. The reduction in durable and non-durable spending is quite large, so that aggregate output falls as in the data. With fully flexible prices the nominal interest rate also increases, similar to the existing models, which is in line with the monetary tightening. Overall, the well-known counterfactual predictions of sticky price models do not arise in this model, and its predictions are consistent with the stylized facts. At the end, the chapter also discusses the potential role of the PTI and LTV ratios as macro-prudential tools in fostering financial stability.

The fourth chapter of the dissertation studies the effectiveness of the LTV and PTI limits in curbing house price inflation amid rising outward foreign direct invest- 
ment from abroad. To assess the usefulness of these macroprudential policy tools, we use a comprehensive database of housing prices, GDP, bank crises, policy rates, Chinese outward investment and macroprudential policy measures covering advanced countries at quarterly frequency from 2003 to 2016. The purpose is to measure empirically the effect of Chinese outward foreign direct investment (OFDI) on the housing markets and to access the need for measures that can mitigate foreign influences on the domestic housing market, using the LTV and PTI limits as macroprudential policy tools. Endogeneity issues that arise as a result of the correlations between unobserved cross-country heterogeneity and the observed variables will be addressed empirically by using panel data econometric techniques with interactive fixed effects. The results suggest that LTV and PTI limits help in reducing house prices and OFDI has a significant positive impact on house prices.

This research is useful in practice because the predictions of the model developed in the dissertation square well with the empirical evidence, and thus may help policy makers in arriving at correct decisions regarding the effects of their policies in the durable goods market and the economy as a whole. It adds new insights to the literature by evaluating how general equilibrium models with financial frictions can explain better the empirical evidence regarding the reaction of key macroeconomic variables, such as durable and non-durable goods, output, and interest rates to monetary shocks. Also, it sheds light on how different combinations of financial frictions, such as collateral and income constraints affect the asset price of durables and the amount of debt or credit growth in the economy. Further, it helps in studying whether monetary authorities should include indicators of financial vulnerability such as credit growth in their monetary policy rules.

The rest of the paper is as follows. Chapter 1 presents the empirical evidence and 
stylized facts related to the co-movement problem. Chapter 2 presents the extended model with agency costs and consumption loans. Chapter 3 presents the extended model with PTI and LTV constraints. Chapter 4 presents the model which studies the effectiveness of macro-prudential measures and Chapter 5 contains some concluding remarks. 


\section{Chapter 2}

\section{EMPIRICAL EVIDENCE}

\section{$2.1 \quad$ Introduction}

In this chapter, we examine empirically the reaction of real durable and non-durable spending, real output, and real household debt in response to a contractionary monetary policy shock. Our results, based on the most recent US and Canadian data, replicate the stylized facts: gross domestic product and consumption spending on both durable and non-durable goods decline, durable spending declines more than non-durable spending; real household debt also declines. Contrary to this evidence, the baseline two-sector New Keynesian model with durable goods predicts a negative co-movement between durable and non-durable consumption: following a monetary tightening, durable consumption increases and non-durable consumption decreases. In addition to reconfirming the results in Monacelli (2009) with more updated US data, we perform similar analysis using Canadian data which generated similar responses. Getting similar stylized facts for both countries is important for the external validity of our models. In the next two chapters, we consider a heterogeneous agent sticky-price DSGE models with durables and non-durable goods that generate predictions which are consistent with these empirical findings.

\subsection{Literature Review}

The VAR framework was first introduced by Christopher Sims in 1980 and ever since then, has provided a credible and coherent approach to data description, forecasting, 
and policy analysis. The VAR framework provides a systematic way to capture rich dynamics in multiple time series, as a result of this, a great deal of VAR literature, adopting both recursive and structural approaches, has been developed to identify monetary policy shocks and to estimate impulse responses of various macroeconomic variables due to these shocks. In order not to produce contaminated measures of policy shock, the VAR model is conditioned on the information the monetary authorities observe when they make decisions.

VAR model has been used in literature by macro-economists and policy makers to address variety of issues of interest. Calza et al. (2007) used VAR to analyse transmission of monetary policy shocks on housing prices in EU countries, the US and Canada. Quarterly VAR model was used to assess the impact of monetary policy shocks for the U.S. economy by Monacelli (2006). In an attempt to identify monetary policy more realistically, Bernanke, Boivin, and Eliasz (2004) conditioned monetary policy simultaneously to a large set of home and foreign variables by using a factoraugmented VAR model, exploiting the indexes or factors of the dynamic factor model.

\subsubsection{Empirical Method: Vector Auto-regression}

Our empirical analysis complements the vector autoregressive (VAR) framework of Monacelli (2009) by including more recent data for the US over the period 1954:12017:3 and Canada over the period 1981:1 to $2017: 3$. We fit the data to the following six-dimensional VAR model

$$
Y_{t}=\alpha_{o}+\alpha_{1} t+\sum_{j=1}^{L} A_{j} Y_{t-j}+u_{t}
$$


Where $u_{t}=B \varepsilon_{t}, \mathbb{E}\left[\varepsilon_{t} \varepsilon_{t}^{\prime}\right]=I, \mathbb{E}\left[u_{t} u_{t}^{\prime}\right]=V=\mathbb{E}\left[B \varepsilon_{t} \varepsilon_{t}^{\prime} B^{\prime}\right]=B B^{\prime}$. The VAR system includes a constant and a time trend, and the vector $Y_{t}$ comprises six variables: (i) real GDP, (ii) real durable consumption, (iii) real non-durable consumption and services, (iv) the GDP deflator, (v) total real household debt and (vi) the federal funds

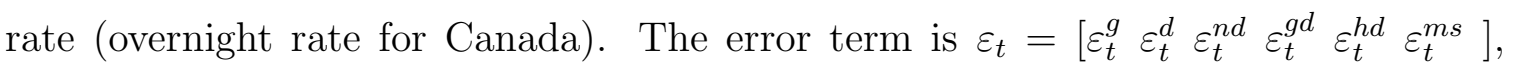
representing GDP, durable and non-durable goods, GDP deflator, households debt and federal funds rate shocks respectively. All variables except the federal funds rate are measured in logs and deflated by GDP deflator. We want to measure the dynamic responses of these variables to one standard deviation increase in $\varepsilon_{t}^{m s}$. To identify $\varepsilon_{t}^{m s}$, we use the standard recursive identification scheme based on the Cholesky decomposition (Christiano et al.,1999). $A_{j}, u_{t}$ and $\mathrm{V}$ can be estimated using ordinary least squares(OLS), so we need to find $\mathrm{B}$ and $\varepsilon_{t}$. The problem is that we have $n^{2}$ unknowns in $\mathrm{B}$, but only $\frac{n(n+1)}{2}$ equations in $B B^{\prime}=V$ which leads identification problem. At least $\frac{n(n-1)}{2}$ identifying restrictions is needed to pin down B. Choleski decomposition of $\mathrm{V}$ which results in a temporal ordering of the variables is used to pin down $\mathrm{B}$. This is referred to as recursive VAR. An alternative, is to allow a more elaborate set of restrictions guided by economic theory referred to as Structural VAR.

\subsubsection{Recursive Assumption in Identifying Monetary Policy Shocks}

The equation that relates monetary policy to the state of the economy is specified as follows:

$$
R_{t}=f(\Omega)+\varepsilon_{t}^{m s}
$$

Where $f$ is a linear function, $R_{t}$ is federal funds rate (or overnight rate for Canada), $\Omega$ is set of variables that monetary authority looks at which comprises of the observed 
values of the variables included in $Y_{t}$ in the VAR model other than $R_{t}, \varepsilon_{t}^{m s}$ is time $t$ policy shock orthogonal to $\Omega$. Following Christiano et al. (1999), we assume that the monetary authority allows money growth to be whatever is necessary to guarantee that equation (2.2) holds. The monetary authority sees the variables in $Y_{t}$ when it makes its choice of $R_{t}$ and the variables in $Y_{t}$ other than $R_{t}$ do not respond at time $t$ to $\varepsilon_{t}^{m s}$.

In our analysis

$$
B=\left(\begin{array}{cccccccc}
1 & & & & & \\
b_{21} & 1 & & & & \\
b_{31} & b_{32} & 1 & & & \\
b_{41} & b_{42} & b_{43} & 1 & & \\
b_{51} & b_{52} & b_{53} & b_{54} & 1 & \\
b_{61} & b_{62} & b_{63} & b_{64} & b_{65} & 1
\end{array}\right)
$$

where $I \varepsilon_{t}=B^{-1} u_{t}$, I is an $\mathrm{n} \times \mathrm{n}$ identity matrix, $b_{i j}$ indicate that variable $\mathrm{j}$ affects variable i instantaneously.

The lag order value is chosen by considering the minimized values of the Final Prediction Error (FPE), Hannan-Quinn (HQ), Akaike (AIC) and Swartz Bayesian (BIC) information criteria. Unit root and co-integration tests suggest that some of the variables in the analysis are non-stationary, I(1), co-integrated processes. Since our goal is to analyse short run effects via impulse responses, nonstationarity is not a concern. Not adding the error correction term will lead to loss of efficiency, but this will not affect forecasting or the impulse responses (Erceg \& Levin 2006). However, as a robustness check, a vector error correction model (VECM) was fit to the data and the results showed similar impulse responses. The empirical impulse response functions for US and Canada are shown in figures 2.1 and 2.2 respectively. The 
dashed red lines represent two standard error bands. As shown, real GDP and both durable and non-durable consumptions fall in response to the monetary tightening. The decline in durable consumption is higher than decline in non-durable consumption and is about 4 to 5 times larger than the decline non-durables. Real household debt also declines.
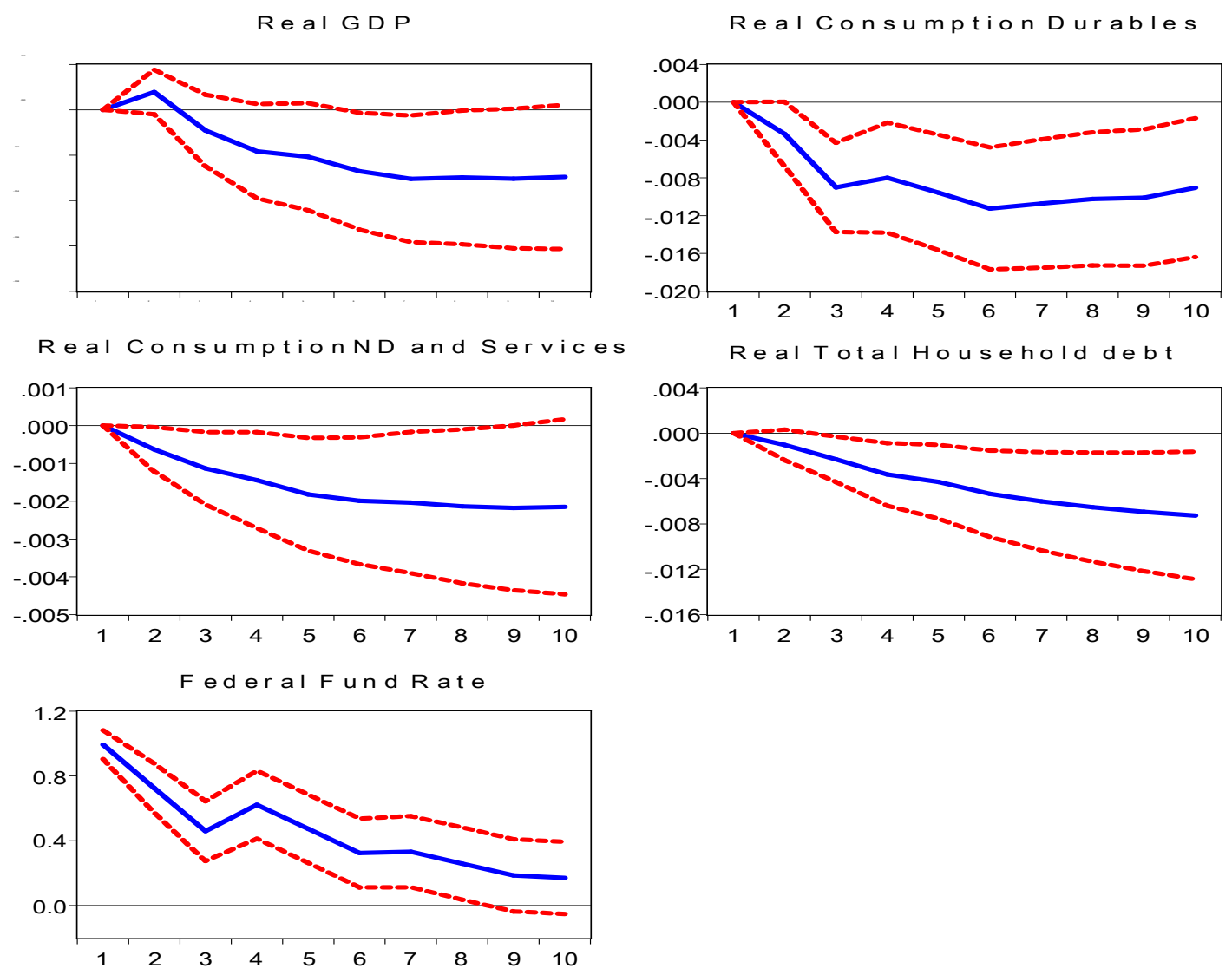

Figure 2.1 Monetary Policy Shock US VAR 


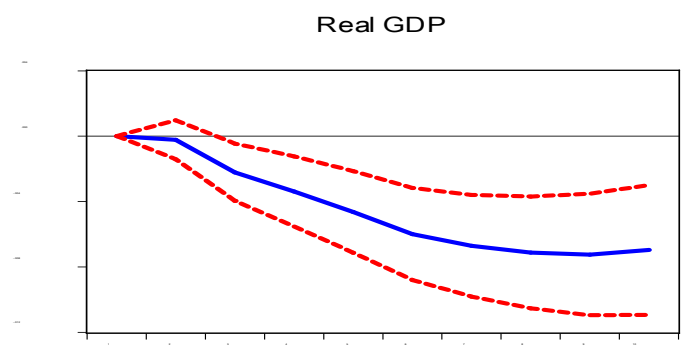

Real Consumption ND and Services
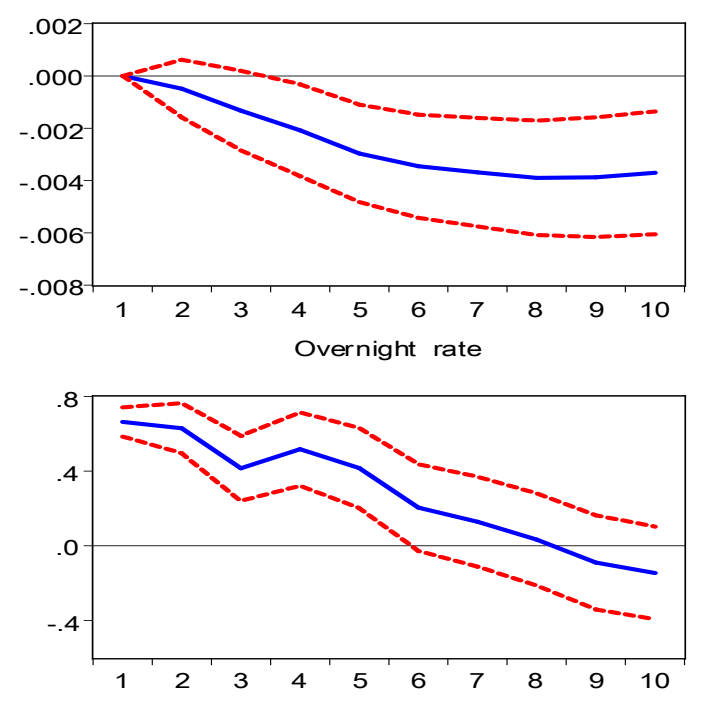

Real Consumption Durables
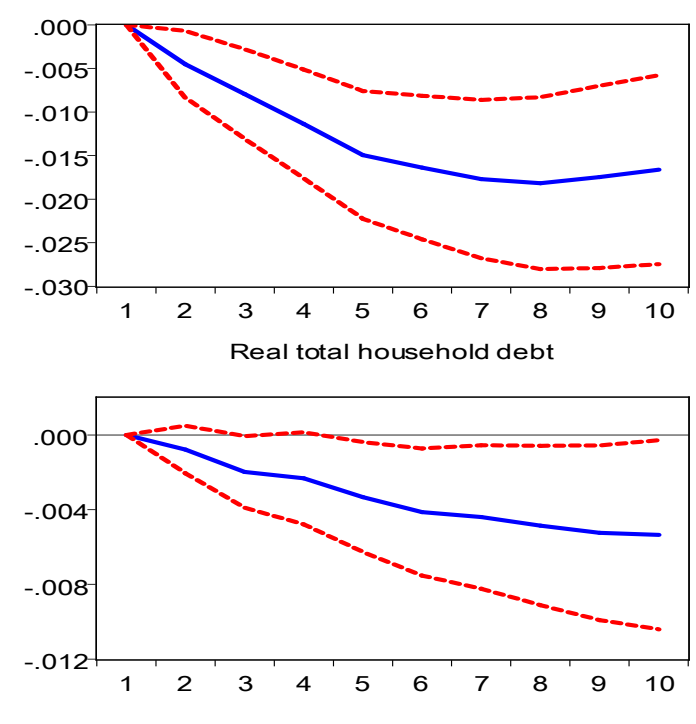

Figure 2.2 Monetary Policy Shock CAN VAR 


\section{Chapter 3}

\section{AGENCY COSTS, CONSUMPTION LOANS AND THE CO-MOVEMENT BETWEEN DURABLE AND NONDURABLE CONSUMPTION}

\subsection{Introduction}

Empirical findings by Barsky et al. (2003), Erceg and Levin (2006) and Monacelli (2009), among others, have shown that durable and non-durable consumption expenditures co-move in response to monetary shocks. However, the basic two-sector New Keynesian model predicts that durable and non-durable purchases move in opposite directions following a monetary shock. Specifically, in response to a monetary contraction, expenditure on durables increases and expenditure on non-durables decreases leading to what is referred to as "co-movement problem". To reconcile the model with the empirical findings, Barsky et al (2003) suggested that credit frictions on borrowing may help to resolve the co-movement problem. The rationale is that with credit constraints, there is reduced ability to borrow following a monetary tightening, and this could then force credit-constrained households to decrease durable purchases. Monacelli (2009) extended the model to include borrowers and lenders in which borrowers face a collateral constraint on borrowing. He was able to generate a co-movement between durable and non-durable expenditures when allowing for twoquarter price stickiness in durable goods. For durable price stickiness less than two quarters the co-movement problem still exists. However, as documented in Barsky et al (2003), durable good prices are relatively flexible compared to non-durable good 
prices. A related issue is the relative importance of price stickiness and financial frictions in the model. Sterk (2010) analysed the model with and without financial frictions and disentangled the effect of price stickiness from the effect of financial frictions. He showed that price stickiness is more important than credit frictions in resolving the co-movement problem. In particular, in the model with a collateral constraint, borrowers borrow less and the bond market clearing condition requires that the lenders lend less than in the case with no frictions. As a result, with credit frictions lenders use their extra savings to increase their purchases of durable goods, which makes it more difficult to resolve the co-movement problem.

The aim of this paper is introduce asymmetric information between borrowers and lenders, agency costs and collateralized consumption loans into the model and study how their interaction with credit frictions can help to resolve the co-movement problem even when durable prices are nearly flexible. To this end, we consider a twosector sticky price model with collateral frictions and default in collateralized loans secured by collateral against the durable good. Agency costs arise naturally in this context from the asymmetric information between borrowers and lenders about the quality of the collateral: the borrowers know the quality of the durable good against which they borrow, but the lenders do not. We assume that loans are non-recourse and borrowers experience idiosyncratic durable investment shocks which are private information. They default on their loans if they experience low realizations of the idiosyncratic shock. Lenders must pay a monitoring cost to observe the quality of borrowers' durable asset used as collateral and the realized return on the durable investment. Also we assume that borrowing households who already own durable goods and have positive equity, can borrow against the durable collateral in order to finance some real outlays. 
In the model, each borrower (indexed by $i$ ) experiences an idiosyncratic quality shock, $\tau_{t}^{i}$, to the value of his/her durable, $P_{d, t} D_{t}$, after a loan contract. Following the shock, the ex-post durable value is $\tau_{t+1}^{i} P_{d, t+1} D_{t}$. The quality shock can cause some loan default in equilibrium. We assume a "costly state verification" of the type first analysed by Townsend (1979), in which lenders must pay a monitoring cost in order to observe the borrowers' durable quality. We follow Forlati and Lambertini (2011) and assume that the monitoring cost is equal to a fraction $\mu$ of the durable value, $\mu \tau_{t+1}^{i} P_{d, t+1} D_{t}$. This implies that loan default causes a decline in the durable stock and services.

There are several reasons to think that loan defaults, monitoring costs, and equity loans influence consumption expenditures on durable and non-durable goods. First, following the most recent financial crisis in the late 2000's, there was an increase in mortgage delinquency rate due to the bursting of housing bubble which made loan repayment more difficult for borrowers. This forced banks to write down several billions in bad loans causing failures of many banks. There was a decrease in credit access, consumption and investment in housing and other durable goods. Second, Mian and Sufi (2011) provide empirical evidence that home owners borrow against their home equity to finance real outlays, such as consumption and home improvements. They find that for every dollar increase in home equity 25 to 30 cents are used for such expenditures. They also find that equity loans by home owners are responsible for a significant fraction of both the sharp rise in U.S. household leverage and the increase in defaults.

The effect of credit frictions on durable purchases has been extensively studied in the literature. However, agency costs, loan default and equity based borrowing have not been considered in resolving the co-movement problem in the the existing studies. 
This paper contributes to the literature by showing that adding these features into the two-sector general equilibrium sticky price model resolves the co-movement problem when durable goods prices are nearly flexible, which is not possible in the model without these features. Also when credit frictions are combined with these features, it is no longer more difficult to resolve co-movement problem. Thus, this model avoids the criticism of credit frictions noted by Sterk (2010). This is because loan defaults, agency costs and consumption loans enhance the propagation of monetary policy shocks by causing a decline in aggregate durable purchases and aggregate output even when the durable prices are nearly flexible. Our findings are thus consistent with the empirical evidence which shows that a rise in nominal interest rate leads to decline in aggregate durable investment, non-durable consumption, household debt and aggregate output.

The rest of the paper is as follows. Section 2 discusses the related literature in more detail. Section 3 presents the extended model with agency costs and consumption loans. Section 4 presents and discusses the calibration results. Section 5 contains some concluding remarks. where $\gamma>\beta$ because, by assumption, lenders are more patient than borrowers, the $\sim$ denotes lender variables similarly to borrowers, and $\tilde{\Gamma}_{j, t}$, $j=c, d$ are aggregate nominal profits from the monopolistic competitive firms.

\subsection{Related Literature}

This paper builds on several existing strands of the literature. It relates to a growing literature that embeds durable goods into the DSGE model with sticky prices. As noted, Barsky, House, and Kimball $(2003,2007)$ introduced durable goods in the standard two-sector sticky-price model and showed that the model generates counter 
factual co-movements between durable and non-durable consumption when durable goods prices are flexible. They suggested several possible modifications of the standard model that could help to resolve this so called co-movement problem. One of the suggestions was to include credit frictions in the model. Monacelli (2009) extended the basic model to include lenders and borrowers with the latter facing collateral constraints on their borrowing. He analysed the effect of monetary tightening on the purchase of durable and non-durable goods and was able to generate a positive co-movement between the two consumption types only when durable price stickiness was about two quarters or more but not less than two quarters. When durable prices were nearly flexible, that is between one and two quarters, the co-movement problem remained unresolved. Equally important, Sterk (2010) criticised demand-side credit frictions by showing that the model with collateral constraints makes it more more difficult to resolve the co-movement problem. The reason is that with credit frictions consumption smoothing lenders increase their durable consumption following a monetary monetary contraction, which may more than offset the reduction of durable consumption by the credit-constrained borrowers. Our model avoids this problem and shows explicitly that credit frictions do not make the co-movement problem more difficult to solve if asymmetric information and the possibility of default are introduced into the model.

Liao and Chen (2014) resolved the co-movement problem by adding capital as another input in the production process along with a collateral constraint for borrowers. With flexible durable prices, a monetary contraction induces capital accumulation which reduces the savers' disposable income in the short run. As a result, savers reduce their expenditures on durables along with non-durables which now have become relatively more expensive. However, capital accumulation leads to a fall in 
the nominal interest rate in their model which is counterfactual given the monetary contraction.

Bouakez et al. (2011) extended the model of Barsky et al. (2007) by adding limited labour mobility and input-output linkages between the two sectors whereby non-durables are used as intermediate inputs in the production of durables and viceversa. Assuming that durable prices are fully flexible and non-durable prices are sticky, they showed that, following a monetary shock, durables and non-durables comove positively and monetary policy is non-neutral with respect to aggregate output. Sudo (2012) considered a similar model and exploiting the non-diagonality of the input-output matrix of the US economy he was able to resolve the co-movement problem. Carlstrom and Fuerst(2010) resolved the co-movement puzzle by adding sticky nominal wage, adjustment cost in housing construction and a large degree of complementarity between consumption of non-durable goods and housing services. Our paper is different from these papers because it aims at resolving the co-movement problem and the other counterfactual predictions of the two-sector sticky price model with durable goods based on credit frictions, agency costs on borrowing and possible loan defaults, all of which affect the demand side of the economy than the supply side.

Forlati and Lambertini (2011) constructed a model with borrowers and lenders, housing, and asymmetric information about the quality of housing. Borrowers use the housing stock as collateral for mortgage loans and experience idiosyncratic housing investment shocks that are private information. Mortgage loans are risky because borrowers will default if the realization of the housing investment shock is bellow a threshold level. The lenders must pay a monitoring cost to observe the realized return of housing. Our model draws on the asymmetric information features from 
their model.

The empirical literature on price-setting behaviour by firms has documented evidence that the frequency of price adjustments differs across sectors. These studies include, among other, Bils and Klenow (2004), and Nakamura and Steinsson (2008) for the U.S. economy, and Alvarez (2006) for Euro area countries. Klenow and Malin (2010) and Nakamura and Steinsson (2013) provide recent reviews of this literature. In their comprehensive study for the US, Bils and Klenow (2004) examined the frequency of price changes of a large number of goods and services representing 70 percent of total consumer spending. They found that durable goods are more flexiblypriced than non-durable goods and that half of the prices change every 4.5 months or 1.5 quarters. In what follows, we attempt to resolve the co-movement problem and some other counterfactual predictions of the sticky model at this empirically relevant price stickiness frequency for durables, which has not been examined in the existing literature.

\subsection{The Model}

The economy is comprised of a continuum of heterogeneous, infinitely-lived households, a continuum of firms in the durables and non-durables sectors that respectively produce differentiated durable and non-durable goods which are used as inputs in the production of the two final goods, and a government which issues money and implements monetary policy. Household heterogeneity arises from differences in the rate of time preferences among households, a constant fraction of whom are less patient and borrow from the more patient households who are the lenders or savers. Thus, debt accumulation reflects intertemporal trading between the borrowers and the lenders. There is asymmetric information between borrowers and lenders regarding the quality 
of the durable good which is put up as collateral by borrowers. Borrowers observe the quality shock to their durable investment but lenders do not, and thus lenders must pay a monitoring cost to assess the quality of the collateral and seize it, if the borrowers default on their loans.

The model combines elements from Monacelli (2009) and from Folarti and Lambertini (2011) as well as the introduction of consumption loans. Our aim is to resolve co-movement problem at low levels of durable price stickiness where in addition to a collateral constraint there are agency costs to borrowing, and borrowers obtain consumption loans secured by their durable collateral. Unlike Monacelli, we do not rely on an exogenous borrowing constraint but derive it endogenously after introducing idiosyncratic risk on new durable investment and possible default. The extended model is then compared to two submodels: Monacelli's model with an exogenous loan-tovalue ratio and no consumption loans, and the model without any financial frictions in order to understand the role played by the collateral constraint, the agency costs and the consumption loans in resolving the co-movement problem.

The economy is populated by a continuum of households in the interval $(0,1)$. There are two types of households, named borrowers and lenders/savers, of measure $\omega$ and $1-\omega$, respectively. Each individual household's time endowment is normalized to 1 . There are also two sectors producing durable and non-durable goods respectively, each populated by a large number of monopolistic competitive firms producing differentiated intermediate products. The two types of households have heterogeneous preferences, with the borrowers being more impatient than the lenders/savers. All households derive utility from the consumption of a non-durable final good and from services of a durable final good. The borrowers are subject to a budget constraint and a collateral constraint, with the borrowing limit tied to the value of the expected 
future value of the stock of durables.

Each household consists of many members indexed by $i$. Risk is introduced in the durable goods market by assuming that each household member $i$ experiences an idiosyncratic quality shock, $\tau_{t}^{i}$, to the value of her durable $D_{t}^{i}$, after a loan contract. The quality shock is private information and is such that the ex-post durable value is $\tau_{t+1}^{i} P_{d, t+1} D_{t}^{i}$. The random variable $\tau_{t}^{i}$ is i.i.d. across the members of the same household and log-normally distributed with a cumulative distribution function $\mathrm{F}\left(\tau_{t}^{i}\right)$ which obeys standard regularity conditions. We choose the mean and variance of $\ln \tau_{t}^{i}$ such that $\mathbb{E}_{t}\left(\tau_{t+1}^{i}\right)=1$ at all times. This implies that although there is idiosyncratic risk at the household-member level there is no risk at the household level and $\mathbb{E}_{t}\left(\tau_{t+1}^{i} D_{t}^{i}\right)=D_{t}$. This result is analytically convenient because the individual household-member problem aggregates into a representative borrower problem. The quality shock $\tau_{t}^{i}$ can cause some loan default in equilibrium. We assume a "costly state verification" of the type first analysed by Townsend (1979), in which lenders must pay a monitoring cost in order to observe borrowers' durable quality. Similar to Bernanke, Gertler and Gilchrist (1999) and Forlati and Lambertini (2011) we assume that the monitoring cost is equal to a fraction $\mu$ of the durable value, $\tau_{t+1}^{i} P_{d, t+1} D_{t}$. This implies that loan default causes a decline in durable stock and services.

\subsubsection{The Borrowers}

A typical borrower consumes an index of consumption services of durable and nondurable final goods specified as

$$
X_{t}=\left((1-\alpha)^{\frac{1}{\eta}}\left(C_{t}\right)^{\frac{\eta-1}{\eta}}+(\alpha)^{\frac{1}{\eta}}\left(D_{t}\right)^{\frac{\eta-1}{\eta}}\right)^{\frac{\eta}{\eta-1}}
$$


where $C_{t}$ denote consumption of the final non-durable good and $D_{t}$ denotes the services from the stock of the final durable good at the end of period $t, \alpha>0$ is the share of durable goods in the composite consumption index and $\eta \geq 0$ is the elasticity of substitution between consumption of durable services and non-durable consumption. The utility function is:

$$
U\left(X_{t}, N_{t}\right)=\log \left(X_{t}\right)-\frac{\nu N_{t}^{1+\varphi}}{1+\varphi}
$$

where, in addition to $X_{t}, N_{t}$ is the labour supply, $\varphi$ is the inverse elasticity of labour supply and $\nu$ is a parameter that indexes the preference for hours worked for each agent.

The representative borrower maximizes

$$
\mathbb{E}_{0}\left\{\sum_{t=0}^{\infty} \beta^{t}\left(\log \left(X_{t}\right)-\frac{\nu N_{t}^{1+\varphi}}{1+\varphi}\right)\right\}
$$

where $\mathbb{E}_{0}$ is the conditional expectation operator evaluated at time 0 and $\beta$ is the discount factor. Borrowers face the sequence of budget constraints specified in nominal terms by

$$
\begin{gathered}
P_{c, t} C_{t}+P_{d, t}\left(D_{t}-(1-\delta)\left(1-G\left(\bar{\tau}_{t-1}\right)\right) D_{t-1}\right)+\left(1-F\left(\bar{\tau}_{t-1}\right)\right) R_{t-1}^{z} B_{t-1}=B_{t}+W_{t} N_{t} \\
-\xi\left(R_{t}-1\right) W_{t} N_{t}+T_{t}
\end{gathered}
$$

where $P_{c, t}$ is the price of non-durable goods, $P_{d, t}$ is the price of durable goods, $R_{t}^{z}$ is the state-contingent interest rate that non-defaulting borrowers pay at time $t$ on loans $B_{t-1}$ taken at time $t-1, W_{t}$ is the nominal wage, $\xi W_{t} N_{t}$ is a fraction of income 
borrowed to finance some real outlays, such as home improvements, and we call this a consumption loan, $G\left(\bar{\tau}_{t-1}\right)$ is the fraction of borrowers' durable stock that will be seized by the lenders as a consequence of default in period $t-1,\left(1-F\left(\bar{\tau}_{t-1}\right)\right)$ is the fraction of loans that is repaid to lenders and $T_{t}$ is money transfers from the government.

After an idiosyncratic shock to durable quality hits the economy at time $t$, the representative borrower decides whether to pay the loan or default depending on the value of the shock relative to the ex-post threshold:

$$
\bar{\tau}_{t+1}=\frac{R_{t}^{z} B_{t}}{(1-\delta) P_{d, t+1} D_{t}} .
$$

If the realized shock $\tau$ falls in the interval $\left[\bar{\tau}_{t}, \infty\right]$, there will be no loan default and borrowers will pay $R_{t}^{z} B_{t}$. If $\tau$ falls in the interval $\left[0, \bar{\tau}_{t}\right]$ borrowers default on their loans. Because the shock is private information, lenders pay a monitoring cost to access and seize the durable collateral when borrowers default on their loans. We consider a one-period loan contract that guarantees lenders a predetermined rate of return on their total loans. At time $t$, lenders make total loans $B_{t}$ to borrowers and demand the gross rate of return $R_{t}$. This rate of return is predetermined at time $t$ and is not state contingent. Hence, the time $t$ collateral constraint of the borrowers or equivalently the participation constraint of the lenders is given by

$$
R_{t} B_{t}+\xi R_{t} W_{t} N_{t}=\int_{0}^{\bar{\tau}} \tau_{t}(1-\mu)(1-\delta) P_{d, t} D_{t} f_{t}(\tau) d \tau+\int_{\bar{\tau}}^{\infty} R_{t}^{z} B_{t} d \tau
$$

where $f_{t}(\tau)$ is the probability density function of $\tau$. Equation (3.6) states that the value of all loans inclusive of the consumption loans should be equal, in equilibrium, to their total return, which is the sum of the durable stock net of monitoring costs 
and depreciation of the defaulting borrowers and the repayment of the non-defaulting borrowers.

To simplify the borrowers' problem, let

$$
G\left(\bar{\tau}_{t}\right)=\int_{0}^{\bar{\tau}_{t}} \tau_{t} f_{t}(\tau) d \tau
$$

be the expected value of the idiosyncratic shock conditional on the shock being less than or equal to the threshold value $\bar{\tau}_{t}$, and let

$$
\Gamma\left(\bar{\tau}_{t}\right)=\bar{\tau}_{t} \int_{\bar{\tau}_{t}}^{\infty} f_{t}(\tau) d \tau+G\left(\bar{\tau}_{t}\right)
$$

be the expected share of durable value, gross of monitoring costs, that goes to lenders. Then the sequence of the collateral/participation constraints can be written in real terms as

$$
R_{t} b_{t}+\frac{\xi R_{t} W_{t} N_{t}}{P_{c, t}}=\left(\Gamma\left(\bar{\tau}_{t}\right)-\mu G\left(\bar{\tau}_{t}\right)\right)(1-\delta) q_{t+1} \pi_{c, t+1} D_{t},
$$

where $q_{t}$ is the relative price of durables in terms of non-durables consumption and $b_{t}=\frac{B_{t}}{P_{c, t}}$ is the real loan in time $t$. The loan-to-value, LTV, ratio is then

$$
\left(\Gamma\left(\bar{\tau}_{t}\right)-\mu G\left(\bar{\tau}_{t}\right)\right)
$$

which measures the size of the loan as a fraction of net durable value. Following the decision to default at time $t$, borrowers are left with the following stock of durables

$$
\int_{\bar{\tau}_{t}}^{\infty} \tau_{t}(1-\delta) q_{t+1} \pi_{c, t+1} D_{t}=\left(1-G\left(\bar{\tau}_{t}\right)\right)(1-\delta) P_{d, t} D_{t} .
$$

Using the relationship between $\bar{\tau}$ and $R^{z}$ in equation (3.5) we can eliminate $R^{z}$ from 
the borrowers budget constraint and rewrite it in real terms as

$C_{t}+q_{t}\left(D_{t}-(1-\delta)\left(1-G\left(\bar{\tau}_{t-1}\right)\right) D_{t-1}\right)+R_{t-1} \frac{b_{t-1}}{\pi_{c, t}}=b_{t}+\frac{W_{t}}{P_{c, t}} N_{t}-\xi\left(R_{t}-1\right) \frac{W_{t}}{P_{c, t}} N_{t}+\frac{T_{t}}{P_{c, t}}$

where $\pi_{c, t}$ is non-durable-good inflation. The borrowing household chooses $\left\{N_{t}, C_{t}, b_{t}, D_{t}, \bar{\tau}_{t}\right\}$ to maximize equation (4.12) subject to (3.12) and (3.9). The respective first-order conditions are

$$
\begin{aligned}
-U_{n, t} & =\lambda_{t} \frac{W_{t}}{P_{c, t}}\left(1-\xi\left(R_{t}-1\right)-\xi R_{t} \psi_{t}\right) \\
U_{c, t} & =\lambda_{t} \\
R_{t} \psi_{t} & =1-\beta \mathbb{E}_{t}\left[\frac{U_{c, t+1}}{U_{c, t}} \frac{R_{t}}{\pi_{c, t+1}}\right] \\
\lambda_{t} q_{t} & =U_{d, t}+\beta(1-\delta) \mathbb{E}_{t}\left(\lambda_{t+1} q_{t+1}\left(1-\mu G\left(\bar{\tau}_{t}\right)\right)\right) \\
& +\lambda_{t} \psi_{t}\left(\Gamma\left(\bar{\tau}_{t}\right)-\mu G\left(\bar{\tau}_{t}\right)\right)(1-\delta) q_{t} \mathbb{E}_{t} \pi_{d, t+1} \\
\beta \lambda_{t+1} \mu G^{\prime}\left(\bar{\tau}_{t}\right) & =\lambda_{t} \psi_{t}\left(\Gamma^{\prime}\left(\bar{\tau}_{t}\right)-\mu G^{\prime}\left(\bar{\tau}_{t}\right)\right) \pi_{c, t+1}
\end{aligned}
$$

where $\lambda_{t}$ is the Lagrangian multiplier on borrowers budget constraint (3.12), $\lambda_{t} \psi_{t}$ is the Lagrangian multiplier on the collateral/participation constraint (3.9), and $U_{i, t}$ is the marginal utility of the variable $i=C, N, D$. Equation (3.13) links the marginal rate of substitution between non-durable consumption and leisure to the opportunity cost of leisure. As shown, it is clear that the presence of consumption loans in the model leads to a decrease in the opportunity cost of leisure, and thus employment. In the absence of consumption loans equation (3.13) reduces to the standard labour market optimality condition. Equation (3.14) equates the marginal utility of non-durable consumption to the shadow value of relaxing the budget constraint. Equation (3.15) 
is a modified Euler equation and reduces to the standard Euler equation when $\psi_{t}=0$. In equation (3.16) the marginal utility of non-durables is equated to shadow value of durables which depends on the gain in utility from consuming additional durables, the expected utility of expanding future consumption and the marginal utility of relaxing the collateral/participation constraint. The marginal utility of relaxing the collateral/participation constraint depends on the monitoring cost parameter and the threshold value of the idiosyncratic shock. Equation (3.17) determines the borrowers' optimal default decision.

Rearranging equation (3.16), we can equate the marginal rate of substitution between durable and non-durable consumption $U_{d, t} / U_{c, t}$ to the user cost of durables $Z_{t}$ given by

$Z_{t}=q_{t}\left[1-\psi_{t}\left(\Gamma\left(\overline{\bar{\tau}}_{t}\right)-\mu G\left(\overline{\bar{\tau}}_{t}\right)\right)(1-\delta) \mathbb{E}_{t}\left(\pi_{d, t+1}\right)\right]-\beta(1-\delta) \mathbb{E}_{t}\left[q_{t+1} \frac{U_{c, t+1}}{U_{c, t}}\left(1-\mu G\left(\bar{\tau}_{t}\right)\right)\right]$

Log-linearizing equations (3.15) and (3.16) around the deterministic steady state, the user cost of durables can be re-written as

$$
\begin{aligned}
\hat{Z}_{t} & =\bar{Z}^{-1}(1-\delta)\left[\Omega \hat{q}-\beta\left(1-\mu G\left(\bar{\tau}_{t}\right)\right) \mathbb{E}_{t} \hat{q}_{t+1}+\gamma R_{r, t}\right. \\
& +(\gamma-\beta)\left(1-\left(\Gamma\left(\bar{\tau}_{t}\right)-\mu G\left(\bar{\tau}_{t}\right)\right) \hat{\psi}_{t}+\hat{\zeta}_{t}\right) \\
& \left.+(\gamma-\beta) \bar{\tau} \bar{\tau}_{t}\left(\Gamma^{\prime}\left(\bar{\tau}_{t}\right)-\mu G^{\prime}\left(\bar{\tau}_{t}\right)\right)\right]
\end{aligned}
$$


where

$$
\begin{aligned}
\Omega & =\frac{\left.\left(1-(1-\delta)(\gamma-\beta) \Gamma_{t}\left(\bar{\tau}_{t}\right)-\mu G_{t}\left(\bar{\tau}_{t}\right)\right)\right)}{(1-\delta)} \\
\hat{R}_{r, t} & =\hat{R}_{t}-\mathbb{E}_{t}\left(\hat{\pi}_{t+1}\right) \\
\hat{\zeta}_{t} & \left.=\mathbb{E}_{t}\left\{\Gamma_{t}\left(\bar{\tau}_{t}\right)-\mu G_{t}\left(\bar{\tau}_{t}\right)\right) \hat{\pi}_{d, t+1}-\pi_{c, t+1}\right\} \\
\bar{Z} & =1-(1-\delta)(\beta(1-\mu G(\bar{\tau}))+\Gamma(\bar{\tau})-\mu G(\bar{\tau}))(\gamma-\beta))
\end{aligned}
$$

in which $R_{r, t}$ is the real interest rate, and $\bar{Z}$ is the steady-state value of the user cost which is positive for all conventional parametrizations. It is clear from equation (3.19) that as long as $\bar{Z}>0$, the user cost is positively correlated with the real interest rate, $R_{r, t}$, the shadow value of borrowing, $\psi_{t}$, and the monitoring cost parameter, $\mu$. Also, as expected, an increase in $\mu$ decreases the loan-to-value ratio and pushes the user cost of durables up. This helps to resolve the co-movement problem and improve the predictions of the model relative to the empirical evidence.

\subsubsection{Analytical Expression for $G\left(\bar{\tau}_{t}\right)$ and $\Gamma\left(\bar{\tau}_{t}\right)$}

For the calibration of the model below, we follow Bernanke, Gertler and Gilchrist (1999) and assume that $\ln (\tau) \sim N\left(-\frac{\sigma_{\tau}^{2}}{2}, \sigma_{\tau}^{2}\right)$ which implies that $\mathbb{E}_{t}(\tau)=1$ and

$\mathbb{E}_{t}(\tau \mid \tau \geq \bar{\tau})=\frac{1-\Phi\left(z-\sigma_{\tau}\right)}{(1-\Phi(z))}$ where where $\Phi($.$) is the c.d.f. of the standard normal and \mathrm{z}$ is related to $\tau$ through $z=\frac{\ln (\bar{\tau})+\frac{\sigma_{\tau}^{2}}{2}}{\sigma_{\tau}}$. Then, we obtain

$$
\begin{aligned}
\Gamma(\bar{\tau}) & =\Phi\left(z-\sigma_{\tau}\right)+\bar{\tau}(1-\Phi(z)) \\
G(\bar{\tau}) & =\Phi\left(z-\sigma_{\tau}\right) \\
\text { and } \Gamma(\bar{\tau})-\mu G(\bar{\tau})) & =(1-\mu) \Phi\left(z-\sigma_{\tau}\right)+\bar{\tau}(1-\Phi(z))
\end{aligned}
$$




\subsubsection{The Lenders/ Savers}

The lenders are owners of the monopolistic competitive firms producing intermediate goods for the production of the two final goods, and each period, they collect the profits from those firms. Like borrowers, they consume, work and earn wages, receive transfers from government, and invest in durable goods. The representative lender is infinitely-lived and seeks to maximizes lifetime expected utility

$$
\mathbb{E}_{0}\left\{\sum_{t=0}^{\infty} \gamma^{t}\left(\log \left(\tilde{X}_{t}\right)-\frac{\nu \tilde{N}_{t}^{1+\varphi}}{1+\varphi}\right)\right\}
$$

subject to

$$
\tilde{C}_{t}+q_{t}\left(\tilde{D}_{t}-(1-\delta) \tilde{D}_{t-1}\right)+R_{t-1} \frac{\tilde{b}_{t-1}}{\pi_{c, t}}=\tilde{b}_{t}+\frac{\tilde{W}_{t}}{P_{c, t}} \tilde{N}_{t}+\frac{\tilde{T}_{t}}{P_{c, t}}+\frac{\tilde{\Gamma}_{c, t}}{1-\omega}+\frac{q_{t} \tilde{\Gamma}_{d, t}}{1-\omega}
$$

where the ${ }^{\sim}$ denotes lender variables similarly to borrowers, and $\tilde{\Gamma}_{j, t}, j=c, d$ are aggregate nominal profits from the monopolistic competitive firms. By assumption $\gamma>\beta$ because lenders are more patient than borrowers.

The representative lender chooses $\left\{\tilde{N}_{t}, \tilde{b}_{t}, \tilde{D}_{t}, \tilde{C}_{t}\right\}$ to maximize (3.20) subject to (3.21). The optimality conditions for this optimization problem are

$$
\begin{aligned}
\frac{-\tilde{U}_{n, t}}{\tilde{U}_{c, t}} & =\frac{\tilde{W}_{t}}{P_{c, t}} \\
\tilde{U}_{c, t} & =\gamma \mathbb{E}\left\{\frac{\tilde{U}_{c, t+1}}{\tilde{\pi}_{c, t+1}} R_{t}\right\} \\
q_{t} & =\frac{\tilde{U}_{d, t}}{\tilde{U}_{c, t}}+\gamma(1-\delta) \mathbb{E}\left\{\frac{\tilde{U}_{c, t+1}}{\tilde{U}_{c, t}} q_{t+1}\right\} .
\end{aligned}
$$


These are standard optimality conditions for economic agents without financial frictions or consumption loans.

\subsubsection{Firms}

There are intermediate and final good producers in both the durable and non-durable sectors.

\subsubsection{Final goods producer}

In each sector, perfectly competitive firms produce the final good $Y_{j, t} j=c, d$. The production function in the $j$-th final goods sector is given by

$$
Y_{j, t}=\left(\int Y_{j, t}^{\frac{\varepsilon_{j}-1}{\varepsilon_{j}}}(i) d i\right)^{\frac{\varepsilon_{j}}{\varepsilon_{j}-1}}
$$

where $Y_{j, t}(i)$ is the intermediate good produced by firm $i$ in sector $j$, and $\varepsilon_{j}>1$, is the elasticity of substitution between intermediate goods in sector $j$.

\subsubsection{Production and pricing of Intermediate Goods}

The production of intermediate goods is undertaken in both sectors of the economy, each populated by a large number of monopolistic competitive firms. The problem

of each monopolistic firm $i$ in sector $j$ is to choose the sequence of $\left\{N_{j, t}(i), P_{j, t}(i)\right\}$ to maximize expected discounted profits

$$
\mathbb{E}_{0}\left\{\sum_{t=0}^{\infty} \Lambda_{j, t}\left(P_{j, t}(i) Y_{j, t}(i)-W_{t} N_{j, t}(i)-\frac{\vartheta_{j}}{2}\left(\frac{P_{j, t}(i)}{P_{j, t-1}}-1\right)^{2} P_{j, t} Y_{j, t}\right)\right\}
$$


subject to equation (3.25) and the linear production function

$$
Y_{j, t}(i)=N_{j, t}(i)
$$

where $N_{j, t}(i)$ is the demand for labour of each monopolistic firm $i$ in sector $j, \Lambda_{j, t}=$ $\gamma \tilde{\lambda}_{t} / \tilde{\lambda}_{0}$ is the lenders' stochastic discount factor and $\tilde{\lambda}_{t}$ is their marginal utility of nominal income. The aggregate output is

$$
Y_{t}=Y_{c, t}+q_{t} Y_{d, t}
$$

In a symmetric equilibrium, where $P_{j, t}(i) / P_{j, t}=1$ for all $i$ and $j$ and all firms employ the same amount of labour in each sector, the optimality conditions of each intermediate producer $i$ in sector $j$ are

$$
\left(\left(1-\epsilon_{j}\right)+\epsilon_{j} m c_{j, t}\right)=\vartheta_{j}\left(\pi_{j, t}-1\right) \pi_{j, t}-\gamma \vartheta_{j} \mathbb{E}\left\{\frac{\Lambda_{j, t+1}}{\Lambda_{j, t}} \frac{P_{j, t+1}}{P_{j, t}} \frac{Y_{j, t+1}}{Y_{j, t}}\left(\pi_{j, t+1}-1\right) \pi_{j, t+1}\right\}
$$

where $\pi_{j, t}=\frac{P_{j, t}}{P_{j, t}}$ is the gross inflation rate in sector $j$, and

$$
\frac{W_{t}}{P_{j, t}}=m c_{j, t}
$$

We note that in equation (3.28) the following relationships hold

$$
\begin{aligned}
& \mathbb{E}\left\{\frac{\Lambda_{j, t+1}}{\Lambda_{j, t}} \frac{P_{c, t+1}}{P_{c, t}}\right\}=\mathbb{E}\left\{\frac{\tilde{U}_{c, t+1}}{\tilde{U}_{c, t}}\right\} \text { if } j=c \text { and } \\
& \mathbb{E}\left\{\frac{\Lambda_{j, t+1}}{\Lambda_{j, t}} \frac{P_{d, t+1}}{P_{d, t}}\right\}=\mathbb{E}\left\{\frac{\tilde{U}_{c, t+1}}{\tilde{U}_{c, t}} \frac{q_{t+1}}{q_{t}}\right\} \text { if } j=d .
\end{aligned}
$$


Finally, sectoral inflation and relative prices are related as follows

$$
\frac{\pi_{d, t}}{\pi_{c, t}}=\frac{q_{t}}{q_{t-1}} .
$$

\subsubsection{Market Clearing Conditions}

Equilibrium in the goods market requires that the production of the final good be allocated to total households' expenditure and to resource costs originating from the adjustment of prices

$$
\begin{aligned}
Y_{c, t} & =\omega C_{t}+(1-\omega) \tilde{C}_{t}+\frac{\vartheta_{c}}{2}\left(\pi_{c, t}-1\right)^{2} Y_{c, t} \\
Y_{d, t} & =\omega\left(D_{t}-(1-\delta)\left(1-\mu G\left(\bar{\tau}_{t-1}\right)\right) D_{t-1}\right)+(1-\omega) \tilde{I}_{t}+\frac{\vartheta_{d}}{2}\left(\pi_{d, t}-1\right)^{2} Y_{d, k}(3 .
\end{aligned}
$$

Output in the durable sector net of monitoring cost is

$$
Y_{d, t}^{N}=Y_{d, t}-\omega(1-\delta) \mu G\left(\bar{\tau}_{t}\right) D_{t}
$$

Equilibrium in the credit/debt and labour markets requires, respectively

$$
\begin{aligned}
\omega b_{t}+(1-\omega) \tilde{b}_{t} & =0 \\
N_{c, t}+N_{d, t} & =\omega N_{t}+(1-\omega) \tilde{N}_{t} .
\end{aligned}
$$




\subsubsection{Monetary Policy}

Monetary policy is assumed to be conducted by means of a simple Taylor-type rule

$$
\begin{aligned}
\frac{R_{t}}{R} & =\left(\frac{\tilde{\pi}_{t}}{\tilde{\pi}}\right)^{\phi_{\pi}} \varepsilon_{t} \quad \phi_{\pi}>1 \\
\tilde{\pi}_{t} & =\pi_{c, t}^{1-a} \pi_{d, t}^{a} \\
\varepsilon_{t} & =\rho \varepsilon_{t-1}+u_{t}
\end{aligned}
$$

where $\tilde{\pi}_{t}=\pi_{c, t}^{1-a} \pi_{d, t}^{a}$ is a composite inflation index, $R$ and $\tilde{\pi}$ are the steady-state levels of the gross nominal interest rate and inflation index, respectively, and $\varepsilon_{t}$ is an exogenous monetary shock.

\subsubsection{Nested Models}

In the calibration below we compare the numerical results from the extended model with agency costs, loan default and consumption loans to two nested models: Monacelli's model with exogenous loan-to-value ratio and no consumption loans, and the model without credit frictions or consumption loans.

\subsubsection{The Monacelli Model}

In this model, the only financial friction is a collateral constraint on borrowers with an exogenous loan-to-value ratio and no loan defaults or consumption loans. The optimization problem of the lender is the same as in section 3.2 above. The problem of the representative borrower is to maximize expected lifetime utility

$$
\mathbb{E}_{0}\left\{\sum_{t=0}^{\infty} \beta^{t}\left(\log \left(X_{t}\right)-\frac{\nu N_{t}^{1+\varphi}}{1+\varphi}\right)\right\}
$$


subject to

$$
\begin{aligned}
P_{c, t} C_{t}+P_{d, t}\left(D_{t}-(1-\delta) D_{t-1}\right)+R_{t-1} B_{t-1} & =B_{t}+W_{t} N_{t}+T_{t} \\
R_{t} B_{t} & \leq \kappa(1-\delta) \mathbb{E}_{t}\left\{D_{t} P_{d, t+1}\right\}
\end{aligned}
$$

where $\kappa$ is the exogenous loan-to-value ratio.

\subsubsection{The Model without Financial Frictions}

This model is the standard two-sector sticky price model with no agent heterogeneity, and no credit frictions. It is a special case of the extended model by setting the fraction of the borrowers $\omega$ and the consumption loan parameter $\xi$ to zero. With no agent heterogeneity, debts are equal to zero in equilibrium $\left(b_{t}=\tilde{b}_{t}=0\right)$, and the collateral constraint is irrelevant. The representative household in this model behaves like the savers in the extended model or Monacelli's model.

\subsection{Calibration}

The models are calibrated to a quarterly frequency and, unless noted otherwise, the parametrization follows that of Monacelli (2009). We target the stickiness of nondurable prices at four quarters and pin down $\vartheta_{c}$ as follows. Let $\theta$ be the probability

of not resetting prices in the standard Calvo-Yun model. We parametrize $\frac{1}{1-\theta}=4 \Longrightarrow$ $\theta=0.75$, and therefore an average frequency of price adjustment of one year. After setting the elasticity $\varepsilon_{j}$, the resulting stickiness parameter satisfies $\vartheta_{j}=\frac{\theta\left(\varepsilon_{j}-1\right)}{(1-\theta)(1-\gamma \theta)}$. As in Lambertini and Forlati (2011), we set $\mu$, the agency cost parameter, to 0.12. Finally, we set the consumption loan parameter $\xi$ equal to 0.30 . This value is motivated by the Mian and Sufi (2011) finding that US households spent about 30 cents of a dollar 
increase their home equity on real consumption expenditures. The parameter values are summarized in Table II.

\begin{tabular}{cccc}
\hline Parameter & Description & Friction & No Friction \\
\hline$\alpha$ & Share of durables in consumption & .20 & .20 \\
$\beta$ & Borrowers discount factor & .98 & - \\
$\gamma$ & Savers discount factor & 0.99 & 0.99 \\
$\delta$ & depreciation rate durable & 0.01 & 0.01 \\
$\varepsilon_{c}, \varepsilon_{d}$ & El. of sub. between varieties & 6 & 6 \\
$\eta$ & El. Durable \& non-durable & 1 & 1 \\
$\phi_{\pi}$ & Coeff. of inflation in Taylor rule & 1.5 & 1.5 \\
$\omega$ & Fraction of borrowers & 0.52 & 0 \\
$\kappa$ & LTV ratio (Monacelli model) & 0.75 & - \\
$\rho$ & Persistent Parameter & 0.5 & 0.5 \\
$\varphi$ & Inv. El. of labour supply & 1 & 1 \\
$\mu$ & Monitoring cost parameter & 0.12 & - \\
$\xi$ & Consumption loan parameter & 0.3 & - \\
\hline
\end{tabular}

\subsubsection{The Co-movement Problem and Related Predictions of Sticky Price Models}

In this section we document and discuss the calibration results relating to the comovement problem and some other counterfactual predictions of the sticky price model. The co-movement problem arises in the benchmark model with perfect financial markets and/or in models with a collateral constraint and relatively high degree of durable price flexibility as in Monacelli (2009). This is illustrated in Figure 1, in 
the model with no credit frictions and three combinations of price stickiness between durable and non-durable goods: sticky non-durable prices, sticky durable prices and equally sticky prices, where price stickiness is set at 4 quarters. The figure shows the impulse response functions (IRFs) of durable and non-durable consumption, the relative price of durables, employment in the two sectors and the nominal interest rate to a 25 basis points increase in the monetary policy interest rate.

As shown in in the first panel of Figure 1, in the case of sticky non-durable prices and flexible durable prices (blue IRFs) durable consumption increases and non-durable consumption falls following the monetary contraction, contrary to the empirical evidence. In the case of sticky durable prices the co-movement problem is resolved but the nominal interest rate declines on impact despite the monetary contraction, which another counterfactual prediction of the two-sector sticky price model with durables. 
Figure 3.1 Impulse responses to a monetary policy tightening without credit frictions
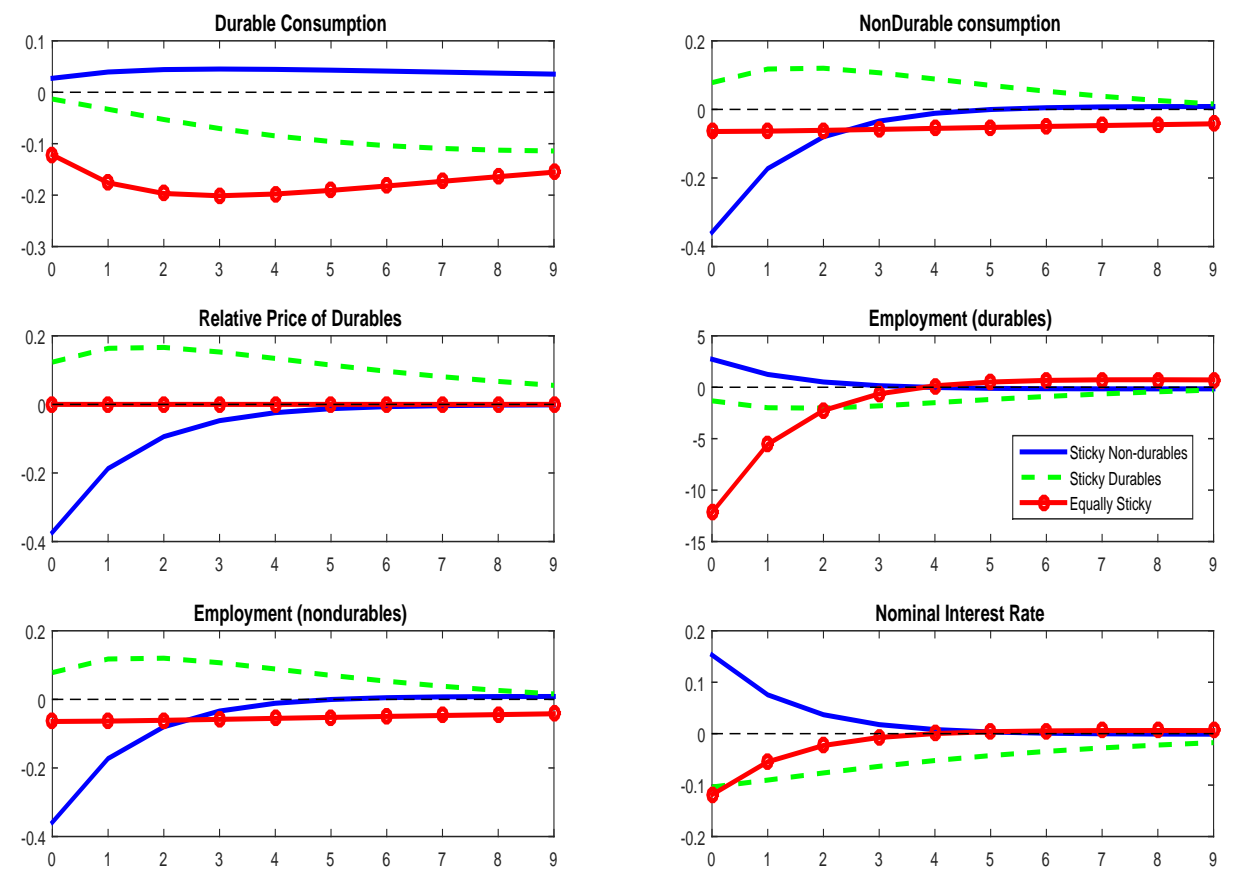

Another undesirable feature of the sticky price model with a credit friction, in the form of a collateral constraint against durables as in Monacelli, is that it makes the co-movement problem more difficult to resolve. This is shown in Figure 2, which plots the IRFs for the nominal interest rate, non-durable and durable purchases and gross output following the monetary contraction, for different degrees of durable price stickiness in the range 1-quarter to 3-quarters. As shown, the blue IRFs for nondurables (durables) in the model with the collateral friction are below (above) those in the model without the friction. As demonstrated by Sterk (2010), the reason for this surprising result is that in the model with the collateral constraint the shadow 
value of durables increases with the interest rate hike, as purchasing one more unit of durables relaxes the collateral constraint and allows the borrower to purchase more durables. In other words, the collateral constraint induces a substitution of durables for non-durables, which is absent in the model with no financial frictions because the shadow value of durables is quasi-constant in the latter model.

Notice also that at high durable price flexibility (e.g., 1-quarter durable price stickiness), the increase in durable purchases is large enough that aggregate output increases, so that contractionary monetary policy is expansionary which contradicts the stylized facts in the literature and the empirical evidence for the US in Section 3 above. 
Figure 3.2 Impulse responses to a monetary contraction with and without credit frictions
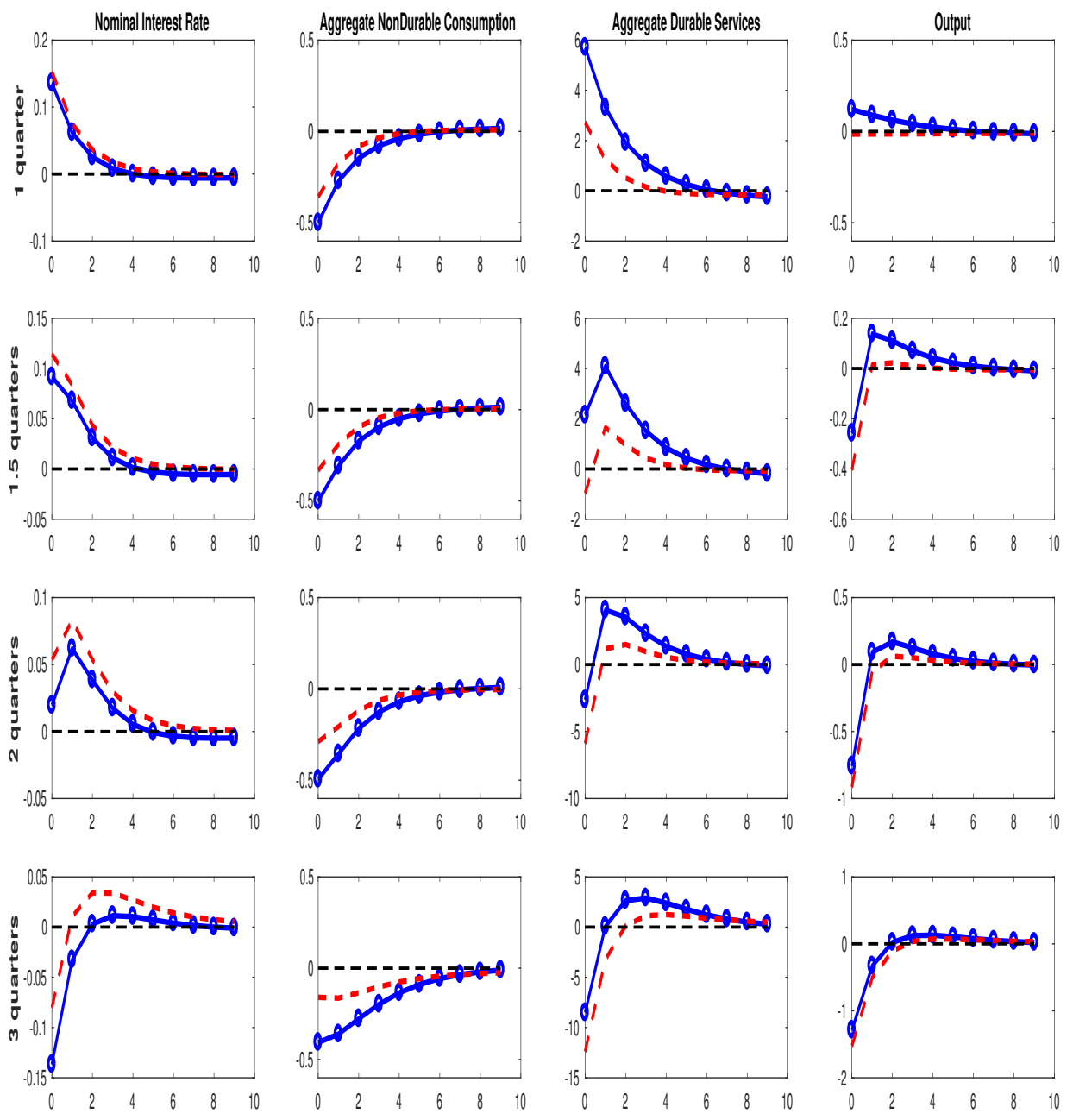

- Model with LTV constraint (Monacelli)

- - Model without friction

Note: The rows correspond to different degrees of durable price stickiness. Responses are plotted as percentage deviations from steady state.

Only at 2-quarter durable price stickiness the model with financial frictions performs well overall: the co-movement problem is resolved, output contracts and the 
nominal interest rate rises slightly after the monetary contraction. At still higher levels of durable price stickiness the co-movement problem is resolved but there is a perverse reaction of the nominal interest rate.

\subsubsection{Improving the Predictions of Sticky Price Models}

Given the predictive weaknesses of the sticky price models noted above, a better

model would be one that improves on or eliminates the counterfactual predictions of the sticky price model with financial frictions at empirically relevant durable price stickiness. In particular it should resolve the co-movement problem between durable and non-durable consumption, aggregate output should fall and the nominal interest rate interest rate would increase, following a monetary contraction.

Our extended model with a collateral constraint, agency costs, and consumption loans improves the predictions of the sticky price model relative to the model with only a collateral constraint or the sticky price model without any credit frictions. This is shown in Figure 3 which plots the impulse responses to the monetary contraction for durable and non-durable consumption, aggregate output and the nominal interest rate at 1.2 and 1.5 durable price stickiness. As shown by the green IRFs, following the monetary contraction the extended model predicts that both durable and nondurable consumption decline, aggregate output falls and the interest rate rises, all of which are in line with the empirical evidence. 
Figure 3.3 Comparing the three sticky price models at nearly flexible durable prices
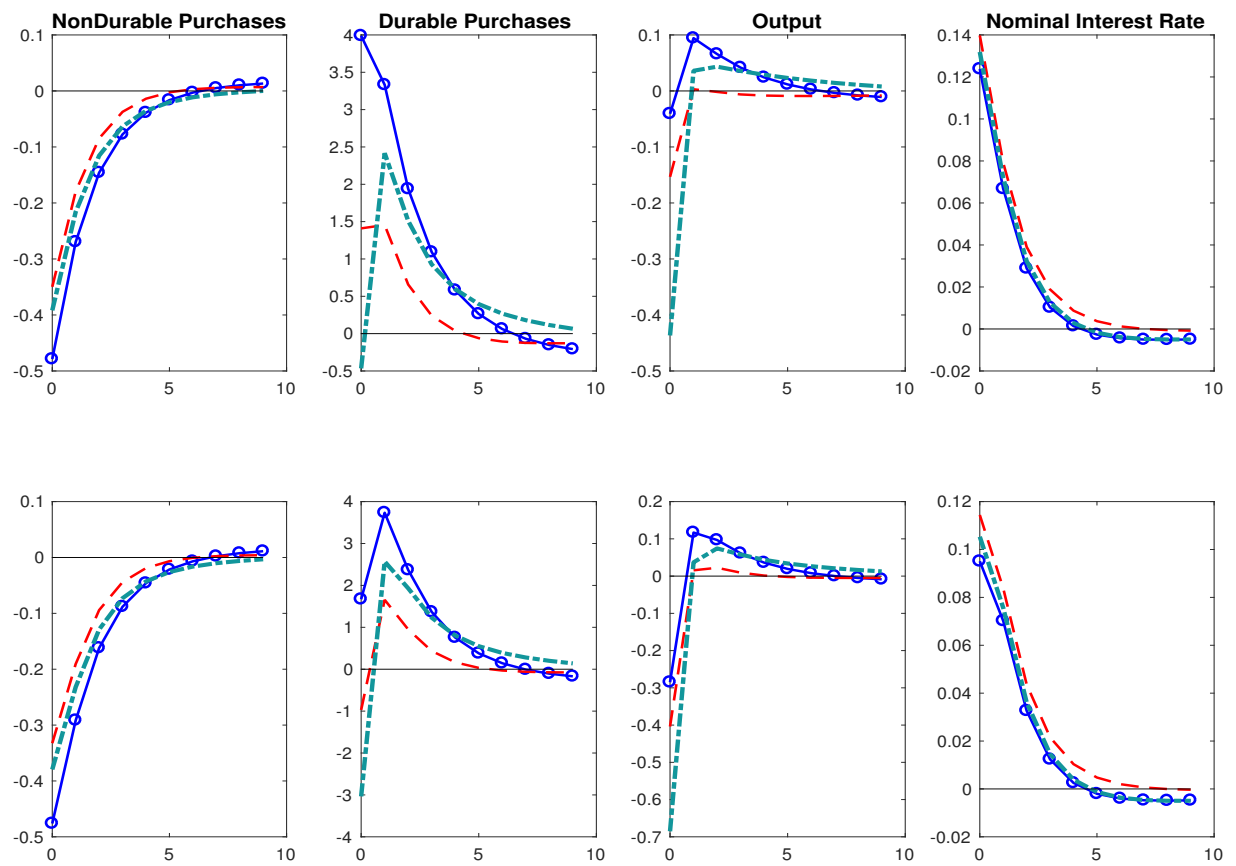

Model with LTV Constraint (Monacelli) - - Model without Friction -----Model with Agency Cost \& Consumption Loan

Note: Durable price stickiness is 1.2 and 1.5 quarters. Responses are plotted as percentage deviations from steady state.

The predictions of the extended model are similar to the model with no frictions regarding non-durable consumption and the nominal interest rate but durable consumption and aggregate output fall by more in the extended model. On the other hand, there is a noticeable difference in the predictions of these two models relative to the model with only a collateral constraint and an exogenous LTV ratio. Non-durable consumption falls by a lot more and durable consumption increases by a lot more, output falls by less and the nominal interest rate increases by less in the latter model.

The main reason for the difference in the prediction across the three models lies in 
the behaviour of the shadow value of durables, following the monetary contraction. As shown by Barksy et al. (2007), owing to the the large stock-to-flow ratio of durables, the shadow value of durables is quasi-fixed in the model with no financial frictions and implies a negative co-movement between durable and non-durable consumption. This is also the source of the other counterfactual predictions of the standard sticky price model. Monacelli's model with a collateral constraint and exogenous LTV ratio breaks the quasi-constancy of the shadow value of durables, which, as noted earlier, rises after the monetary contraction, thus causing a substitution of durables for nondurables and thus making the co-movement problem harder to resolve especially at nearly flexible durable prices. In the extended model the shadow value of durables also rises, but it rises by less than in Monacelli's model. The increase in the shadow value of durables is moderated due to the endogenous LTV ratio in extended model. Following a monetary contraction, loan defaults increase and the LTV ratio in equation (3.10) decreases which tightens the collateral/participation constraint. As a result, the shadow value of durables rises by less in this model than in Monacelli's model.

Another reason that the extended model provides better predictions than the other two models is the presence of consumption loans, which affects the labour market equilibrium condition (3.13) for borrowers. Following the monetary contraction and the fall in the LTV ratio, borrowers can relax their collateral constraint by working more. But in the presence of consumption loans, the increase in the interest rate reduces the opportunity cost of leisure and thus the borrowers' labour supply. As a result, a rise in gross output is prevented from this channel, which helps to improve the predictions of the model relative to the other two models.

In order to illustrate the differences between the three models analytically consider first the shadow value of durables in the model with no financial frictions. In the case 
the optimality condition of the representative household coincides with the optimality condition of the lenders/savers in the model(s) with frictions, such as equation (3.24). Rearranging this equation, the savers' optimality condition can be written as

$$
q_{t} \tilde{U}_{c, t}=\tilde{U}_{d, t}+\gamma(1-\delta) \mathbb{E}\left\{\tilde{U}_{c, t+1} q_{t+1}\right\}
$$

The right hand side of equation (3.43) is the shadow value of durable for savers. Forward iteration of (3.43) gives

$$
q_{t} \tilde{U}_{c, t}=\tilde{V}_{t}=\mathbb{E}_{t} \sum_{k=o}^{\infty} \gamma^{k}(1-\delta)^{k} \tilde{U}_{d, t+k} \approx \text { constant }
$$

where $\tilde{V}_{t}$ denotes the shadow value of durables.

The shadow value of durables depends on the marginal utility of durables which depends on the stock of durables. The stock of durables does not respond to changes in the flow of durables and for this reason, the shadow value of durable is quasiconstant (Barsky et al., 2007).

For Monacelli's model with a collateral constraint the shadow value of borrowing turns out to be

$$
V_{t}^{M}=\frac{U_{d, t}+\beta(1-\delta) \mathbb{E}_{t} V_{t+1}}{1-\kappa(1-\delta) \psi_{t}^{M} \mathbb{E}_{t} \pi_{d, t+1}},
$$

where $\kappa$ is the exogenous LTV ratio.

The monetary contraction tightens credit conditions and increases the shadow value of borrowing $\psi^{M}$, which, in turn, increases the shadow value of borrowing in equation (3.45). This causes a substitution of durables for non-durables and makes it more difficult to resolve the co-movement problem. Also as a consequence of this 
feature of the model, aggregate employment and output will tend to rise at low levels of durable price stickiness (Sterk, 2010).

For the extended model the shadow value of durables is

$$
V_{t}^{E}=\frac{U_{d, t}+\beta(1-\delta) \mathbb{E}_{t} V_{t+1}\left(1-\mu G\left(\bar{\tau}_{t}\right)\right)}{1-\psi_{t}^{E}\left(\Gamma\left(\bar{\tau}_{t}\right)-\mu G\left(\bar{\tau}_{t}\right)\right)(1-\delta) \mathbb{E}_{t} \pi_{d, t+1}},
$$

which is different from $V_{t}^{M}$ in that the LTV ratio $\left(\Gamma\left(\bar{\tau}_{t}\right)-\mu G\left(\bar{\tau}_{t}\right)\right)$ is now endogenous and depends also on the monitoring cost parameter $\mu$.

Clearly, an increase in $\mu$ reduces the LTV ratio and raises $V_{t}^{E}$. More important, the LTV ratio changes with the monetary policy shock through its effect on the threshhold $\bar{\tau}_{t}$ of the durable investment shock. Specifically, and increase in the nominal interest rate $R_{t}$ reduces the durable price and raises the state contingent interest rate $R_{t}^{z}$. From equation (3.5), this implies an increase in $\bar{\tau}_{t}$, and thus an increase in $G\left(\bar{\tau}_{t}\right)$ and a fall in the LTV ratio, or, equivalently, a decline in the net share of durable value that goes to the lenders. That is, the increase in the policy interest rate tightens credit conditions, raises the rate of loan defaulting borrowers and the fraction of their durable stock that is seized by the lenders. As a result, because of the presence of positive monitoring costs the share of durable value that is appropriated by the lenders declines. Further, the tighter credit conditions caused from the decline of the LTV ratio reduce the shadow value of borrowing $\psi^{E}$ in the extended model compared to the shadow value of borrowing $\psi^{M}$ in Monacelli's model in which the LTV ratio is exogenous. Overall, these results imply that $V_{t}^{E}$ increases less than $V_{t}^{M}$ after a monetary contraction. As a consequence, borrowers have less incentive to substitute durables for non-durables and this helps to resolve the co-movement problem and also align the other predictions of the extended model with the empirical evidence. 
The second factor, which reinforces the effects of the endogenous LTV, is the presence of consumption loans in the model, which impinges on the labour supply decision of the borrowers, and therefore on aggregate employment and output. To see this analytically, substitute equation (14) into equation (13) and set $\varphi=1$ in $U_{n}, t$. Manipulating the resulting expression gives

$$
N_{t}=V_{t}^{E} \frac{w_{t}}{\nu}\left[1-\xi\left(R_{t}-1\right)-\xi R_{t} \psi_{t}\right]
$$

where $w_{t}=W_{t} / P_{d, t}$ is real wage in units of durables. It is clear from equation (3.47) that equilibrium employment for the borrowers depends on the policy interest rate $R_{t}$ as long as $\xi>0$. Following a monetary tightening, the real wage is nearly constant with nearly flexible durable prices. Also, as noted above, the response of the shadow value of durables $V_{t}^{E}$ is pretty small and closer to the case of the model without credit frictions. Hence, the increase in $R_{t}$ will tend to reduce total employment for borrowers by reducing the effective real wage or equivalently the effective opportunity cost of leisure. For the savers, total employment is given by $\tilde{N}_{t}=\frac{w_{t}}{\nu} \tilde{V}_{t}$, which, owing to the near constancy of $w_{t}$ and $\tilde{V}_{t}$, is also nearly constant. Thus aggregate employment $N^{a g g}$ depends on borrower's employment $N_{t}$. The lower value of $V_{t}^{E}$ and the increase in $R_{t}$ lead to a decrease in $N_{t}$ relative to the model with an exogenous LTV ratio, such that aggregate employment and output decline relative to that model.

These properties of the extended model are important in resolving the co-movement problem and eliminating the other counterfactual predictions of existing sticky price models at the empirically relevant durable price stickiness. This is achieved by relying on factors that affect primarily the demand side of the economy, rather than supply factors that have been considered in the literature in order to improve the predictions 
of sticky price models. Nonetheless a new feature of our model is that demand factors such as consumption loans affect supply decisions by altering the effective real wage in the face of monetary shocks.

\subsection{Conclusions}

Empirical evidence suggests that aggregate durable and non-durable expenditures decline jointly in response to a monetary contraction. The standard two-sector sticky price model with durable goods and flexible durable prices is at odds with this empirical evidence. This is known as the co-movement problem in the literature. Sticky price models with a collateral constraint against durables and an exogenous loanto-value ratio, such as Monacelli (2009), have also limited success in resolving the co-movement problem and in reconciling the other counterfactual prediction of sticky price models with the empirical evidence. This especially the case when durable goods are relatively more flexibly priced compared to non-durables.

This paper extends the sticky price model with agency costs and loan default which render the loan-to-value ratio endogenous, alone with consumption loans against durable equity, and compares the predictions of the extended model to the empirical evidence. Its is shown that the extended model resolves the co-movement problem at the empirically relevant durable price stickiness of 1.5 - quarters, and eliminates the counterfactual predictions of the sticky price models, including those with demandside credit frictions, regarding the response of gross output and the nominal interest rate to the monetary contraction. This is achieved because the endogenous loanto-value-ratio declines with a monetary tightening, which tightens credit conditions and causes expenditures on durable goods to decline, along with expenditures on nondurables, which have become relatively more expensive. The presence of consumption 
loans also helps to improve the predictions of the model by linking the monetary policy shock to the effective real wage of the borrowers, and their labour supply decision, employment and output.

The improved performance of the extended model relies on factors that affect primarily the demand side of the economy, rather than supply factors that have been considered in the literature in order to improve the predictions of sticky price models. Nonetheless a new feature of our model is that demand factors such as consumption loans affect supply decisions by altering the effective real wage or the opportunity cost of leisure in the face of monetary shocks. 


\section{Chapter 4}

\section{FINANCIAL FRICTIONS, DURABLE GOODS AND MONETARY POLICY}

\subsection{Introduction}

When households purchase durable goods such as homes, automobiles and other big ticket items, most often they pay for them with a partial cash downpayment and the remainder with loans through borrowing. Lenders on the other hand try to secure their loans with collateral requirements, and, equally important, employment and income information in order to make sure that borrowers will be able to meet the flow of their periodic debt and interest payments. Such requirements, are important parts of credit or financial frictions in the recent macro-finance literature. Although this literature has given extensive consideration to collateral frictions, income constraints on durable purchases have received less attention.

In this paper we re-examine the reaction of durable and non-durable consumption, and related macroeconomics variables to monetary shocks in the context of the twosector sticky price model with financial frictions. In contrast to the majority of the existing literature, we consider a broader set of financial frictions consisting of loan-to-value (LTV) limits, and payment-to-income (PTI) limits on borrowing. The LTV limits are standard and constrain the debt issued to borrowers to be a net-ofdownpayment fraction of the expected future value of the durable goods, whereas the PTI limits constrain interest payments on the debt to be a specific fraction of the borrowers' labour income. It is shown that the extension to this type of credit frictions 
is important in reconciling the predictions of the model with the empirical facts. In particular the PTI constraint is crucial in resolving the "co-movement problem" between durables and non-durables in response to monetary shocks, even with fully flexible durable prices, and in avoiding some other counterfactual predictions that have plagued the sticky price model. The implication of our results is that, relative to sticky prices, financial frictions on aggregate demand go a long way in determining the predictive properties of the model.

In the recent macroeconomics literature, monetary policy has been considered within dynamic stochastic general equilibrium models with sticky prices and durable goods. Notable contributions in this line of research include, among others, Barsky, House and Kimball (2003, 2007), Iacoviello (2005), and Erceg and Levin (2006). It is well known that with perfect financial markets the standard sticky price model with durable goods generates some counterfactual predictions, including the so-called co-movement problem. Namely, for low levels of durable price stickiness, the model predicts a negative correlation between durables and non-durables in response to a monetary shock. For example, a monetary contraction causes a fall in non-durable consumption and a rise in durable consumption, a prediction which contradicts the empirical evidence which shows that both types of consumption fall, and durables fall more than non-durables; Bernanke and Gertler (1995), Barsky et al (2003), Erceg and Levin (2006). Further, if the predicted rise in durables is large enough to offset the fall in non-durables, aggregate output will be unchanged; and with increasing price stickiness the nominal interest rate falls despite the monetary tightening.

Barsky et al $(2003,2007)$ noted that these counterfactual results arise from the near constancy of the shadow value of durables, and suggested that financial frictions may improve the predictive power of sticky price models. Monacelli (2009) introduces 
collateral or LTV ratio constraints on borrowing in the two-sector new Keynesian model with borrowers and lenders. Household debt in the model reflects trade between households with different rates of time preference. Collateral constraints break the near constancy of the shadow value of durables, and this helps to resolve the comovement problem and the perverse reaction of the interest rate for a limited range of durable price stickiness, around the 2-quarter mark, relative to the benchmark of 4-quarter price stickiness for non-durables. For durable price stickiness below this range, or for full durable price flexibility the co-movement problem remained unresolved. The implication of Monacelli's main findings is that financial frictions on borrowing reduce the importance of price stickiness in determining the model's behaviour.

Sterk (2010) disentangled the relative importance of price stickiness and financial frictions by comparing the predictions of Monacelli's model with and without financial frictions. He showed that collateral constraints, in fact, make it more difficult to resolve the co-movement problem. This striking result is due to the general equilibrium implications of the bonds or debt market. Specifically, the presence of collateral constraints reduces the ability of lenders to lend more to borrowers. As a result, they use their extra savings to smooth their consumption by buying more durable goods. If the increase in lenders' durable purchases is large enough it is then possible that total durable consumption is higher with credit frictions than in the model without frictions. Also with flexible durable prices, aggregate output may even expand following a monetary contraction in the model with credit frictions, contrary to the empirical evidence. Sterk's results reinstated the importance of price stickiness and down played the importance of credit frictions on demand in sticky price models. He went on to conclude that supply frictions, such as lending by firms to households 
considered by Carlstrom and Fuerst (2006), provide a more satisfactory approach to resolving the co-movement problem.

Although collateral requirements alone may not be enough to align the predictions of the sticky price model with the empirical evidence, demand-side financial frictions can still be very useful in improving the predictions of the model. As we show below, when credit frictions are extended to include both collateral and income requirements, they provide an effective and realistic way to resolving the co-movement problem and the other counterfactual predictions of the sticky price model. Our framework is the heterogeneous agent two-sector sticky price model with financial frictions consisting of random combinations of LTV and PTI borrowing constraints, similar to Greenwald (2016). In this setting, the amount of collateralized debt is determined randomly by shocks to the borrowers' labour income. If the borrowers' income is above a threshold value the LTV constraint binds, and if it is below the threshold the PTI constraint binds. The actual collateralized debt obtained by borrowers is the minimum of the two debt levels associated with the two constraints. A monetary tightening in this context causes the consumption of both durable and nondurable goods to fall even when durable prices are fully flexible. Aggregate output also decreases and the nominal interest rate increases as would be expected with a monetary contraction. Further, household debt declines more sharply in this model than in the model with collateral constraints alone.

To see how these predictions arise, it is important to understand how the interaction of the collateral and income constraints changes the dynamics of a monetary tightening in the model with collateral constraints alone. One reason for the change is the link between the monetary policy shock and the opportunity cost of leisure, and hence the labour supply of the borrowers. Another reason is the response of the 
shadow value of borrowing which varies with the monetary shock.

Regarding the former, the opportunity cost of leisure for the borrowers depends on the interest rate through the PTI constraint. A monetary tightening which raises the interest rate decreases the opportunity cost of leisure and reduces the labour supply of the borrowers. As a result production and consumption of durables and nondurables is reduced. This helps resolve the co-movement problem between durables and non-durables, even with flexible durable prices.

The monetary tightening affects also the shadow value of borrowing and the shadow value of durables. Both increase, but the rise in each is less with both constraints than with the collateral constraint alone. The reason is that the increase in the interest rate tightens credit conditions more through the PTI constraint. The borrower can relax this constraint by working more but the increase in the interest rate dictates working less by reducing the current opportunity cost of leisure. Since the tighter credit conditions reduce the amount of the debt and the relative price of the durable good, the only way a borrower can purchase a more valuable durable is to pay dollar-for-dollar beyond the price that satisfies both constraints. This is not the case in an economy with only a collateral constraint, as in this case purchases of additional units of the durable relax the LTV constraint, which allows the borrower to accumulate more debt. This option is not available when the PTI constraint binds. As a result the rise in the shadow value of borrowing and the shadow value of durables is less in the latter case than in the former. Equivalently the user cost of durables rises by more in the two frictions case than in the case with only a collateral friction. The implication is that there is less incentive in the present model with two frictions to substitute durables for non-durables which would otherwise tend to exacerbate the co-movement problem relative to frictionless economy, as noted by Sterk (2010). 
The rest of the paper is as follows. Section 2 discusses the related literature. Section 3 presents a simple example to analyse and provide intuition for the interaction of the PTI and LTV constraints. Section 4 presents the empirical evidence and stylized facts related to the co-movement problem. Section 5 presents the theoretical model and discusses the optimality conditions for borrowers and lenders. Section 6 reports and discusses the simulation results. Section 7 contains some concluding remarks.

\subsection{Related Literature}

This paper complements existing strands of the literature on durable goods. Ohanian et al. (1995) discuss the co-movement problem in a general equilibrium two-sector model without financial frictions, in which one good has a flexible price and the other has a sticky price. They show that a monetary policy shock may induce a negative co-movement of sectoral outputs. Barsky et al. (2003) note that the standard twosector sticky price model generates counterfactual co-movements between durable and non-durable consumption and suggested two different mechanisms that could help match the model's predictions with the empirical evidence: on the supply-side, wage stickiness and an the demand side: credit frictions. Monacelli (2009) extends the basic model to include lenders and borrowers with the latter facing collateral constraints on their borrowing. He is able resolve the co-movement problem for a limited degree of durable price stickiness, but not for the case of maximum durable price flexibility. Also in his model the nominal interest rate falls when the degree of durable price stickiness increases, despite the monetary contraction. Sterk (2010) shows that collateral constraints in fact make it more difficult to resolve the comovement problem both because they increase the shadow value of durables for the borrowers and because they induce consumption smoothing lenders to purchase more 
durables.

Kim and Katiyama (2013) modify the two-sector sticky price model to allow for non-separable preferences and complementarity between non-durable consumption and labour supply. With flexibly priced durables, a monetary contraction decreases consumption and production of non-durables and the labour supply. In turn, this raises the real wage and decreases the consumption and production of durable goods. More recently, Chen and Liao (2014) resolve the co-movement problem by adding capital as another input in the production process along with a collateral constraint for borrowers. With flexible durable prices, a monetary contraction induces capital accumulation which reduces savers' disposable income in the short run. As a result, savers reduce their expenditures on durable along with non-durables which have now become relatively more expensive. Nonetheless, capital accumulation leads to a counterfactual fall in the nominal interest rate in their model.

Another strand of the literature attempts to deal with the co-movement problem by considering the supply side of the economy with a representative agent. Carlstrom and Fuerst (2006) consider a model with nominal wage stickiness and firm-level adjustment costs on durable production, and generated a positive co-movement between durable and non-durable goods. Bouakez, Cardia, and Ruge-Murcia (2011) and Sudo (2012) show that introducing factor demand linkages help to generate a positive comovement between non-durable and durable spending after a monetary shock, thus overcoming the limits of the standard two-sector models that feature varying degrees of price stickiness across sectors.

There is also a small emerging literature which incorporates PTI constraints in dynamic macroeconomic models with financial frictions ${ }^{1}$. Corbae and Quintin (2013)

\footnotetext{
${ }^{1}$ In contrast, following the seminal paper by Kyotaki and Moore (1997), the literature of hetero-
} 
incorporate a PTI constraint in their model and use it to explain the housing boom in the US, and its relationship to default risk and credit growth. Greenwald (2016) presents empirical evidence for the importance of PTI limits for the recent boom-bust cycle of the US housing market, and studies their interaction with LTV limits in a general equilibrium model with prepayable mortgage debt. He shows that PTI limits amplify greatly the effects of nominal interest rate shocks on mortgage debt and the macroeconomy.

In the present paper we introduce PTI and LTV limits in our analysis similar to Greenwald. Given the practical importance of the two constraints in actual credit markets, we exploit their interaction in order to provide a realistic alternative resolution to the co-movement problem between durable and non-durable spending. Our analysis is different from the existing literature in that we rely solely on demand-side financial frictions to resolve the co-movement problem even with fully flexible durable prices, which cannot be done in models with collateral constraints alone. An added advantage of our model is that it predicts the correct response of output and the nominal interest rate to monetary shocks.

\subsection{The Interaction of the PTI and LTV Constraints}

In this section we present a numerical example in order to illustrate the significance of the PTI and LTV constraints, and show how their interaction affects the borrowing capacity of the borrowers. Also it provides intuition on how monetary policy can alter the dynamics of the model relative to the case of an LTV constraint alone.

geneous agent models with collateral constraints has grown very large, especially during the great moderation and after the financial crisis and the role that the US housing sector played in them. See among others Iacoviello (2005), Iacoviello and Neri (2010), Calza et. al (2013) and Justiniano et al (2015). 
In practice both constraints are important. In order to extend loans to borrowers, lenders evaluate the credit worthiness and the ability of borrowers to pay back the principal and interest. The PTI ratio is used to measure the borrower's ability to manage monthly payments and debt repayment. It measures how much of monthly income goes toward paying the credit card bills, mortgage, car payment and other long-term and significant short-term monthly debts. For many lenders, the PTI limits is set at between 28 and 36 percent of a borrower's average monthly income ${ }^{2}$. On the other hand, the LTV ratio is the ratio of the debt to the value of the collateral. Most lenders set the LTV ratio at $80 \%$ or less. The aim of the PTI limit is to prevent default, and the purpose of the LTV limit is to reduce the probability of debt repudiation by borrowers. When both constraints are considered, the amount of the debt issued to a borrower is the minimum of the debt amounts implied by the PTI and LTV limits. This is illustrated in the following example.

Consider a borrower with average monthly income of $\$ 6000$, facing a PTI ratio of $28 \%$ and an LTV ratio of $80 \%$ or equivalently a $20 \%$ downpayment. Then his/her maximum monthly payment consistent with the PTI limit is $\$ 1680$ per month. If the borrower is quoted an effective interest rate of $4 \%$ on a loan with an amortization period of 20 years, the annualized rate will be $4.074 \%$ and the maximum loan amount based on PTI limit will be $\$ 275,457.30$. Because the borrower has to satisfy the LTV constraint as well, this amount has to be exactly equal to $0.80 P_{\max }$, implying $P_{\max }=$ $\$ 344,321.63$, where $P_{\max }$ is the maximum price of the durable good that satisfies both constraints. Further, for prices in the range $\left(0, P_{\max }\right)$ the LTV constraint binds and for prices above $P_{\max }$ the PTI constraint binds. In the former case the borrower can

\footnotetext{
${ }^{2}$ Fannie Mae makes exceptions to the maximum allowable PTI ratios for particular mortgage transactions, maximum limits may be higher or lower
} 
increase purchases of the durable good by paying $20 \%$ cash and borrowing $80 \%$ for the balance. In the latter case, purchasing a higher-priced durable entails paying dollar-for-dollar with cash beyond $P_{\max }$. Next, consider a monetary policy shock which raises the interest rate from $4 \%$ to $5 \%$. Now, the maximum amount of debt allowed by the PTI constraint is $\$ 252,104.18$, and the corresponding maximum price is $P_{\max }^{\prime}=\$ 315,130.23$. These results are summarized in Table 1 .

\begin{tabular}{ccl}
\hline \hline Interest rate & Max PTI loan & Max durable price \\
\hline \hline $4 \%$ & $\$ 275,457.30$ & $\$ 344,321.63$ \\
$5 \%$ & $\$ 252,104.18$ & $\$ 315,130.23$ \\
\hline \hline
\end{tabular}

Table 4.1: Maximum Loan due to the PTI limit

Note, the interest rate hike has decreased the collateralized debt and the price of the durable by $9.26 \%$. More important, because $P_{\max }^{\prime}<P_{\max }$ and the PTI constraint binds, the monetary contraction has reduced the shadow value of borrowing, as now the borrower has to pay fully with cash if s/he is willing to purchase a more valuable durable than $P_{\max }^{\prime}$. Clearly, that is not the case when the LTV constraint binds, as in this case the borrower can purchase a more valuable durable and use it as collateral to relax the LTV constraint and accumulate more debt to finance $80 \%$ of the additional cost. This collateral constraint effect which is present when the LTV constraint binds, is shut-off when the PTI constraint binds. In the latter case, the borrower can relax the PTI constraint by increasing his/her labour income, that is, by working more. Because borrowers are more impatient than lenders, and as a result they wish to tilt consumption in the present, the shadow value of borrowing is positive in both cases. However, following the increase in the interest rate, the shadow value of borrowing 
should be expected to rise by less in economies with both financial frictions than in economies with only an LTV friction.

As we show below, this insight has important implications for the dynamics of the two sector general equilibrium sticky price model with PTI and LTV frictions. As noted by Sterk (2010), models with LTV frictions alone make it harder to resolve the co-movement problem between durables and non-durables relative to models without financial frictions, because the monetary contraction increases the shadow value of borrowing and the shadow value of durables, and thus results in a substitution of durables for non-durable purchases. This substitution effect is reduced when both frictions are present and the PTI constraint binds, as then the rise in the shadow value of borrowing is relatively small. This is an important reason why the presence of the two frictions helps to resolve the co-movement problem even with fully flexible durable prices. Another important reason is that the PTI constraint affects directly the opportunity cost of leisure and hence the labour supply of the borrowers. In particular, the increase in the interest rate reduces the opportunity cost of leisure and the borrowers' labour supply. As a results the consumption and production of durables and non-durables both fall.

\subsection{The model}

We extend the two-sector heterogeneous agent sticky-price model with durable and non-durable goods, whereby borrowers are subject to both an LTV constraint and a PTI constraint. In this framework, we examine the effects of a monetary contraction on durable and non-durable consumption, output, real household debt and the nominal interest rate. 


\subsubsection{Households}

The economy has two types of representative households, impatient borrowers and patient savers/lenders, of measure $\omega$ and $1-\omega$, respectively. Each individual household's time endowment is normalized to 1 . All households derive utility from the consumption of a non-durable final good and from the services of a durable final good. Debt accumulation reflects intertemporal trading between the borrowers and the savers. The borrowers are subject to two constraints: a collateral constraint, where the borrowing limit tied to the expected future value of the stock of durables, and an income constraint such that the amount of the loan secured by the borrowers is limited by their random employment income.

\subsubsection{The Borrowers}

Following the literature, a typical borrower consumes a composite of a non-durable good and the services from a durable good indexed by

$$
X_{t}=\left((1-\mu)^{\frac{1}{\eta}}\left(C_{t}\right)^{\frac{\eta-1}{\eta}}+(\mu)^{\frac{1}{\eta}}\left(D_{t}\right)^{\frac{\eta-1}{\eta}}\right)^{\frac{\eta}{\eta-1}}
$$

where $C_{t}$ denote consumption of the final non-durable good and $D_{t}$ denotes services from the stock of the final durable good at the end of period $t, \mu>0$ is the share of durable goods in the composite consumption index and $\eta \geq 0$ is the elasticity of substitution between services of durable and non-durable consumption. The instantaneous utility function of the borrowers is given by

$$
U\left(X_{t}, N_{t}\right)=\log \left(X_{t}\right)-\frac{\nu N_{t}^{1+\varphi}}{1+\varphi}
$$


where $N_{t}$ is the labour supply, $\varphi$ is the inverse elasticity of labour supply and $\nu$ is a parameter that indexes the preference for hours worked for each borrower.

A new loan $B_{i, t}$ by borrower $i$ must satisfy both the LTV and PTI constraints, defined by

$$
\begin{gathered}
R_{t} B_{i, t}^{l t v} \leq \kappa^{l t v}(1-\delta) E_{t}\left\{D_{i, t} P_{d, t+1}\right\} \\
\left(R_{t}-1+\tau\right) B_{i, t}^{p t i} \leq \kappa^{p t i} W_{t} N_{i, t} e_{i, t}
\end{gathered}
$$

where $P_{d, t}$ is the price of durables, $R_{t}$ is the gross nominal interest rate, $\delta$ is the rate of depreciation of durables, $\kappa^{l t v}$ and $\kappa^{p t i}$ are the exogenous LTV and PTI ratios, $\tau$ accounts for taxes, insurance, and other borrowing costs associated with debt issuance and payment, and $e_{i, t}$ is a random shock to the borrower's labour income which is log-normally distributed with mean 1 and c.d.f $F_{e}$. The LTV limit is standard and constrains the debt issued to each borrower to be a net-of-downpayment fraction of their expected future value of the durable goods. On the other hand, the PTI limit constrains interest payments on the debt to be a specific fraction of each borrower's random labour income. Since each borrower must satisfy both constraints, $B_{i, t}$ must be the minimum of the two debt limits implied by the LTV and PTI constraints: $B_{i, t}=\min \left(B_{i, t}^{p t i}, B_{i, t}^{l t v}\right)$.

The labour income shock induces borrower heterogeneity, and determines endogenously the fraction of borrowers with a binding PTI limit in equilibrium. Let 


$$
\begin{gathered}
\bar{B}_{t}^{l t v}=\frac{\kappa^{l t v}(1-\delta) E_{t}\left\{D_{t} P_{d, t+1}\right\}}{R_{t}} \\
\bar{B}_{t}^{p t i}=\frac{\kappa^{p t i} W_{t} N_{t}}{\left(R_{t}-1+\tau\right)}
\end{gathered}
$$

be the maximum average LTV and PTI debt limits, respectively, when $E\left(e_{i t}\right)=1$. Also let $\bar{e}_{t}=\bar{B}_{t}^{\text {ltv }} / \bar{B}_{t}^{p t i}$ be the threshold value of the income shock $e_{i, t}$ such that when $e_{i, t}<\bar{e}_{t}$ the PTI constraint binds, and when $e_{i, t}>\bar{e}_{t}$ the LTV constraint binds. Then, the combined average borrower debt $\bar{B}_{t}$ is given by

$$
\begin{aligned}
& \bar{B}_{t}=\int \min \left(\bar{B}_{t}^{p t i} e_{i}, \bar{B}_{t}^{l t v}\right) d F_{e}\left(e_{i}\right) \\
= & \int_{0}^{\bar{e}_{t}} \bar{B}_{t}^{p t i} e_{i} d F_{e}\left(e_{i}\right)+\int_{\bar{e}_{t}}^{\infty} \bar{B}_{t}^{l t v} d F_{e}\left(e_{i}\right) \\
= & \underbrace{\bar{B}_{t}^{p t i} \int_{0}^{\bar{e}_{t}} e_{i} d F_{e}\left(e_{i}\right)}_{\text {PTI Constrained }}+\underbrace{\bar{B}_{t}^{l t v}\left(1-F_{e}\left(\bar{e}_{t}\right)\right)}_{\text {LTV Constrained }}
\end{aligned}
$$

where the first and second terms in (4.7) represent the borrowing capacity of PTI and LTV constrained households, respectively. The properties of the lognormal distribution imply the closed form expression

$$
\begin{gathered}
G_{e}\left(\bar{e}_{t}\right)=\int_{0}^{\bar{e}_{t}} e_{i} d F_{e}\left(e_{i}\right)=\Phi\left(\frac{\log \bar{e}_{t}-\frac{\sigma_{e}^{2}}{2}}{\sigma_{e}}\right) \\
F_{e}\left(\bar{e}_{t}\right)=\Phi\left(\frac{\log \bar{e}_{t}+\frac{\sigma_{e}^{2}}{2}}{\sigma_{e}}\right)
\end{gathered}
$$

where $\Phi($.$) is the cumulative distribution function of the standard normal distribution.$ This is convenient since the borrower's problem aggregates into a single representative borrower (Greenwald, 2016). 
In this setting, the representative borrower maximizes expected discounted lifetime utility based on information available at time 0 :

$$
E_{0}\left\{\sum_{t=0}^{\infty} \beta^{t}\left(\log \left(X_{t}\right)-\frac{\nu N_{t}^{1+\varphi}}{1+\varphi}\right)\right\}
$$

subject to the debt constraint

$$
B_{t} \leq \bar{B}_{t}
$$

and the average budget constraint

$$
P_{c, t} C_{t}+P_{d, t} I_{t}+R_{t-1} B_{t-1}=B_{t}+W_{t} N_{t}+T_{t}
$$

where, in addition, $P_{c, t}$ is the price of non-durables, $I_{t}=D_{t}-(1-\delta) D_{t-1}$ are real purchases of new durables, $B_{t}$ is nominal debt at the end of period $t, W_{t}$ is the nominal wage rate, and $T_{t}$ is lump-sum money transfers from the government.

For optimization in units of non-durable consumption, the budget constraint (4.14) is given by

$$
C_{t}+q_{t} I_{t}+R_{t-1} \frac{b_{t-1}}{\pi_{c, t}}=b_{t}+\frac{W_{t}}{P_{c, t}} N_{t}+\frac{T_{t}}{P_{c, t}}
$$

where $q_{t} \equiv \frac{P_{d, t}}{P_{c, t}}$ is the relative price of the durable goods, $\pi_{c, t} \equiv \frac{P_{c, t}}{P_{c, t-1}}$ is non-durable good inflation, and $b_{t}=\frac{B_{t}}{P_{c, t}}$ is real debt. Similarly, letting $\bar{b}_{t}=\frac{\bar{B}_{t}}{P_{c, t}}$ and 


$$
\begin{gathered}
\bar{b}_{t}^{l t v}=\frac{B_{t}^{l t v}}{P_{c, t}}=\frac{\kappa^{l t v}(1-\delta) E_{t}\left\{D_{t} P_{d, t+1}\right\}}{R_{t} P_{c, t}} \\
\bar{b}_{t}^{p t i}=\frac{B_{t}^{p t i}}{P_{c, t}}=\frac{\kappa^{p t i} W_{t} N_{t}}{\left(R_{t}-1+\tau\right) P_{c, t}}, \\
\bar{b}_{t}=\bar{b}_{t}^{p t i} \int_{0}^{\bar{e}_{t}} e_{i} d F_{e}\left(e_{i}\right)+\bar{b}_{t}^{l t v}\left(1-F_{e}\left(\bar{e}_{t}\right)\right)
\end{gathered}
$$

we can write the real debt constraint as

$$
b_{t} \leq \bar{b}_{t} .
$$

The representative borrower chooses the real quantities $\left\{C_{t}, N_{t}, D_{t}, b_{t}\right\}$ to maximize expected lifetime utility. The Lagrangian for this problem is

$$
\begin{aligned}
L=\sum_{t=0}^{\infty} & {\left[\beta ^ { t } \left[\left(\log \left(X_{t}\right)-\frac{\nu N_{t}^{1+\varphi}}{1+\varphi}\right)\right.\right.} \\
& +\lambda_{t}\left(b_{t}+\frac{W_{t}}{P_{c, t}} N_{t}+\frac{T_{t}}{P_{c, t}}-C_{t}-q_{t}\left(D_{t}-(1-\delta) D_{t-1}\right)-R_{t-1} \frac{b_{t-1}}{\pi_{c, t}}\right) \\
& \left.\left.+\lambda_{t} \psi_{t}\left(\bar{b}_{t}^{p t i} G_{e}\left(\bar{e}_{t}\right)+\bar{b}_{t}^{l t v}\left(1-F_{e}\left(\bar{e}_{t}\right)\right)-b_{t}\right)\right]\right]
\end{aligned}
$$

where $\lambda_{t}$ and $\lambda_{t} \psi_{t}$ are the multipliers associated with the budget constraint and combined debt constraint, respectively. 
The optimality conditions for the borrowers' maximization problem are

$$
\begin{aligned}
\frac{-U_{n, t}}{U_{c, t}}= & \frac{W_{t}}{P_{c, t}}\left[1+\psi_{t} \frac{\kappa^{p t i}}{R_{t}-1+\tau} G_{e}\left(\bar{e}_{t}\right)\right] \\
U_{c, t} q_{t}= & U_{d, t}+\beta(1-\delta) E_{t}\left[q_{t+1} U_{c, t+1}\right] \\
& \quad+U_{c, t} \psi_{t} q_{t}\left[\frac{\kappa^{l t v}(1-\delta) E_{t}\left(\pi_{d, t+1}\right)}{R_{t}}\left(1-F_{e}\left(\bar{e}_{t}\right)\right)\right] \\
\psi_{t}= & 1-\beta E_{t}\left[\frac{U_{c, t+1}}{U_{c, t}} \frac{R_{t}}{\pi_{c, t+1}}\right] .
\end{aligned}
$$

Equation (4.20) sets the marginal rate of substitution between consumption and leisure equal to the opportunity cost of leisure. The latter is the product of the real wage in terms of non-durables times the term in the square brackets which is positive when the PTI constraint is binding, such that $\psi_{t}>0$ and $G_{e}\left(\bar{e}_{t}\right)>0$. With the LTV constraint alone, $\kappa^{p t i}=0$ and the term in the square brackets is unity, in which case equation (4.20) becomes the standard labour market condition. Thus, the opportunity cost of leisure is higher in the present model with both LTV and PTI constraints than in the model with only the LTV constraint because an extra hour of work generates more income and relaxes the PTI constraint. Further, condition (4.20) depends explicitly on the interest rate $R_{t}$, so that the opportunity cost of leisure changes with monetary policy shocks. For instance, a monetary contraction by raising $R_{t}$ reduces the opportunity cost of leisure resulting in a reduction in the borrowers' labour supply. This is important for the propagation of monetary shocks in the economy and the dynamics of the model relative to models with only collateral frictions.

Equation (4.21) sets the marginal utility of non-durable consumption equal to the shadow value of durables. The latter has three components: i) the direct marginal 
utility of one unit of the durable in period $t$, ii) the discounted expected utility from selling one unit of the durable and using the proceeds to expand future non-durable consumption, and iii) the marginal utility of relaxing the collateral constraint through the purchase of an additional unit of the durable. Notice that this is proportional to $\psi_{t}$, which measures the tightness of the collateral constraint, and to $\left(1-F_{e}\left(\bar{e}_{t}\right)\right)$, the fraction of borrowers with a binding collateral constraint. When the LTV constraint is not binding, both of these terms are equal to zero and the shadow value of one unit of durables reduces to the sum of the first two terms.

Equation (4.22) is the Euler equation for debt. The shadow value of borrowing, $\psi_{t}$, is the extra utility that would result from borrowing an extra dollar, using it to increase current consumption and reducing consumption next period by an appropriate amount. When the debt constraint $b_{t} \leq \bar{b}_{t}$ is binding, $\psi_{t}>0$ and at the constrained optimum, the marginal utility of current consumption is greater than the discounted expected marginal utility of future consumption. When the debt constraint is not binding $\psi_{t}=0$, and this condition reduces to the standard Euler equation.

Equation (4.21) can be rewritten to equate the marginal rate of substitution between durables and non-durables, $U_{d, t} / U_{c, t}$, to the user cost of durables, $Z_{t}$, given by

$$
\begin{aligned}
Z_{t}=q_{t}\left[1-\psi_{t}\right. & \left.\left(\frac{\kappa^{l t v}(1-\delta) E_{t}\left\{\pi_{d, t+1}\right\}}{R_{t}}\left(1-F_{e}\left(\bar{e}_{t}\right)\right)\right)\right] \\
& -\beta(1-\delta) E_{t}\left\{\frac{U_{c, t+1}}{U_{c, t}} q_{t+1}\right\}
\end{aligned}
$$

Log linearizing equation (4.23) around the deterministic steady state we obtain 


$$
\begin{gathered}
\hat{z}_{t}=\bar{Z}^{-1}(1-\delta)\left[\Upsilon_{1} \hat{q}_{t}-\beta E_{t} \hat{q}_{t+1}+\gamma \hat{R}_{r, t}+(\gamma-\beta)\left(\left(\left(1-\kappa^{l t v}\right)+\kappa^{l t v} F(\bar{e})\right) \hat{\psi}_{t}-\hat{\zeta}_{t}\right)\right. \\
\left.\quad-\gamma(\gamma-\beta) \kappa^{l t v}\left[1-F_{e}(\bar{e})\right] \hat{R}_{t}\right]
\end{gathered}
$$

in which

$$
\begin{aligned}
\Upsilon_{1} & =\frac{\left(1-\gamma \kappa^{l t v}(1-\delta)(\gamma-\beta)\left[1-F_{e}(\bar{e})\right]\right)}{1-\delta} \\
\hat{\zeta} & =E_{t}\left(\kappa^{l t v}\left(1-F_{e}(\bar{e})-\pi_{c, t+1}\right)\right. \\
\bar{Z} & =1-(1-\delta)\left(\beta+\gamma \kappa^{l t v}(\gamma-\beta)\left[1-F_{e}(\bar{e})\right]\right) \\
\hat{R}_{r, t} & =\hat{R}_{t}-E_{t}\left[\hat{\pi}_{c, t+1}\right]
\end{aligned}
$$

where $\bar{Z}$ is the steady state value of the user cost and $\hat{R}_{r, t}$ is the real interest rate steady-state deviation in units of non-durables.

It is clear from equation (4.24), that the user cost of durables rises with changes in the relative price of durables, $q_{t}$, the shadow value of borrowing, $\psi_{t}$, and the nominal interest rate, $R_{t}$, and falls with expected future changes in the relative price of durables. With perfect financial market, $\psi_{t}=0$ and $\beta=\gamma$, and the user cost of durables reduces to the well-known result

$$
\hat{z}_{t}=(1-\beta(1-\delta))^{-1}(1-\delta)\left(\frac{\hat{q}_{t}}{1-\delta}-\beta E_{t} \hat{q}_{t+1}+\beta \hat{R}_{r, t}\right)
$$




\subsubsection{The Savers}

The savers are owners of the monopolistic competitive firms which produce the intermediate goods, and in each period, they collect the monopolistic profits. Like borrowers, they consume, work and earn wages, and receive transfers from government. The representative saver is infinitely-lived and seeks to maximize expected discounted lifetime utility

$$
E_{0}\left\{\sum_{t=0}^{\infty} \gamma^{t}\left(\log \left(\tilde{X}_{t}\right)-\frac{\nu \tilde{N}_{t}^{1+\varphi}}{1+\varphi}\right)\right\}
$$

subject to

$$
\tilde{C}_{t}+q_{t} \tilde{I}_{t}+R_{t-1} \frac{\tilde{b}_{t-1}}{\pi_{c, t}}=\tilde{b}_{t}+\frac{\tilde{W}_{t}}{P_{c, t}} \tilde{N}_{t}+\frac{\tilde{T}_{t}}{P_{c, t}}+\frac{\tilde{\Gamma}_{c, t}}{1-\omega}+\frac{q_{t} \tilde{\Gamma}_{d, t}}{1-\omega}
$$

where a $(\sim)$ over a variable denotes saver quantities, $\gamma$ is the saver's discount factor

such that $\gamma>\beta, \tilde{b}_{t}$ is end-of-period $t$ real debt (credit), and $\tilde{\Gamma}_{j, t}, j=(c, d)$ are aggregate nominal profits from the monopolistic competitive firms.

The saver chooses $\left\{\tilde{N}_{t}, \tilde{C}_{t}, \tilde{b}_{t}, \tilde{D}_{t}\right\}$ to maximizes equation (4.26) subject to equation (4.27). The optimality conditions for this problem are

$$
\begin{gathered}
\frac{-\tilde{U}_{n, t}}{\tilde{U}_{c, t}}=\frac{\tilde{W}_{t}}{P_{c, t}} \\
\tilde{U}_{c, t}=\gamma E\left\{\frac{\tilde{U}_{c, t+1}}{\tilde{\pi}_{c, t+1}} R_{t}\right\} \\
q_{t}=\frac{\tilde{U}_{d, t}}{\tilde{U}_{c, t}}+\gamma(1-\delta) E\left\{\frac{\tilde{U}_{c, t+1}}{\tilde{U}_{c, t}} q_{t+1}\right\} .
\end{gathered}
$$

These are conventional optimality conditions for perfect financial markets, as savers 
are not subject to any financial frictions.

\subsubsection{Firms}

There are intermediate and final goods producers in both the durable and non-durable sectors.

\subsubsection{Final goods producers}

In each sector, perfectly competitive firms produce the final good $Y_{j, t} j=c, d$. The production function in the $j$-th final goods sector is given by

$$
Y_{j, t}=\left(\int Y_{j, t}^{\frac{\varepsilon_{j}-1}{\varepsilon_{j}}}(i) d i\right)^{\frac{\varepsilon_{j}}{\varepsilon_{j}-1}}
$$

where $Y_{j, t}(i)$ is the intermediate good produced by firm $i$ in sector $j$, and $\varepsilon_{j}>1$, is the elasticity of substitution between intermediate goods in sector $j$.

\subsubsection{Production and pricing of Intermediate Goods}

The production of intermediate goods is undertaken in both sectors of the economy, each populated by a large number of monopolistic competitive firms. The problem of each monopolistic firm $i$ in sector $j$ is to choose the sequence of $\left\{N_{j, t}(i), P_{j, t}(i)\right\}$ to maximize expected discounted profits

$$
E_{0}\left\{\sum_{t=0}^{\infty} \Lambda_{j, t}\left(P_{j, t}(i) Y_{j, t}(i)-W_{t} N_{j, t}(i)-\frac{\vartheta_{j}}{2}\left(\frac{P_{j, t}(i)}{P_{j, t-1}}-1\right)^{2} P_{j, t} Y_{j, t}\right)\right\}
$$

subject to equation (4.31) and the linear production function

$$
Y_{j, t}(i)=N_{j, t}(i)-F_{j}
$$


where $\Lambda_{j, t}=\gamma \tilde{\lambda_{t}} / \tilde{\lambda_{0}}$ is the savers' stochastic discount factor, in which $\tilde{\lambda_{t}}$ is the is the savers' marginal utility of nominal income, and $\frac{\vartheta_{j}}{2}\left(\frac{P_{j, t}(i)}{P_{j, t-1}}-1\right)^{2} P_{j, t} Y_{j, t}$ is a quadratic price adjustment cost proportional to output, where the parameter $\vartheta_{j}$ measures the degree of sectoral nominal price stickiness. In particular, when $\vartheta_{j}=0$, prices are fully flexible in sector $j . F_{j} \geq 0$ is fixed cost of production reflecting cost of adjusting the labour input, as in Christiano et al (2005) and Notarpierto and Siveiro (2015). In a symmetric equilibrium $P_{j, t}(i) / P_{j, t}=1$ for all $i$ and $j$, and all firms employ the same amount of labour in each sector. In this case, the optimality condition of the intermediate producer in sector $j$ is

$$
\left(\left(1-\epsilon_{j}\right)+\epsilon_{j} m c_{j, t}\right)=\vartheta_{j}\left(\pi_{j, t}-1\right) \pi_{j, t}-\gamma \vartheta_{j} E\left\{\frac{\Lambda_{j, t+1}}{\Lambda_{j, t}} \frac{P_{j, t+1}}{P_{j, t}} \frac{Y_{j, t+1}}{Y_{j, t}}\left(\pi_{j, t+1}-1\right) \pi_{j, t+1}\right\}
$$

where $\pi_{j, t}=\frac{P_{j, t}}{P_{j, t}}$ is the gross inflation rate in sector $j$, and

$$
\frac{W_{t}}{P_{j, t}}=m c_{j, t} .
$$

For the interpretation of these conditions, we note that

$$
\begin{aligned}
& \mathbb{E}\left\{\frac{\Lambda_{j, t+1}}{\Lambda_{j, t}} \frac{P_{c, t+1}}{P_{c, t}}\right\}=\mathbb{E}\left\{\frac{\tilde{U}_{c, t+1}}{\tilde{U}_{c, t}}\right\} \text { if } j=c \text { and } \\
& \mathbb{E}\left\{\frac{\Lambda_{j, t+1}}{\Lambda_{j, t}} \frac{P_{d, t+1}}{P_{d, t}}\right\}=\mathbb{E}\left\{\frac{\tilde{U}_{c, t+1}}{\tilde{U}_{c, t}} \frac{q_{t+1}}{q_{t}}\right\} \text { if } j=d
\end{aligned}
$$

Finally, sectoral inflation and relative prices are related by

$$
\frac{\pi_{d, t}}{\pi_{c, t}}=\frac{q_{t}}{q_{t-1}}
$$




\subsubsection{Equilibrium}

A competitive equilibrium for this model is defined as the sequence of variables $N_{t}, N_{j, t}, \tilde{N}_{t}, \tilde{N}_{j, t}, b_{t}, \tilde{b}_{t} D_{t}, C_{t}, \tilde{C}_{t}, \tilde{D}_{t}$ for $j=c, d$ and prices $P_{c, t}, P_{d, t}, \frac{W_{t}}{P_{c, t}}, \frac{\tilde{W}_{t}}{P_{c}, t}, R_{t}$, $q_{t}, \pi_{c, t}, \pi_{d, t}$ such that

1. Given prices, $\left\{N_{t}, b_{t}, D_{t}, C_{t}\right\}$ solves the borrowers problem.

2. Given prices, $\left\{\tilde{N}_{t}, \tilde{b}_{t}, \tilde{D}_{t}, \tilde{C}_{t}\right\}$ solves the savers problem.

3. Given inflation, $R_{t}$ satisfies the monetary policy rule.

4. The goods, labour and credit markets clear.

\subsubsection{Market Clearing Conditions}

Equilibrium in the goods market requires that the production of the final goods be allocated to total households' expenditures and to resource costs originating from the adjustment of prices

$$
\begin{aligned}
& Y_{c, t}=\omega C_{t}+(1-\omega) \tilde{C}_{t}+\frac{\vartheta_{c}}{2}\left(\pi_{c, t}-1\right)^{2} Y_{c, t} \\
& Y_{d, t}=\omega I_{t}+(1-\omega) \tilde{I}_{t}+\frac{\vartheta_{d}}{2}\left(\pi_{d, t}-1\right)^{2} Y_{d, t} .
\end{aligned}
$$

Equilibrium in the credit and labour markets requires, respectively

$$
\begin{gathered}
\omega b_{t}+(1-\omega) \tilde{b}_{t}=0 \text { and } \\
N_{c, t}+N_{d, t}=\omega N_{t}+(1-\omega) \tilde{N}_{t} .
\end{gathered}
$$




\subsubsection{Monetary Policy}

Monetary policy follows the simple Taylor-type rule

$$
\begin{gathered}
\frac{R_{t}}{R}=\left(\frac{\tilde{\pi}_{t}}{\tilde{\pi}}\right)^{\phi_{\pi}} \exp \left(\varepsilon_{t}\right) \quad \phi_{\pi}>0 \\
\tilde{\pi}_{t}=\pi_{c, t}^{1-\mu} \pi_{d, t}^{\mu} \\
\varepsilon_{t}=\rho \varepsilon_{t-1}+u_{t}
\end{gathered}
$$

where $\tilde{\pi}_{t}=\pi_{c, t}^{1-\mu} \pi_{d, t}^{\mu}$ is a composite inflation index, $R$ and $\tilde{\pi}$ are the steady-state levels of the gross nominal interest rate and inflation index, respectively, and $\varepsilon_{t}$ is an exogenous monetary shock.

\subsection{Calibration}

In this section we calibrate the model to quarterly frequency, and unless otherwise specified, most parameters were drawn from Monacelli (2009). The parameter values are summarized in Table 2. We set the savers' discount factor $\gamma$ to 0.99 and the borrowers discount factor $\beta$ is set at $0.98^{3}$. The steady-state gross quarterly interest rate, $R$, was determined by the savers discount factor at 1.01 . The quarterly depreciation rate for durable goods, $\delta$, was set at 0.01 . The elasticity of substitution between varieties, $\varepsilon_{j}$, was set to 6 in both sectors, $j=c, d$, which yields a steady-state mark-up of $20 \%$. The parameters for nominal price stickiness were set according to $\vartheta_{j}=\frac{\theta\left(\varepsilon_{j}-1\right)}{(1-\theta)(1-\gamma \theta)}$, where $\theta$ is the probability of a firm not resetting prices in the standard Calvo-Yun model, $(1 / 1-\theta)$ is the average frequency of price adjustment. The non-durable price stickiness parameter $\vartheta_{c}$ was pinned down by setting $\theta=0.75$, which

\footnotetext{
${ }^{3}$ The steady state value of $\psi_{t}$ was determined from the borrowers' pseudo-Euler equation, as $\psi=(\gamma-\beta) / \gamma$.
} 
implies an average frequency of non-durable price adjustment of four quarters. In the main experiment we wanted to measure the reaction of the endogenous variables to a monetary tightening when durable prices are fully flexible. Accordingly, we set $\vartheta_{d}=0$, that is, one quarter durable price stickiness. For the sensitivity analysis the value of $\vartheta_{d}$ was changed to allow for 1.5, 2 and 3 quarters durable price stickiness. The elasticity of substitution between durables and non-durables $\eta$ was set at 1 , and the share of durables in total consumption $\mu$ was set at 0.20 . The preference parameter $\nu$ was set such that the borrowers and savers' labour supplies are equal to $1 / 3$ of their total normalized time. We set the fraction of borrowers $\omega=0.55$, an intermediate value between Monacelli's value of 0.50 and 0.61 which is the value estimated by Justiano et al (2015) based on data from the Survey of Consumer Finances. The inverse elasticity of the labour supply $\varphi$ was set at 1 . The coefficient on inflation in the Taylor rule $\phi_{\pi}$ was set at 1.5 , and the persistence parameter $\rho$ of the monetary shock was set at 0.5 . The LTV and PTI ratios $\kappa^{l t v}$ and $\kappa^{p t i}$ were set at 0.75 and 0.28 , respectively. The latter value is the same as in Greenwald (2016). Following Greenwald (2016), we set the debt cost parameter $\tau$ at 0.024. Similarly, the values of the borrowers' labour income shock $e_{i, t}$ were simulated from the log-normal distribution

$$
\log \left(e_{i t}\right) \sim N\left(\frac{-\sigma_{e}^{2}}{2}, \sigma_{e}\right)
$$

by setting the borrowers' income dispersion, $\sigma_{e}$ to 0.411 . Finally, we carried out an additional simulation by assuming adjustment costs to the purchases of new durable goods. In that case, discussed below, the durable adjustment cost parameter, $\Theta$, was chosen such that the volatility of new durable investment was about 4 to 5 times the volatility of non-durable spending. 


\begin{tabular}{llll}
\hline Parameter & Description & Both Constraints & LTV Constraint \\
\hline$\beta$ & Borrowers discount factor & .98 & .98 \\
$\gamma$ & Savers discount factor & 0.99 & 0.99 \\
$\delta$ & Depreciation rate of durables & 0.01 & 0.01 \\
$\varepsilon_{c}, \varepsilon_{d}$ & El. of sub. between varieties & 6 & 6 \\
$\eta$ & El. of sub. b/w dur. and non-dur. & 1 & 1 \\
$\mu$ & Share of durable consumption & 0.20 & 0.20 \\
$\omega$ & Fraction of borrowers & 0.55 & 0.55 \\
$\phi_{\pi}$ & Coeff. of inflation in Taylor rule & 1.5 & 1.5 \\
$\rho$ & Persistence of monetary shock & 0.5 & 0.5 \\
$\varphi$ & Inv. El. of labour supply & 1 & 1 \\
$\kappa^{l t v}$ & LTV ratio & 0.75 & 0.75 \\
$\kappa^{p t i}$ & PTI limit & 0.28 & - \\
$\tau$ & Debt cost parameter & 0.024 & - \\
$\sigma_{e}$ & Income dispersion & 0.411 & - \\
$\Theta$ & Investment adjustment cost & 0.0027 & - \\
\hline
\end{tabular}

Table 4.2: Parameter Values

\subsection{Results of Monetary Contraction}

We simulate a monetary contraction by a positive shock to $\varepsilon_{t}$ in the monetary policy rule, which raises the nominal interest rate by 25 basis points. As noted above, our main focus in the simulations is the case with fully flexible durable prices by setting $\vartheta_{d}=0$.

\subsubsection{Results}

First, we present some useful results which clarify the way in which the present model with two credit frictions resolves the co-movement problem relative to the model with only an LTV friction. Figure 2 plots the impulse response functions (IRFs) for the relative price of durables, the real debt, the shadow value of borrowing, the shadow 
value of durables, the borrowers' user cost of durables and their marginal utility from durable consumption.

Figure 4.1 Comparison of the models with two frictions and one friction
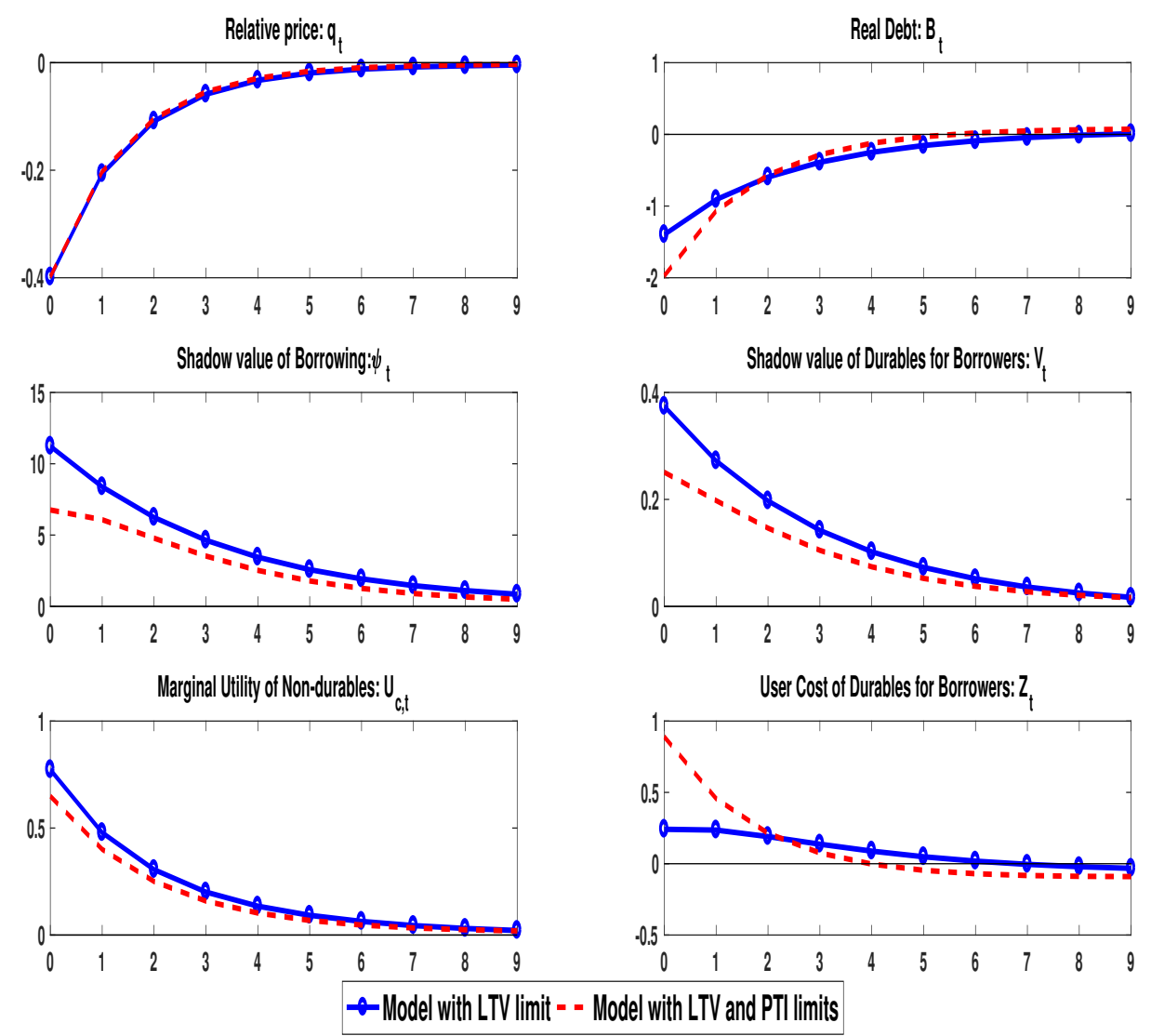

These results are consistent with the two models' predictions. Following the increase in the nominal interest rate, the relative price of durables falls by the same percentage in the two models, thus causing similar tightening in the two LTV constraints. However when the interest rate increases, the PTI constraint binds more often, and as a result the percentage fall in the borrowers' real debt is greater in the model with the two financial frictions than in the model with an LTV friction alone. 
Since the borrowers are constrained by their labour income, they can buy more valuable durables than those allowed by their PTI limit, by paying dollar-for-dollar for the difference. This implies that the shadow value of borrowing in the economy with both financial frictions, $\psi_{t}^{2}$, rises by less on impact than in the economy with only the LTV friction, $\psi_{t}^{1}: \psi_{t}^{2}<\psi_{t}^{1}$, as shown in Figure 4.1. In turn, this means that $V_{t}^{2}$ $<V_{t}^{1}$ for the corresponding shadow values of durables. To establish this formally, let $V_{t}^{2} \equiv U_{c, t} q_{t}$ denote the shadow value of durables in the model with the two frictions, and use the optimality condition (4.21) to obtain

$$
V_{t}^{2}=\frac{U_{d, t}+\beta(1-\delta) E_{t} V_{t+1}^{2}}{1-\psi_{t}^{2}\left(\frac{\left(\left(\kappa^{l t v}(1-\delta) E_{t} \pi_{d, t+1}\right)\right.}{R_{t}}\left(1-F_{e}\left(\bar{e}_{t}\right)\right)\right.}
$$

The corresponding $V_{t}^{1}$ for the model with one friction is

$$
V_{t}^{1}=\frac{U_{d, t}+\beta(1-\delta) E_{t} V_{t+1}^{1}}{1-\psi_{t}^{1}\left(\frac{\left(\left(\kappa^{l t v}(1-\delta) E_{t} \pi_{d, t+1}\right)\right.}{R_{t}}\right)}
$$

Since $\psi_{t}^{2}<\psi_{t}^{1}$ and $\left(1-F\left(\bar{e}_{t}\right)\right)<1$, it follows that $V_{t}^{2}<V_{t}^{1}$. Equivalently, borrowers tend to consume more non-durables than durables in the model with two frictions than the model with one friction. Consequently, the marginal utility of nondurable consumption $U_{c, t}$ is larger in the former case than in the later. This result is useful because, as noted by Sterk (2010), a high value for $V_{t}^{1}$ makes the co-movement problem harder to resolve with collateral frictions than no frictions at all.

Also, as a consequence of these results the user cost of durables with two credit frictions tends to be larger than the case with a collateral friction, as shown in Figure 4.1. Formally, writing the user cost $Z_{t}$ in equation (4.23) explicitly in terms of $\psi_{t}$ and $V_{t+1}$ we have 


$$
\begin{aligned}
Z_{t}=q_{t}\left[1-\psi_{t}\left(\frac{\kappa^{l t v}(1-\delta) \mathbb{E}_{t}\left\{\pi_{d, t+1}\right\}}{R_{t}}\left(1-F_{e}\left(\bar{e}_{t}\right)\right)\right)\right] \\
-\beta(1-\delta) \mathbb{E}_{t}\left\{\frac{V_{t+1}}{U_{c, t}}\right\},
\end{aligned}
$$

from which it can be easily seen that $Z_{t}^{2}>Z_{t}^{1}$.

\subsubsection{Resolving the Co-movement Problem}

Given the results above, we can now show that two-sector DSGE model with LTV and PTI frictions provides an adequate resolution to the co-movement, even when durable prices are fully flexible. Further, the monetary contraction results in a fall in aggregate output, and a rise in nominal interest, as is the case with the empirical evidence.

Consider the reaction of borrowers and lenders to the interest rate hike. Given flexible durable prices, the monetary tightening reduces the relative price of durables and results in a reduction in the consumption of non-durables for both borrowers and lenders. Thus, the aggregate consumption of non-durables falls. At the same time the tighter credit conditions reduce the amount of real debt that the borrowers can obtain due to the binding PTI constraint. As a result, they cut back on their purchases of durables. Because $Z_{t}^{2}>Z_{t}^{1}$ the fall in durable purchases is greater than the level implied by the LTV constraint alone. Also because $V_{t}^{2}<V_{t}^{1}$ borrowers have less of an incentive to substitute durables for non-durables, which prevents durable purchases from rising and non-durable purchases from declining further, and this makes it easier to resolve the co-movement problem. On the other hand lenders are now forced to reduce their lending activity and since they do not face any frictions, they spend 
their extra savings to smooth their consumption by purchasing more durables goods. However, the increase in their durables purchases is not large enough to offset the large reduction of durable purchases by borrowers. As a result, as shown in Figure 4.2 , aggregate purchases of durables also decline.

Figure 4.2 Impulse response of durable purchases

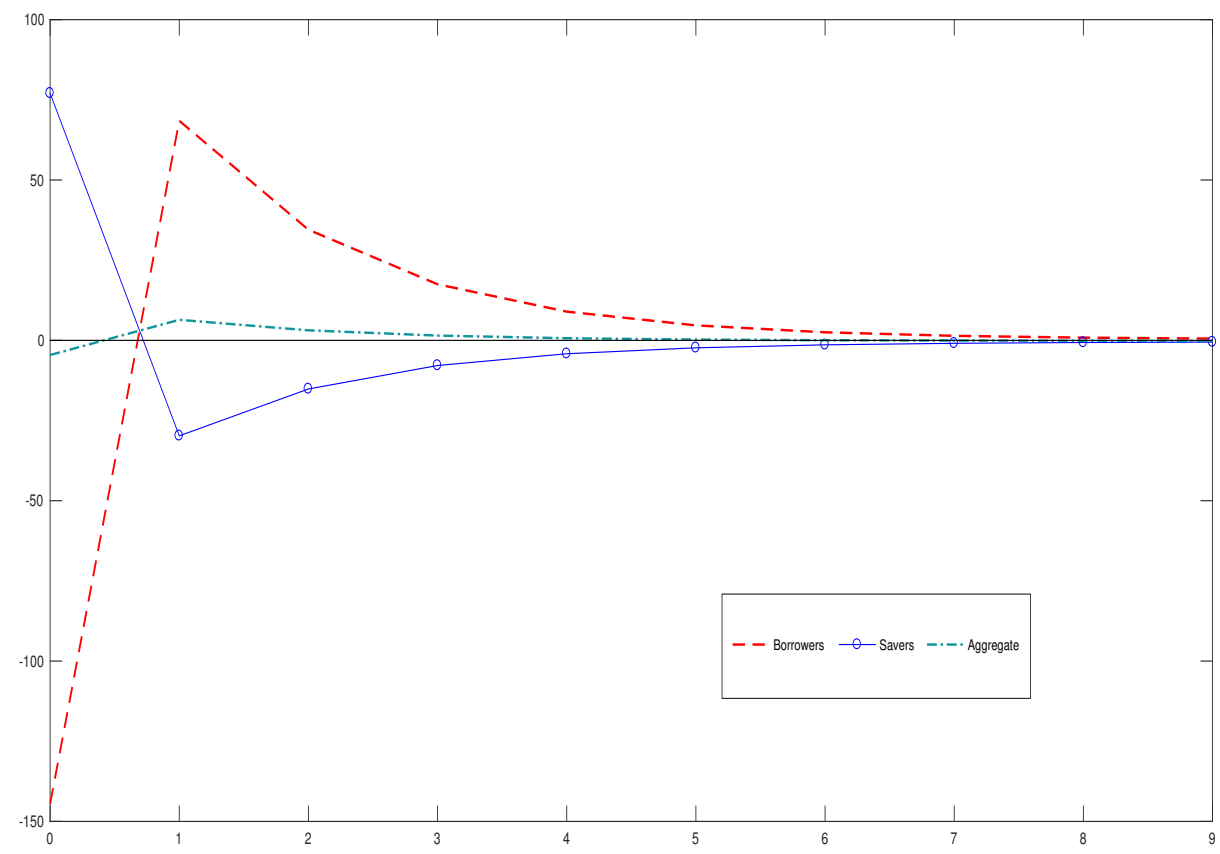

Note: Fully flexible durable prices.

With both aggregate non-durables and durable purchases falling after the monetary tightening so does aggregate output, as is the case in the data. With flexible durable prices, the nominal interest rate also increases, consistent with conventional wisdom and the empirical evidence. Figure 4.3 shows these results and compares the predictions of the present model with two credit frictions to the model with an LTV 
friction, and the model without any credit frictions. As shown, unlike the model with two credit frictions, non-durable and durable purchases move in the opposite direction in the model with the LTV constraint and the model with no credit frictions. Clearly, at fully flexible durable prices the co-movement problem remains unresolved in these two models, and in the model with the LTV friction the reaction of durables is much greater than in the model with no frictions. As a result, output expands counterfactually in the model with the LTV constraint despite the monetary contraction.

Figure 4.3 Comparison of the models: two frictions, one friction, and no frictions.
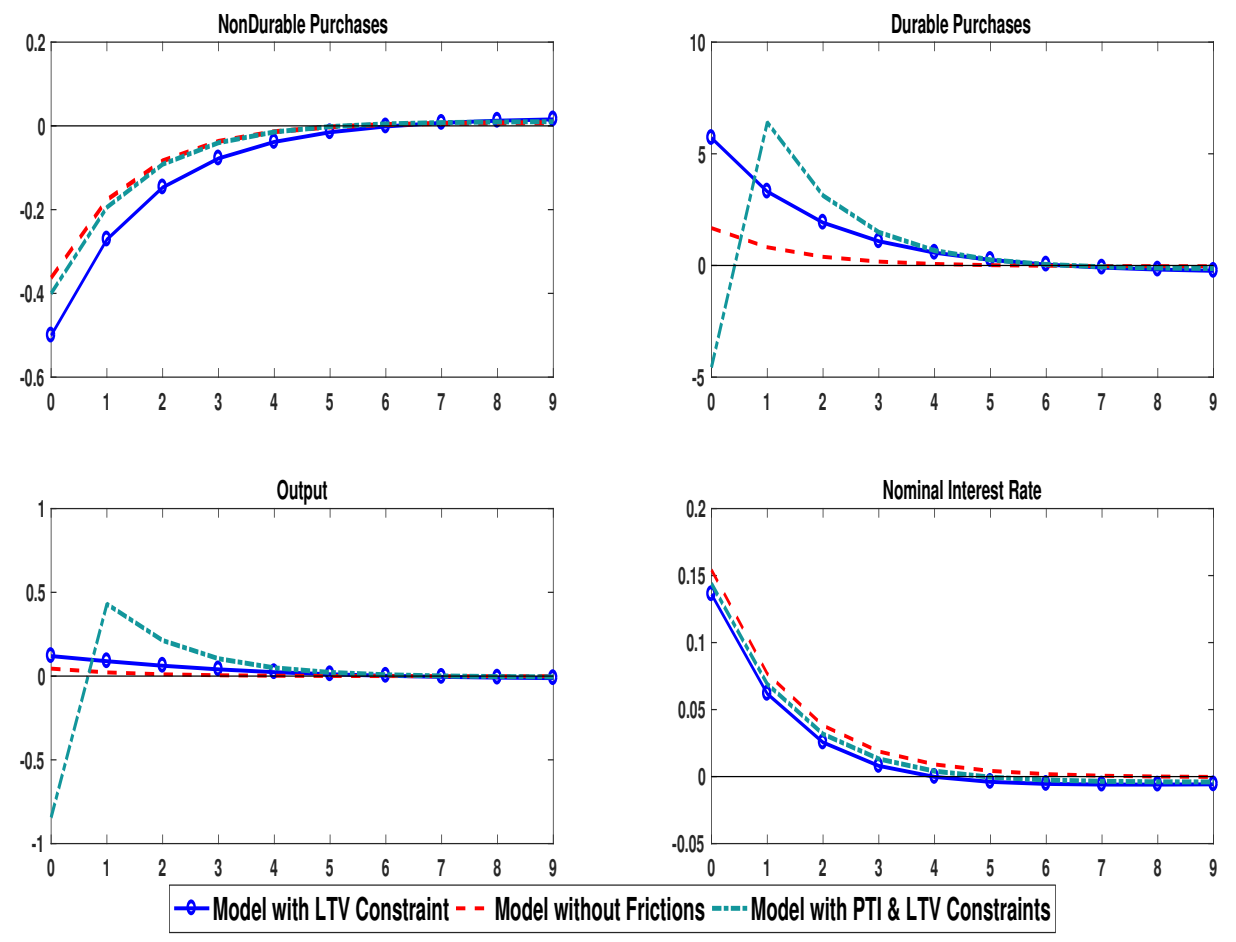

Note: Impulse responses are plotted as a percentage deviations from the steady state at fully flexible durable prices. 


\subsubsection{Adding Adjustment Costs to Durables}

The empirical evidence suggests that the reaction of durable purchases to a monetary contraction is about 4 to 5 times larger than the reaction of non-durable purchases. The impulse responses in figure 4 show that the decline in durables in the model with two credit frictions is larger than what the empirical evidence suggests. In this subsection, we add adjustment costs to durable investment in order to reduce the volatility of durables closer to that observed in the data.

Following Christiano et al. (2005) we assume that the services from the stock of the final durable goods evolves as

$$
D_{t}=(1-\delta) D_{t-1}+\Theta_{D}\left(I_{t}, I_{t-1}\right)
$$

where $\Theta_{D}\left(I_{t}, I_{t-1}\right)$ is a function representing adjustment costs to purchases of new durable goods, $I_{t}$. The adjustment cost function is given by

$$
\Theta_{D}\left(I_{t}, I_{t-1}\right)=\left(1-S\left(\frac{I_{t}}{I_{t-1}}\right)\right) I_{t}
$$

where $S($.$) satisfies the following conditions: S(1)=S^{\prime}(1)=0$, and $S^{\prime \prime}(1)>0$. These

conditions imply that changing $I_{t}$ results in increasing costs, which dissipate to zero in the steady-state.

For the simulations, $S($.$) was parameterized by the function$

$$
S\left(\frac{I_{t}}{I_{t-1}}\right)=\frac{\Theta}{2}\left(\frac{I_{t}}{I_{t-1}}-1\right)^{2}
$$

where $\Theta$ is an adjustment cost parameter. The Appendix contains the optimality conditions for this problem. 
As shown in the IRFs in figure 4.4 the model with adjustment costs to durable investment provides a more realistic co-movement between durable and non-durable spending. Now, the decline in durable consumption is about four times larger than the decline in non-durable consumption, which is closer to the stylized facts.

Figure 4.4 Impulse responses with adjustment cost to durable
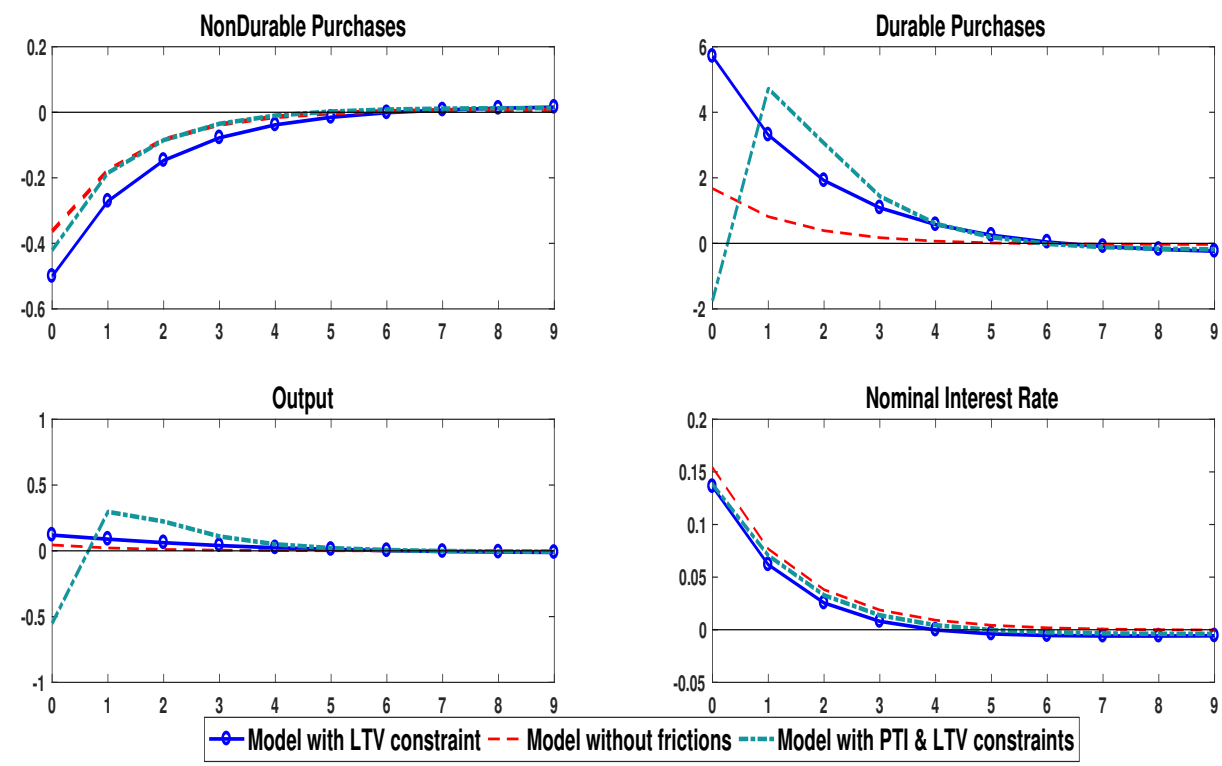

Note: Impulse responses are plotted as a percentage deviation from steady state at fully flexible

durable prices.

\subsection{Sensitivity analysis}

In this section we consider the sensitivity of the quantitative results to changes in the degree of durable price rigidity, and alternative values of the LTV and PTI ratios. 


\subsubsection{Durable price rigidity}

We examine the sensitivity of the simulation results to successive increases in the degree of durable price stickiness in the range 1, 1.5, 2, and 3 quarters, while keeping non-durable price stickiness at 4 quarters. We compare the numerical results for the three models: the model with the two financial frictions; the model with an LTV friction, and the frictionless model. For ease of comparison with the existing models we drop durable adjustment costs for these simulations. Figure 4.5 shows the impulse response functions of non-durable and durable purchases, output and the nominal interest rate at different degrees of durable price stickiness, following the monetary contraction.

As shown, the results are broadly consistent with the results reported in Monacelli (2009) and Sterk (2010) at durable price stickiness of 2 quarters or higher. The model with LTV constraint resolves the co-movement problem at 2 quarter or higher durable price stickiness. Also, because durable purchases are higher in the model with LTV friction than no friction at all, the comovement problem becomes more difficult to solve with LTV friction as pointed out by Sterk.

In contrast, the model with both the PTI and LTV constraints avoids the Sterk criticism. Also, the model with both financial constraints does better than the other models in that it resolves co-movement problem for all levels of durable price stickiness, including the case of fully flexible durable prices. Only the nominal interest rate declines at 3 quarter durable price stickiness despite the monetary contraction. This result is common to sticky price models at high levels of durable price stickiness, as in this case the nominal interest moves one-to-one with expected durable price deflation. 
Figure 4.5 Comparison of the models at different levels of durable price stickiness.
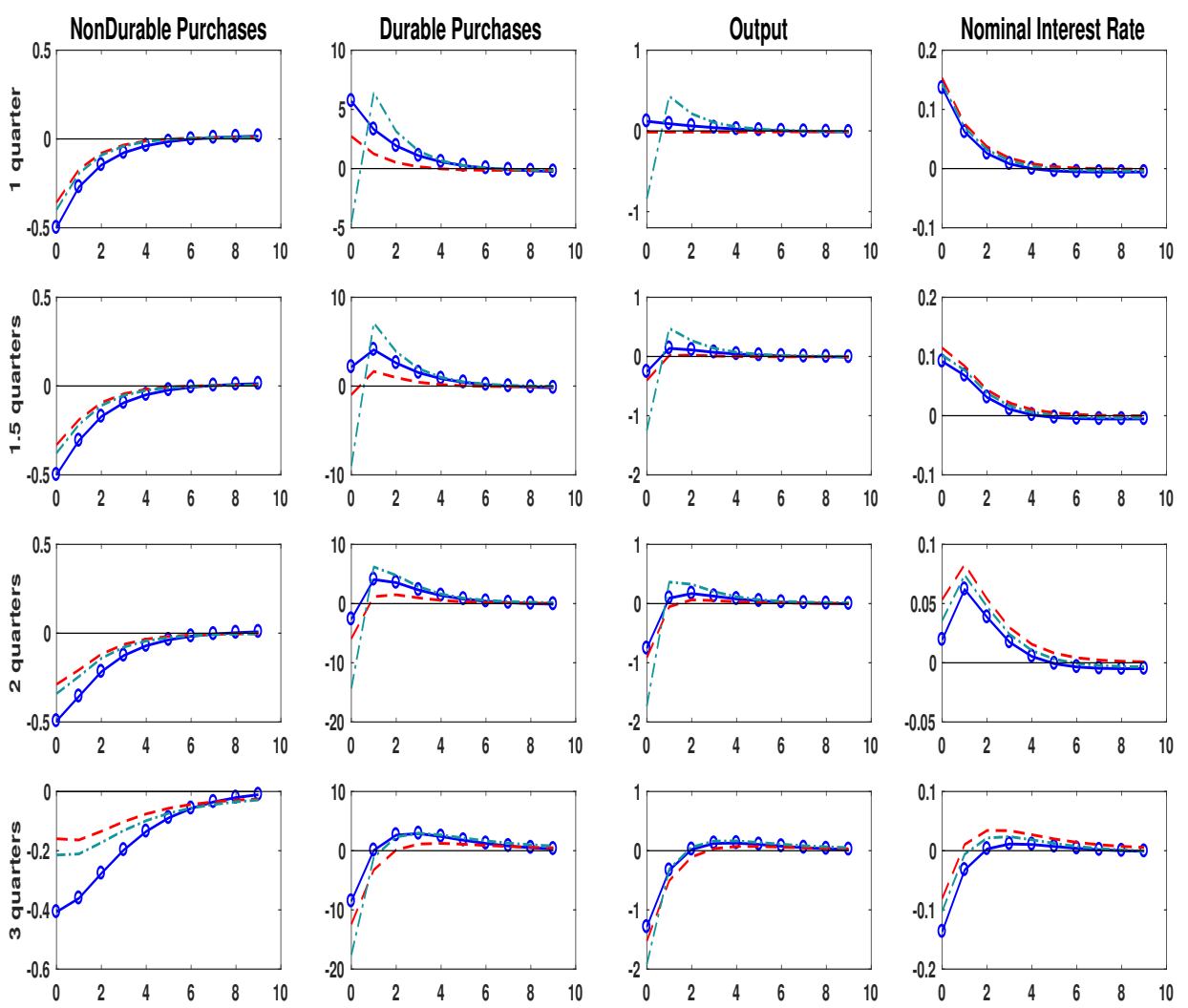

--Model with LTV constraint - - Model without frictions --- Model with PTI \& LTV constraints

Note: The rows correspond to different degrees of durable price stickiness. Responses are plotted as percentage deviation from steady state.

\subsubsection{Alternative LTV and PTI ratios}

The LTV and PTI ratios have been discussed in the literature as instruments of macroprudential policy. In order study how they interact with monetary policy, we carried out another simulation by considering different values for the two ratios, and 
compare the results for the model with both constraints. First, we analyse the effects of a monetary contraction with a higher LTV ratio on durable consumption, output and household debt.

As shown in Figure 7, the increase in the LTV ratio from 0.65 to 0.95 leads to a larger fall in durable demand, relative prices of durables and real household debt. The reason is that in the presence of a binding PTI constraint resulting from the increase in the nominal interest rate, the higher LTV ratio does not lead to a higher level of durable purchases. Note that this result is different from the model with only an LTV constraint, where a higher LTV ratio leads to an increase in durable demand.

Figure 4.6 Impulse responses at different LTV ratios.

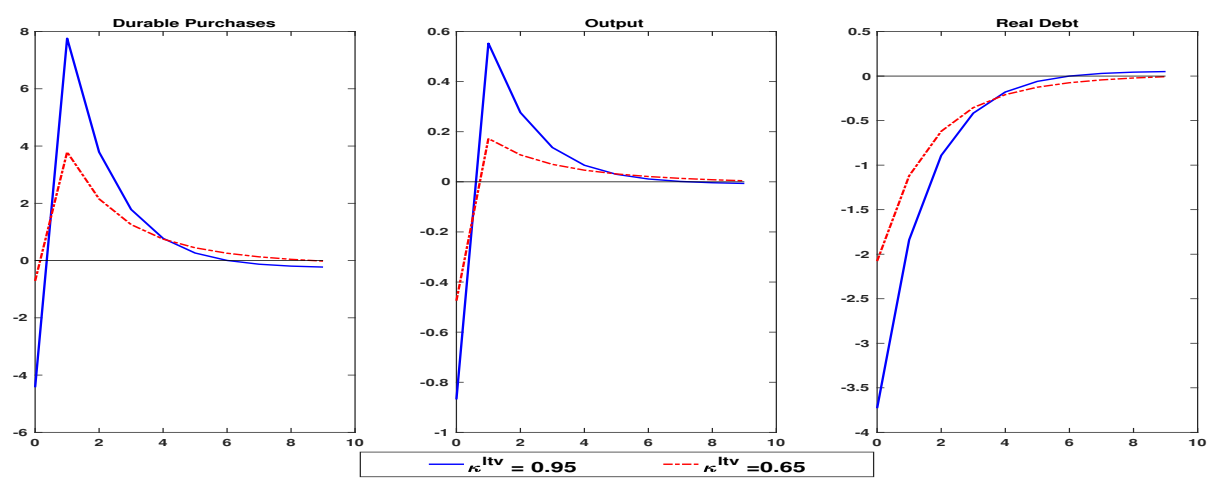

Note: The blue line is for $k^{l t v}=0.95$ and the red line is for $k^{l t v}=0.65$.

On the other hand, an increase in the nominal interest rate, with a lower PTI ratio from 0.40 to 0.20 , leads a large decrease in durable consumption, output and household debt. These results are shown in figure 4.7. 
Figure 4.7 Impulse responses at different PTI ratios.

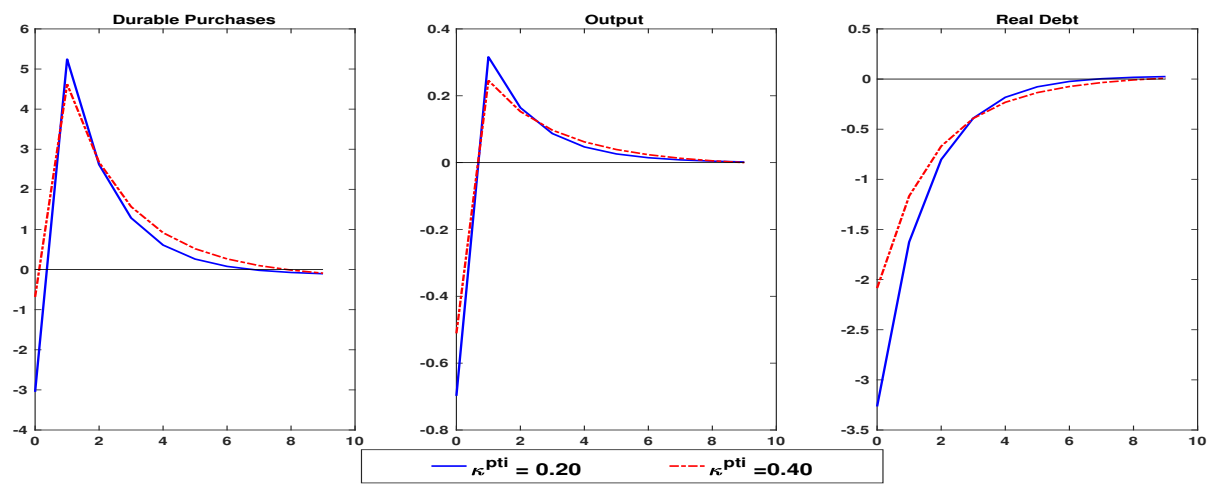

Note: The blue line is for $k^{p t i}=0.20$, and the red line is for $k^{p t i}=0.40$.

Clearly, different PTI and LTV ratios have significant quantitative effects on these key macroeconomic variables in the face of monetary shocks. The PTI limit seems to be more important for these results than the LTV limit. Our simulation results suggest that both ratios should be part of macroprudential policy, which can be used by policy makers alongside with monetary policy in order to achieve a desirable level of financial stability.

\subsubsection{Changing the elasticity of labour supply}

The effect of the change in the Frisch inverse elasticity of labour supply depends on the degree of price stickiness. If $\varphi<1$, the elasticity of labour supply is larger and the labour supply is more elastic. When durable prices are fully flexible, output and employment decline by less compared to when the prices are sticky. This is because real wage is constant and a leftward shift in labour supply reduces employment at the constant real wage. In the case of sticky durable prices, there is an additional reduction in labour supply due to a fall in real wage. The effects are shown in figure 
4.8. The red line indicates the impulse response of employment when the durable price is sticky and the blue line shows the impulse response when durable prices are fully flexible.

Figure 4.8 Impulse responses of employment at different degrees of price stickiness.

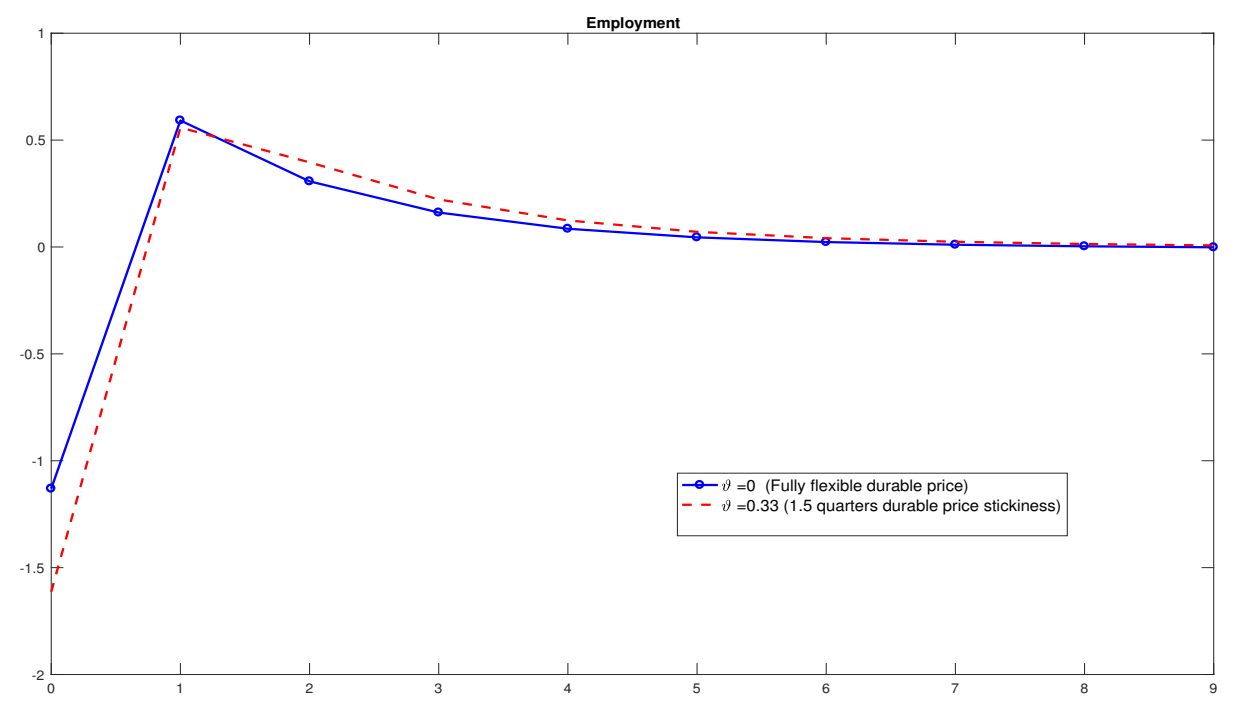

\subsection{Conclusion}

In this paper we extended the two sector DSGE sticky price model with durable and non-durable goods to include both collateral, LTV, and income, PTI, constraints on borrowers. The two credit constraints are randomly combined by shocks to the borrowers' labour income and determine jointly the amount of collateralized loans that the borrowers can obtain. We used this model to resolve the well-known co-movement problem between durable and non-durable consumption following a monetary contraction, when durable prices are fully flexible.

In this context, an increase in the nominal interest rate increases the threshold 
level of the labour shock and results in a greater fraction of borrowers with a binding PTI constraint. As a result there is a fall in the relative price of durables and a sharp decline in the amount of collateralized loans to the borrowers, who cut back on their purchases of durables, along with the relatively more expensive non-durables. The lenders decrease their purchases of non-durables but increase their purchases of durables by an amount less than the fall in durable purchases by borrowers. As a consequence, aggregate durable purchases fall and co-move positively with nondurables as in the data. Aggregate output also declines and the nominal interest rate rises consistent with the empirical evidence. Thus the model resolves the co-movement problem in an empirically adequate way, based solely on credit frictions that include PTI limits on borrowers. Our results imply that financial frictions on the demand side of the economy are still important in re-solving the co-movement problem even with flexible durable prices, and complement to a large extent the results from other strands of literature that rely on supply side frictions or non-separable preferences.

Also, changes in the LTV and PTI ratios have significant effects on the macroeconomy in the face of monetary shocks. In that sense both ratios should be part of macroprudential policy, which can be implemented along with monetary policy to achieve financial stability.

The results in the present paper generate further questions for future research. One would be to undertake a thorough empirical investigation of the importance of PTI limits in household credit growth based on extensive information of loan-based panel data, as studied by Greenwald for mortgage debt in the US. Another extension would be to examine in detail the welfare implications of LTV and PTI frictions, and their role in designing better macroprudential policy rules. A third extension would be to study the effects of LTV and PTI constraints in the context of other models with 
alternative preferences, such as non-separable preferences, and production functions with capital accumulation. 


\section{Chapter 5}

\section{HOUSE PRICES, FINANCIAL FRICTIONS AND RISING CHINESE OUTWARD DIRECT INVESTMENT}

Historically, the analysis of the housing market has been based on domestic supply and demand, in isolation of the other markets or open economy considerations. However, the real estate sectors of many countries has experienced significant internalization recently, through rising outward direct investment (OFDI) from abroad. Many big cities in the world have recently experienced a surge in outward foreign direct investment (OFDI) into their real estate sectors. This is believed to have pushed up real estate prices beyond affordability of local residents. In an attempt to contain the increase in housing prices, policy makers have considered combinations of monetary and macroprudential measures aimed at the factors that affect housing demand and supply. We study the interactions of housing prices, financial frictions and monetary policy in a sample of developed countries amid rising OFDI in real estate. We consider Chinese OFDI because China is documented as a major investor in real estate across global cities.

Following the 2007-2008 financial crisis, there has been a rise in Chinese OFDI in real estate. A survey on juwai.com, the No. 1 Chinese international property portal, shows that in 2016 mainland Chinese buyers have acquired more than $\$ 130$ billion

of international real estate. The United States is the top destination for Chinese investors, followed by Australia and Hong Kong. Canada is in fourth place, ahead of the United Kingdom and other countries. It is also shown that the 2016 total OFDI 
in real estate represents a $25.4 \%$ increase over 2015 and an $845 \%$ increase over the previous five years.

With both strong domestic demand and large capital inflows, housing prices in many developed economies have grown rapidly in recent years. Although capital inflows into the real estate sector may contribute to economic growth, the potential increase in property prices associated with them has concerned policy makers. Among others, the increase in household indebtedness and rising housing prices constitute a major risk to financial stability in Canada. Price stability, the primary focus of monetary policy, is widely known to be insufficient for financial stability. Besides the traditional monetary policy tools other policy tools such as macroprudential measures, which strengthen the resilience of the financial system and decrease the build-up of systemic risk, have been adopted by many policy makers to ensure financial stability. It is also important to note that monetary policy and macroprudential measures are not perfect substitutes. Macroprudential measure could be used to target specific sectors where the risk to financial stability is believed to be excessive, whereas the monetary policy rate impacts all lending activities regardless of whether they pose a threat to financial stability. Many countries have expanded their regulatory toolkits with macroprudential instruments because consumer price and asset price inflation might not comove, so that targeting consumer price and asset price stability might require a combination of monetary policy and macroprudential tools. It is therefore important to know how effective these tools are amid rising capital inflows.

The correlation between housing prices and Chinese OFDI, which is estimated to be 0.80 for Canada, has motivated us to explore the empirical association between OFDI and housing prices and as well the policy implications in 21 developed countries. Asset price bubbles are known to affect the economy negatively, and the best possible 
way to prevent these bubbles are still contested. This paper studies the effectiveness of macro-prudential policies in controlling housing price inflation in countries that are open to foreign direct investment from China. It also studies how these investments are correlated with housing prices and the need for measures that can reduce foreign influences on the domestic market. According to the house price data center of the Globe and Mail, since June 2005, housing prices in 11 major Canadian cities have gone up by $106.41 \%$. It is also worth noting that Canada's housing boom, fuelled by low interest rates, has contributed to an increase in household debt, which stood at $165 \%$ of disposable income in 2015 . The rising household debt is likely to lead to financial strain, and also make Canadian economy more vulnerable to interest rate hikes and other unanticipated shocks, and this is a big concern for policy makers. Other developed countries are in a similar situation, thereby making it important to study the effectiveness of these policy tools.

In what follows we construct a data set from various sources, such as the IMF and the Bank of International Settlements (BIS) and use it to analyse the effect of Chinese ODFI on housing prices, and the effectiveness of macro-prudential measures in 21 advanced countries by estimating a dynamic panel data model with interactive effects.

In earlier studies, there is a presumption that time effects and country-specific effects can capture adequately the unobserved heterogeneity in the data. However, the unobserved heterogeneity might have evolved in a more complex way, because common shocks may affect housing price inflation and macro-prudential policies differently across countries. In this paper, we allow shocks to have heterogeneous impacts through interactive effects. The interactive fixed effects approach captures time varying common factors with individual loadings representing different degrees of im- 
pacts of the common factors across countries. The interactive fixed effects model is also beneficial in accounting for potential serial correlation in the data and thus provides more reliable statistical inferences. We also provide simulation evidence through Monte-Carlo experiments in order to show the robustness of the interactive fixed effects approach to the presence of unobserved heterogeneity in dynamic fixed effects model with finite sample size.

Our results show that Chinese OFDI has a small but positive effect on housing prices and this suggests that house price inflation in the countries in the sample is partly driven by OFDI. Further, macroprudential policy measures are shown to impact housing price movements negatively and are therefore important for keeping housing prices under control.

The remainder of the paper is organized as follows. Section 2 presents a review of the existing literature, Section 3 discusses the data and the summary statistics. Section 4 describes the econometric dynamic panel model. Section 5 presents and discusses the empirical results. Section 6 provides some simulation results to examine the robustness of our approach. Section 7 contains some conclusions.

\section{$5.1 \quad$ Literature Review}

Following the global financial crisis, researchers and policy makers have developed a growing interest on macroprudential policy measures and their effectiveness. This paper relates to a number of previous contributions in this literature. The first is a growing class of empirical papers on the use and effectiveness of macroprudential policies such as LTV and PTI limits in controlling credit growth and asset prices. These papers include Cerrutti et al. (2015), who find that such policies are associated with lower growth of asset prices, and the effect is less in financially more open 
economies. Igan and Kang (2011) find that the adopting maximum LTV and PTI ratios in Korea in the second half of the 2000s was successful in slowing down inflation in house prices. Claessens et al. (2013) find that measures aimed at borrowers reduce banks liability growth. Craig and Hua (2011) find that imposing maximum on LTVs and stamp duties on property transactions help to reduce property price inflation in Hong Kong. DellAriccia et al. (2012) find that macroprudential measures reduced credit boom incidents and the probability of booms ending badly. Vandenbussche et al.(2015) construct policy measures covering 16 countries at a quarterly frequency and use them to investigate whether they had an impact on housing price inflation. They find that capital measures and non standard liquidity measures appear to be more effective. None of these papers considered the impact of OFDI on housing price inflation.

This paper is also related to another strand of the literature that studies the relationship between capital inflows and housing price inflation. Chow et al. 2017 try to identify the direction of causality between housing prices and Chinese OFDI. Tillman (2012) address the response of property prices to an inflow of foreign capital in Asian emerging market economies. A panel vector auto-regression model is used in Tillman (2012) to identify capital inflow shocks based on sign restrictions.

Our paper is also related to empirical work on the use of interactive fixed effects in panel data analysis, including Kim and Oka (2014) and Lu and Su (2016). These studies do not study the relationship between to capital inflows and housing price inflation, but shed some light on how interactive fixed effect models can be applied applied in empirical analysis.

In the existing literature on the effectiveness of macroprudential policies, most studies employ static fixed effect models, difference generalized method of moment 
(GMM) (Arelano-Bond) or system GMM (Blundell-Bond). However most optimizing macroeconomic models have a dynamic structure, including those that study housing, financial frictions and government policies. For this reason in the present study we adopt an explicit dynamic panel data model to carry our our empirical analysis. Although, the Arelano-Bond estimator is consistent in dynamic panel models, it has some drawbacks. One issue is that it uses deeper lags of the predetermined and endogenous variables as instrument and these deeper lags tend to be weak instruments in terms of explaining the endogenous variables, and this may lead to finite sample bias. The Blundel-Bond system GMM estimator overcomes this problem by using instruments which include first difference in addition to lagged levels; however, it does not capture time varying heterogeneity. Another issue with the Arellano-Bond estimators is that they have poor finite-sample performance and require a large number of cross-sectional units.

In the present empirical study we use a more flexible dynamic panel model with interactive fixed effects. This model, developed recently by Moon and Wiedner (2017), captures time varying common factors with different individual loadings, representing different degrees of impacts of the common factors across countries. The MoonWeidner estimator performs better than the above estimators, as it allows for endogenous regressors, and it corrects for bias due to correlation or heteroscedasticity of the idiosyncratic error term, and bias due to predetermined regressors. Also, the bias corrected version of this estimator works well in finite samples.

\section{$5.2 \quad$ Data}

This section describes the data including the construction of a database of macroprudential measures. The measures we consider are borrower-based policies such as 
LTV and PTI limits which are recently used relatively more in advanced countries. We describe the relationship between housing prices and OFDI and issues with data availability. We also consider countries that are destination for Chinese real estate investments.

\subsubsection{Housing Prices and Chinese OFDI}

As the world's second largest economy, China's influence on the global economy is expanding at a very fast pace and part of this expansion is a growing outward foreign direct investment, not just from Chinese state enterprises, but also from individual Chinese citizens and from private Chinese companies. Over the past several years, there has been an increase in OFDI in the real estate from China to global cities. This rise in the real sector OFDI is attributed to the liberalization of investment regime, low relative housing prices in global cities and an expectation of yuan depreciation. According to Chinese global property investment report (2017), Chinese outbound property investments surpassed the $\$ 100$ billion mark in 2016. Chinese outbound commercial and residential property investment in 2016 is estimated at $\$ 101.4$ billion worldwide, representing a $25.4 \%$ increase over our 2015 estimate of $\$ 80$ billion. The United states, Australia, Hong Kong and Canada are top destinations for Chinese investment by aggregate value since 2013 when Juwai.com began tracking the trends. Similarly, housing prices rose rapidly across major global cities in the countries that

are destination for Chinese OFDI. As shown in figures 5.1, 5.2,5.3 and 5.4, after the 2007-2008 financial crisis, total Chinese OFDI has increased significantly and there is a positive correlation between the total OFDI and real housing prices in Canada, USA and Australia which are the top destinations for Chinese OFDI. 


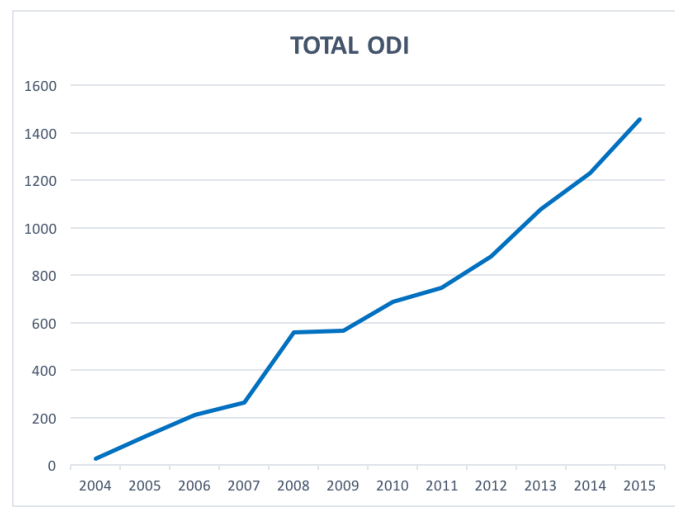

Figure 5.1 Total Chinese OFDI

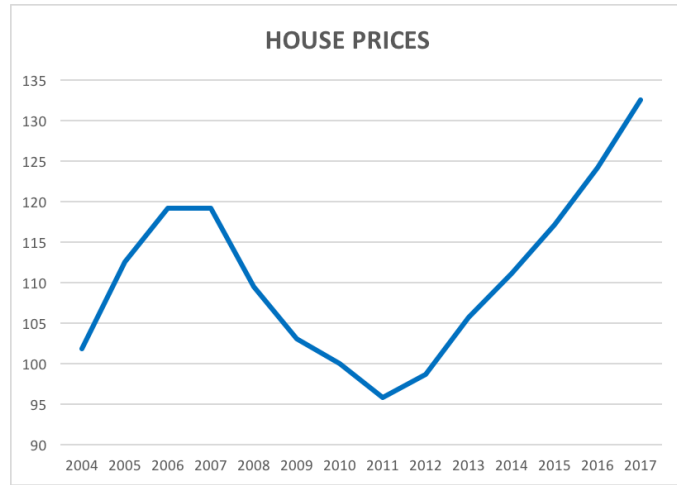

Figure 5.3 House Prices USA

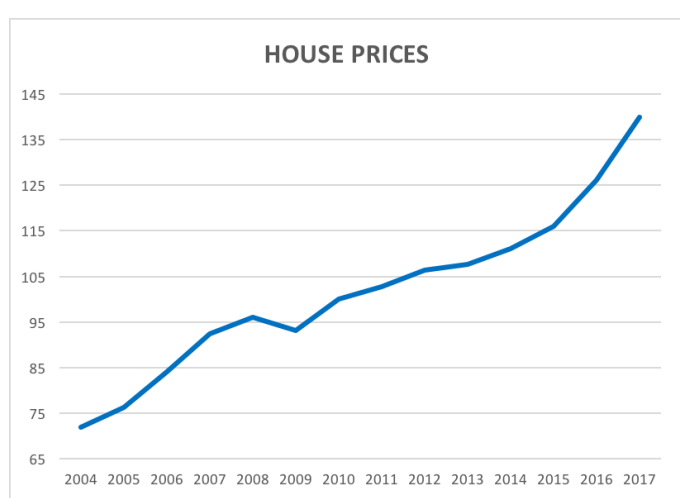

Figure 5.2 House Prices Canada

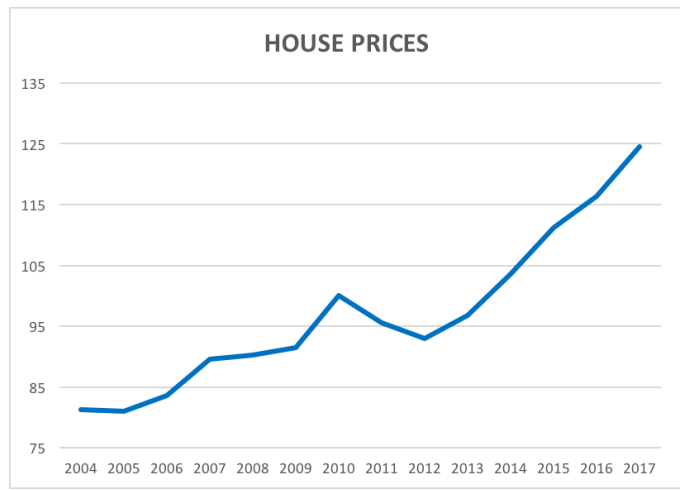

Figure 5.4 House Prices Australia

\subsubsection{Available Data}

Although there is data for Chinese OFDI by sector, which includes real estate, in order to preserve the number of observations, we use data on Chinese OFDI by destination country as proxy. As shown in figure 5.5, the share of real estate in total OFDI from 2005 to 2017 is $9.95 \%$. More important, the correlation between total Chinese OFDI and total real estate sector OFDI is 0.92 . Such a high correlation should make total OFDI a good proxy for real estate sector OFDI. 


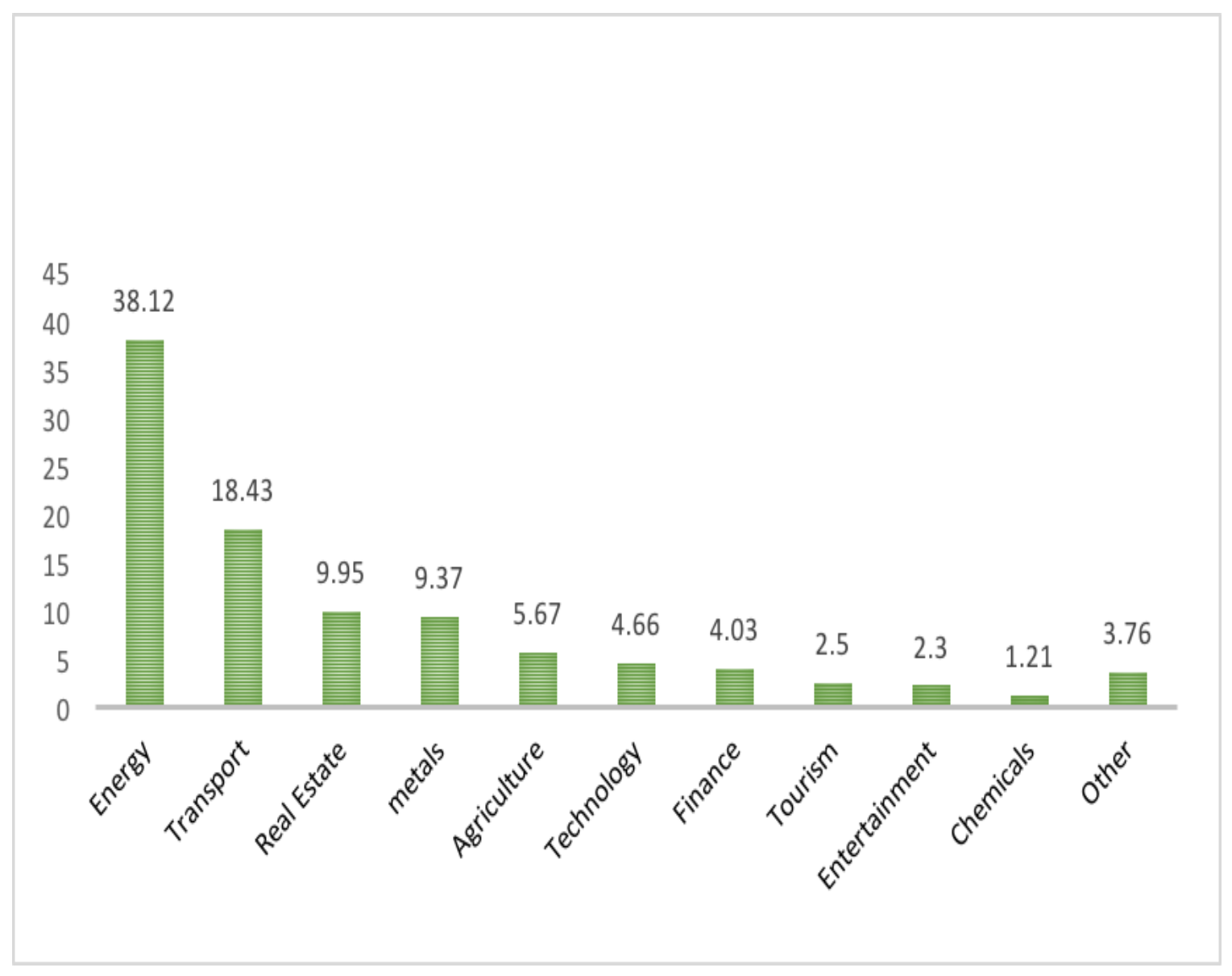

Figure 5.5 Sector distribution of Chinese outward direct investment (2005-2017) Source:Chinese Global Investment Tracker (CGIT)

The graph of the total OFDI and the real sector OFDI are shown in figures 5.6 and 5.7 showing positive correlation. This data was used for similar analysis in Kwan (2017) and Tillman (2013). 


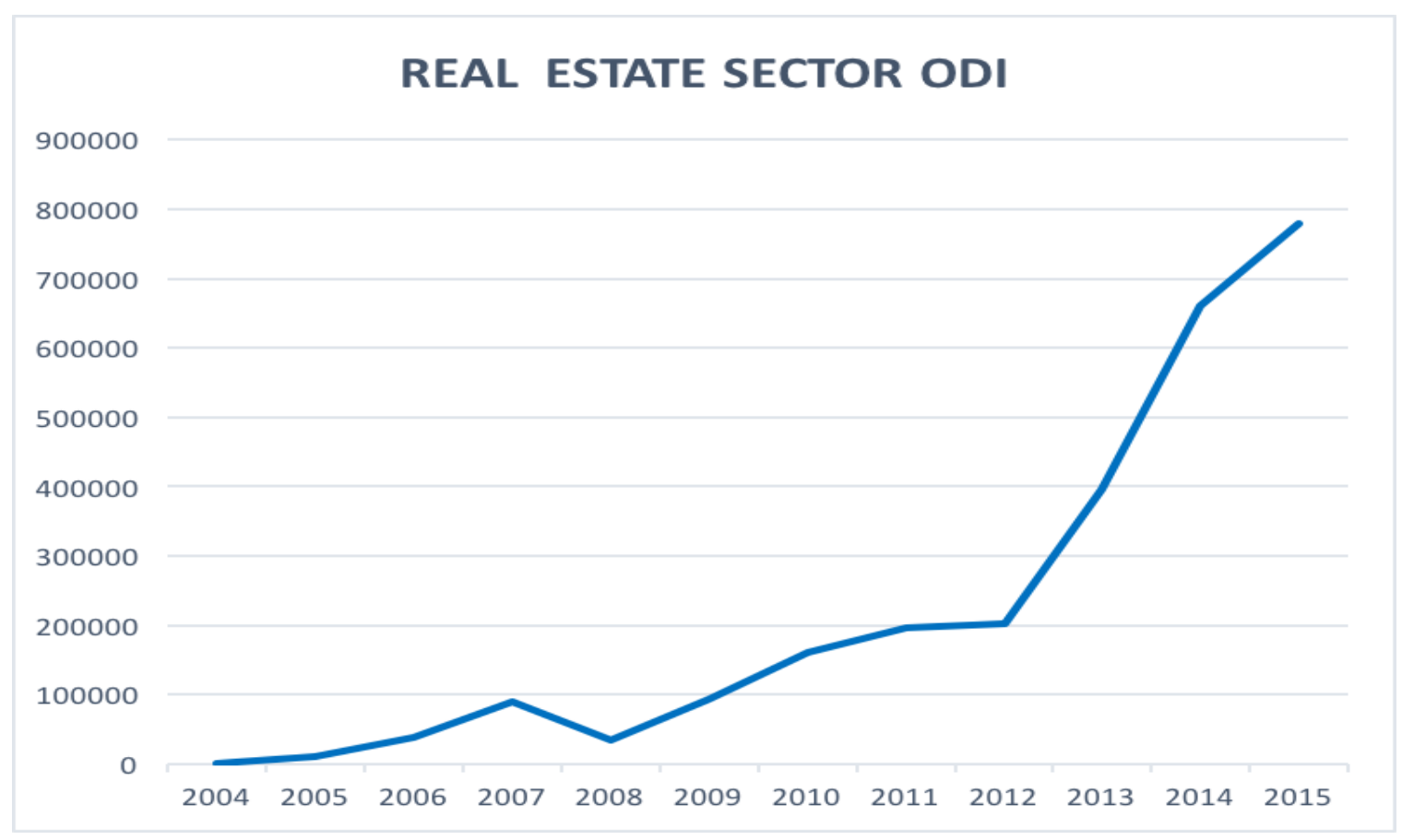

Figure 5.6 Chinese total real estate sector outward direct investment (2004-2015) in 10,000 USD

Data Source:National Bureau of Statistics China 


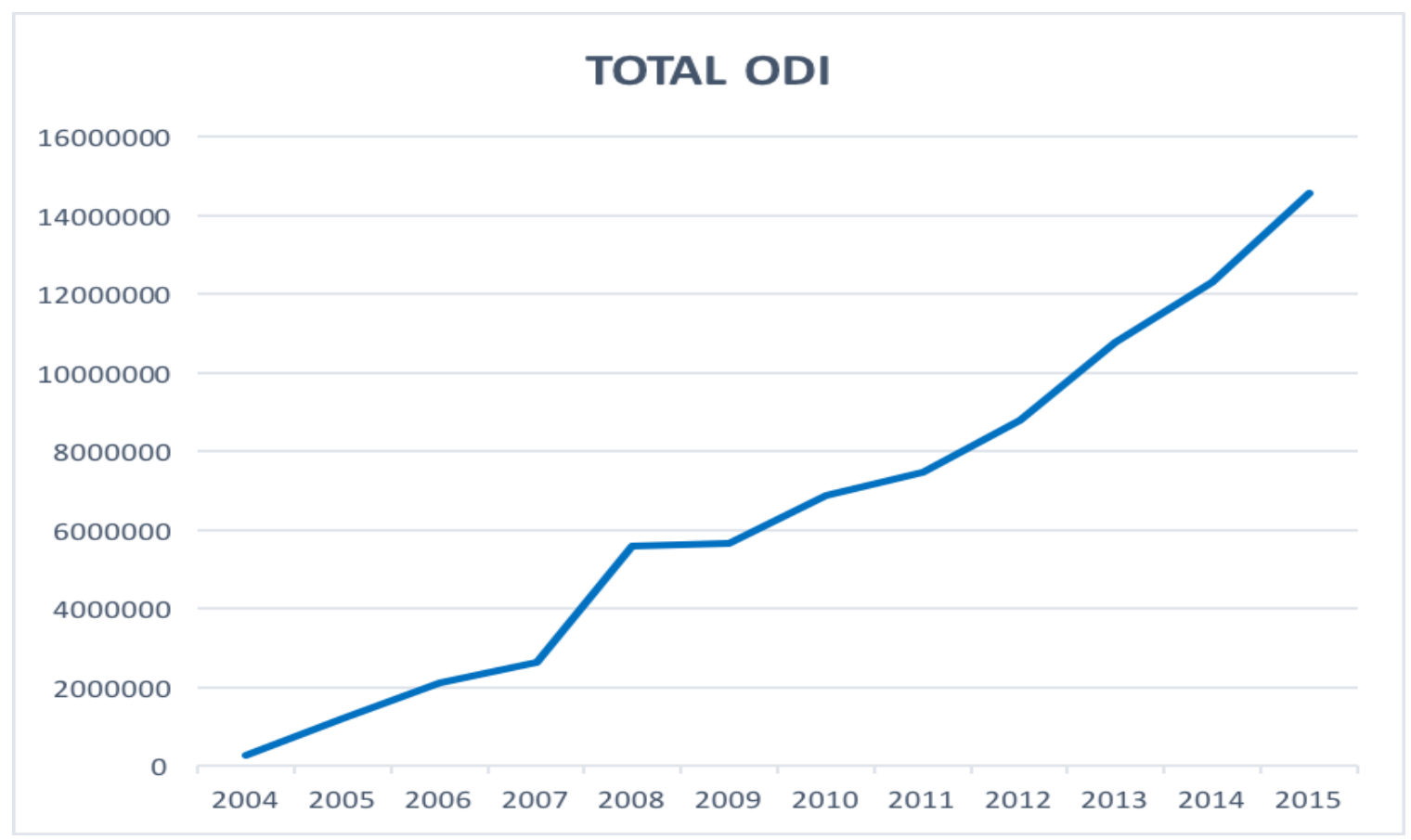

Figure 5.7 Chinese total outward direct investment (2004-2015) in 10,000 USD Data Source:National Bureau of Statistics China

\subsubsection{Macroprudential Measures}

An important part of the empirical analysis is to build a database of macroprudential measures for the countries in our sample. To do this, we rely on data from different sources. We use data from policy action table from the Bank for International Settlements (BIS) database for actions on housing markets which provides data of policy actions for 60 countries from 1990 through 2012 (Shim et al., 2013). We also used information from national sources to update the database to 2016. We crossed-checked our database against country databases by Cerutti et al (2015)and Lim et al.(2011). Following Akinci et al.(2018), we construct the database for policies that are targeted for the housing market. The first is the LTV ratio which restricts the amount of mortgage loans to a certain fraction of the total property value. This is the most 
commonly used tool in our sample as many countries in sample have used it to limit mortgage lending. We also construct data on $\mathrm{PTI}^{1}$ limits which restrict the amount of debt relative to income. The other housing related data that we considered is not easily classified and we call this "other housing related tools". This includes, among others, property tax gains, quantitative limits on mortgage lending, credit growth limits, capital requirements, and consumer loan limits.

We follow Akinci et al.(2018) to assign a value of zero if no policy action was taken in a quarter, a value of one if a tightening policy action was taken in a given quarter, and a value of negative if the policy tool was loosened in a given quarter. Policy action data from individual countries are used to update the data to 2016.

The 21 countries in the sample are Australia, Belgium, Canada, Denmark, Finland, France, Germany, Hong Kong, Ireland, Israel, Italy, Japan, Korea, New Zealand, Singapore, Spain, Sweden, Switzerland, Thailand, UK and US.

\subsection{Empirical framework}

This section specifies the dynamic panel model with interactive fixed effects, and discusses the estimation steps that we follow in order to estimate the effects of LTV and PTI policies on housing prices amid rising Chinese OFDI. The estimation procedure has the advantage of addressing issues of country heterogeneity, and any possible endogeneity between the dependent variable and the predictors of housing prices. We estimate how OFDI and macro-prudential policies (MPPs) relate to housing prices through dynamic panel data analysis. Our analysis builds on Cerruti et al. $(2015)^{2}$ who use differenced GMM estimation method introduced by Arellano and

\footnotetext{
${ }^{1}$ This is the same as debt-to-income (DTI) limit.

${ }^{2}$ Cerruti et al (2015) did not include time fixed effect
} 
Bond (1991). A variant of the following regression model is used for the empirical analysis:

$Y_{i t}=\alpha Y_{i, t-1}+\beta M P P_{i, t-1}+\gamma G D P_{i, t-1}+\delta B C_{i, t-1}+\theta R_{i, t-1}+\mu O F D I_{i, t-1}+\lambda_{i}+f_{t}+\varepsilon_{i, t}$

where $Y_{i t}$ is real housing prices in country $\mathrm{i}$ at time $t, M P P_{i t}$ is macro-prudential policy at time $t, G D P_{i, t-1}$ is the GDP growth rate in the previous period, $B C_{i, t-1}$ is bank crisis in the previous period, $R_{i, t-1}$ is the policy interest rate in the previous period, $O F D I_{i, t}$ is outward Chinese foreign direct investment, $\lambda_{i}$ is a country fixed effect to capture any non-time varying country specific conditions such as financial and economic development, financial intermediation, structure of financial system and other institutional characteristics, $f_{t}$ is a time fixed effect that accounts for common shocks across the countries which include conditions in global capital markets that would influence capital flows among these countries, and $\varepsilon_{i, t}$ is a random error term.

The independent variables are all lagged one period, and they include the lagged dependent variable. The inclusion of lagged housing prices makes the panel model dynamic. MPP is lagged because its effect is assumed to be realized with a time lag. Lagging the other country variable such as GDP, bank crisis and policy rate helps to avoid the problem of simultaneity.

In principle, the Arelano-Bond (AB) method and related dynamic panel models are very useful in tackling endogeneity problems caused by unobserved heterogeneity; and the $\mathrm{AB}$ estimator can be readily obtained from estimating model (5.1). However, the $\mathrm{AB}$ approach is known to suffer from weak instrument problems which can distort inference. In addition, the $\mathrm{AB}$ estimator requires a large number of cross sectional units $(\mathrm{N})$, and performs poorly in small samples. 
Further, in many cases including the present study, there is a concern that model (5.1) is somewhat restrictive. For example, if $f_{t}$ denotes an economic shock, then, model (5.1) indicates that the shock has identical effects on all cross-sectional units. In practice, it is very unlikely that economic shock will have identical effect on all cross-sectional units. To relax the restriction inherent in equation (5.1), we incorporate interactive fixed effects into the model. The advantage of this interactive fixed effect approach is that it does not impose a priori a specific form for the unobserved heterogeneity and therefore if there exists no common factors in the data and the correct specification is the traditional two-way fixed effects approach, the factor model approach still performs well. To relax the restriction of model (5.1), we consider the following dynamic panel regression model with interactive fixed effects

$$
Y_{i}=X_{i} \beta+f \lambda_{i}+\varepsilon_{i}
$$

where

$$
Y_{i}=\left[\begin{array}{c}
Y_{i 1} \\
Y_{i 2} \\
\vdots \\
Y_{i T}
\end{array}\right], \quad X_{i}=\left[\begin{array}{c}
X_{i 1}^{\prime} \\
X_{i 2}^{\prime} \\
\vdots \\
X_{i T}^{\prime}
\end{array}\right], \quad f=\left[\begin{array}{c}
f_{1}^{\prime} \\
f_{2}^{\prime} \\
\vdots \\
f_{T}^{\prime}
\end{array}\right], \quad \varepsilon_{i}=\left[\begin{array}{c}
\varepsilon_{i 1}^{\prime} \\
\varepsilon_{i 2} \\
\vdots \\
\varepsilon_{i T}
\end{array}\right]
$$

We define

$$
\Lambda=\left[\lambda_{1}, \lambda_{2}, \cdots, \lambda_{N}\right]^{\prime}
$$

an $N \times r$ matrix. For notational simplicity, the model equation (5.2) can be rewritten in matrix form as

$$
Y=X \beta^{*}+F \Lambda^{\prime}+\varepsilon
$$


where $Y=\left[Y_{1}, Y_{2} \cdots Y_{n}\right]$ is $T \times N$ vector of housing prices, $X$ is a $T \times N \times k$ vector of the lagged-regressors, $\mathrm{k}$ is the number of regressors, $\beta^{*}$ is a $k \times 1$ vector of the coefficients. The lagged regressors are as described in equation (5.1). Common time-specific effects $F_{t}$, called factors, interact with the individual fixed effects $\lambda_{i}$, called factor loadings. The conventional individual specific effects and time-specific effects are contained in the interactive fixed effect specification as special cases but the latter is more flexible because it allows factors to affect each individual country with a different loading. In the model $f_{t}$ has heterogeneous effects on cross-sectional units through $\lambda_{i}$.

The sample consists of quarterly data for the 21 countries over the period 2003 to 2016 , i.e., $\mathrm{N}=21$ and $\mathrm{T}=56$. The choice of the 21 countries is determined by a country's use of the LTV and/or PTI limits as macroprudential policy instruments, a country being a host to China's real estate OFDI, and availability of data. The data sources include the IFS data base of the IF, the data base of BIS, and the World Bank World Development Indicators (WDI). ${ }^{3}$.

Theoretical results on how to accommodate interactive fixed effects when both $\mathrm{T}$ and $\mathrm{N}$ are large has been developed in the literature. Bai (2009) investigates the least squares estimator for a linear panel regression model with known number of factors using principal component analysis. In addition to accommodating interactive fixed effects, Moon and Weidner (2017) accommodate lagged-dependent variables as regressors, thus allowing for panel dynamics in the model. Monte Carlo simulations show that the bias-corrected least squares estimator works well in finite samples.

We adopt the method of Moon and Weidner (2017) for our estimation. Then the regression coefficients in equation (5.3) can be obtained by minimizing the sum of

\footnotetext{
${ }^{3}$ See Appendix B for more details
} 
squared residuals:

$$
\mathrm{L}_{N T}(\beta, F, \Lambda)=\frac{1}{N T} \operatorname{Tr}\left[\left(Y-\beta . X-\Lambda F^{\prime}\right)^{\prime}\left(Y-\beta . X-\Lambda F^{\prime}\right)\right]
$$

Least squares estimator that jointly minimizes $\mathrm{L}_{N T}(\beta, F, \Lambda)$ over $\beta, F$ and $\Lambda$ is considered. The estimator for the main parameter of interest $\beta$ is given by

$$
\hat{\beta}=\underset{\beta \in \mathrm{B}}{\arg \min } L_{N T}(\beta)
$$

where

$$
L_{N T}(\beta)=\min _{F, \Lambda} L_{N T}(\beta, F, \Lambda)
$$

$L_{N T}(\beta)$ is the minimum value of $\mathrm{L}_{N T}(\beta, F, \Lambda)$ over $\mathrm{F}$ and $\Lambda$. Since $\mathrm{F}$ and $\Lambda$ are not observable, iterative method of Bai (2009) is used. Given F and $\Lambda$ estimate of $\hat{\beta}$ is obtained. Given $\hat{\beta}$ the estimates of $\hat{F}$ and $\hat{\Lambda}$ are obtained via the principal component analysis (PCA) method under the identification restrictions: $\frac{F^{\prime} F}{T}=I_{r}$ and $\Lambda^{\prime} \Lambda$ is a diagonal matrix. Specifically, $\hat{F}$ and $\hat{\Lambda}$ solves:

$$
\left[\frac{1}{N T} \sum_{i=1}^{N}\left(Y_{i}-X_{i} \hat{\beta}\right)\left(Y_{i}-X_{i} \hat{\beta}\right)\right] \hat{F}=V_{N T} \hat{F}
$$

and

$$
\hat{\Lambda}=\frac{1}{T}\left(Y-\sum_{k=1}^{K} \hat{\beta}_{k} X_{k}\right)
$$

Where $V_{N T}$ is a diagonal matrix consisting of the $\mathrm{r}$ largest eigenvalues of the matrix in the square bracket in equation (5.7) arranged in descending order. Following Moon and Weidner (2015) the number of factors $r_{o}$ is found such that for $r \geq r_{o}$ the limiting 
distribution of the least squares estimate for $\beta$ is independent of $r$, the number of unobserved factors used in the estimation. In our estimation, $r=3$ is used because it is the value after which further increase in $\mathrm{r}$ does not affect the estimated values. Another important issue in the simulation is the choice of bandwidth, we chose a bandwidth of 4 and changing the bandwidth had little or no effect on the estimated

values. $\hat{\beta}^{c}$ the bias corrected version of $\hat{\beta}$ is obtained using the formula in Moon and Weidner (2017). The final version of $\hat{F}$ and $\hat{\Lambda}$ are obtained using equations (5.7) and (5.8) by replacing $\hat{\beta}$ with $\hat{\beta}^{c}$.

\subsection{Panel unit root and co-integration test}

Im, Pesaran and Shin (2003), called the IPS test, is one of the most commonly used tests for unit roots in panels. However, the IPS test procedure is not valid when the errors, $e_{i, t}$, are dependent across $\mathrm{i}$, and its use can lead to spurious inference. We consider Pesaran (2006) panel unit root tests that allow for possible cross section dependence in panels. First, we show the result for the 10 advanced countries where China invests most on real estate. Next, we consider the results for the 21 countries analysed. The results are shown in table 5.1 for the 10 countries and table 5.2 for the 21 countries. The tests show that all the variables exhibit a non-stationary kind of behaviour with the exception of OFDI and GDP. The differenced series are stationary and this makes us conclude that a panel unit root is present in the level series. The results of panel co-integration test provide evidence of no co-integration for all the variables. We use the first difference of the series with unit root in our empirical analysis to make the series stationary. 


\begin{tabular}{lllll}
\hline & \multicolumn{2}{c}{ Intercept only } & \multicolumn{2}{c}{ Intercept and trend } \\
\hline Variables & $\mathrm{lag}=1$ & $\mathrm{lag}=2$ & $\mathrm{lag}=1$ & $\mathrm{lag}=2$ \\
\hline \hline House price & -1.018 & -0.903 & -1.275 & -1.019 \\
MPP & 2.610 & 2.610 & 1.700 & 1.700 \\
OFDI & $-3.730^{* * * *}$ & $-2.990^{* * * *}$ & $-3.941^{* * * *}$ & $-3.261^{* * * *}$ \\
GDP & $-2.293^{* * *}$ & -1.742 & -2.454 & -1.838 \\
$R$ & -2.008 & -1.640 & -2.407 & -2.128 \\
BC & -0.320 & -0.581 & -0.822 & -1.121 \\
\hline
\end{tabular}

The Pesaran (2006) test is performed using the Stata pescadf command written by Piotr Lewandoski.

The statistical significance are denoted as ${ }^{*} p<0.15,{ }^{* *} p<0.10,{ }^{* * *} p<0.05,{ }^{* * * *} p<0.01$ for $15 \%, 10 \%$, $5 \%$ and $1 \%$ significant levels respectively

Table 5.1: Pesaran's Panel Unit Root Test Results (10 Countries)

\begin{tabular}{lllll}
\hline & \multicolumn{2}{c}{ Intercept only } & \multicolumn{2}{c}{ Intercept and trend } \\
\hline Variables & $\mathrm{lag}=1$ & $\mathrm{lag}=2$ & $\mathrm{lag}=1$ & $\mathrm{lag}=2$ \\
\hline \hline House price & -0.984 & -1.421 & -1.384 & -1.984 \\
MPP & 2.610 & 2.610 & 1.700 & 1.700 \\
OFDI & $-3.333^{* * * *}$ & $-2.827^{* * * *}$ & $-3.633^{* * * *}$ & $-3.106^{* * * *}$ \\
GDP & $-2.698^{* * * *}$ & $-2.100^{* * *}$ & $-3.041^{* * * *}$ & -2.427 \\
$R$ & -1.235 & -1.364 & -1.833 & -1.789 \\
$B C$ & -0.320 & -0.581 & -0.822 & -1.121 \\
\hline
\end{tabular}

The Pesaran (2006) test is performed using the Stata pescadf command written by Piotr Lewandoski.

The statistical significance are denoted as ${ }^{*} p<0.15,{ }^{* *} p<0.10,{ }^{* * *} p<0.05,{ }^{* * * *} p<0.01$ for $15 \%, 10 \%$,

$5 \%$ and $1 \%$ significant levels respectively

Table 5.2: Pesaran's Panel Unit Root Test Results (21 Countries) 


\subsection{Estimation Results}

First, we show the result for the 10 advanced countries where China invests most on real estate. Next, we show the results for the 21 countries. Table 5.3 shows the result for all the 10 countries we considered. The countries are Australia, Canada, Finland, France, Germany, Italy, Spain, Switzerland, United Kingdom and United States. MPP is an index of macro-prudential policy constructed to be 1 if either LTV or PTI limit is tightened, -1 if either of the constraints is loosened and 0 otherwise. We consider three models. Following Akinci et al (2018), we use overall macroprudential policy measures in our analysis because macroprudential measures can affect house price not just in the quarter it was implemented but in subsequent quarters and it is difficult to know when macroprudential regulations impose binding constraints on borrowers. In model I, the independent variables are the lags of housing price, MPP, OFDI, GDP, bank crisis and policy rate. Model II is similar to model I except that OFDI is excluded as an independent variable. The regression result shows that borrower based measures have significant negative effect on house prices which suggests that macro-prudential policy measures have significant mitigating effect on house price inflation even in the presence of capital inflow. The results show that Chinese OFDI has a significant positive association with house prices. 5.3. The re-

sult also shows that bank crisis and policy rate have significant negative relationship with house prices. 


\begin{tabular}{|c|c|c|}
\hline Variables & Model I & Model II \\
\hline & \multicolumn{2}{|c|}{ House Prices $(\triangle H P)$} \\
\hline \multirow[t]{2}{*}{$\triangle M P P_{t-1}$} & $-0.5686^{* * * *}$ & $-0.5673^{* * * *}$ \\
\hline & $(0.2770)$ & $(0.2803)$ \\
\hline \multirow[t]{2}{*}{$\Delta H P_{t-1}$} & $0.7852^{* * * *}$ & $0.7865^{* * * *}$ \\
\hline & $(0.0315)$ & $(0.0316)$ \\
\hline \multirow[t]{2}{*}{$O F D I_{t-1}$} & $0.0032^{* * * *}$ & \\
\hline & $(0.0001)$ & \\
\hline \multirow[t]{2}{*}{$G D P_{t-1}$} & $0.1089^{* * * *}$ & $0.1130^{* * * *}$ \\
\hline & $(0.0321)$ & $(0.0317)$ \\
\hline \multirow[t]{2}{*}{$\Delta R_{t-1}$} & $-0.0443^{* * * *}$ & $-0.0462^{* * * *}$ \\
\hline & $(0.0267)$ & $(0.0268)$ \\
\hline \multirow[t]{2}{*}{$\Delta B C_{t-1}$} & $-0.1442^{* * * *}$ & $-0.1390^{* * * *}$ \\
\hline & $(0.1741)$ & $(0.1749)$ \\
\hline
\end{tabular}

Standard errors in parentheses

${ }^{*} p<0.15,{ }^{* *} p<0.10,{ }^{* * *} p<0.05,{ }^{* * * *} p<0.01$

Table 5.3: Regression results for dynamic panel data model

In table 5.4 we present the results of estimating equation (5.3) for all the 21 countries. The regression results show that the macro prudential policy measures, and housing price are negatively correlated and the impact is significant. OFDI has a significant but small positive effect on the house price. The results are qualitatively similar to the results in the previous analysis, but the impacts are quantitatively 
different.

\begin{tabular}{lll}
\hline Variables & Model I & Model II \\
\hline$\Delta M P P_{t-1}$ & $-1.3670^{* * *}$ & House Prices $(\Delta H P)$ \\
\hline & $(0.3259)$ & $-1.3540^{* * * *}$ \\
$\Delta H P_{t-1}$ & $0.5080^{* * * *}$ & $0.3171)$ \\
& $(0.0012)$ & $\left(0.5070^{* * * *} .0015\right)$ \\
$O F D I_{t-1}$ & $0.0007^{* * * *}$ & \\
& $(0.0001)$ & $0.6090^{* * * *}$ \\
$G_{t-1}$ & $0.5970^{* * * *}$ & $(0.0446)$ \\
& $(0.0430)$ & $-0.122^{* *}$ \\
$\Delta B C_{t-1}$ & $-0.147^{* * *}$ & $(0.0216)$ \\
& $(0.0200)$ & $-0.687^{* * * *}$ \\
& $-0.742^{* * *}$ & $(0.3025)$ \\
\hline
\end{tabular}

Standard errors in parentheses

${ }^{*} p<0.15,{ }^{* *} p<0.10,{ }^{* * *} p<0.05,{ }^{* * * *} p<0.01$

Table 5.4: Regression results for dynamic panel data model

\subsection{Simulation Results}

In our model, we have a panel data with finite sample size, large $\mathrm{T}$ and small $\mathrm{N}$, and predetermined regressors. Panel techniques like first-differenced GMM, e.g. Arellano 
and Bond (1991) are often used to estimate this type of model. However, GMM often entails finite sample biases, especially when the instruments are weak. Also, such estimation methods do not allow for interactive fixed effects. In this section, we assess the extent to which interactive fixed effects can cause bias in the least squares estimate in finite sample through a small scale Monte Carlo simulation. The model is a dynamic panel model with one regressor. Following Moon and Weidner (2016), we consider an $\operatorname{AR}(1)$ model with one factor $(R=1)$;

$$
Y_{i t}=\rho Y_{i, t-1}+\lambda_{i} f_{t}+e_{i, t}
$$

which we estimate as an interactive fixed effect model with no distributional assumptions made on $\lambda_{i}$ and $f_{t}$. We are interested in estimating the parameter $\rho$. We first consider the OLS estimator which ignores the presence of factors, the least squares estimator with interactive fixed effects and its bias corrected versions for different combination of sample sizes are shown in tables B.1, B.2 and B.3. The bias corrected versions are denoted as LSBC1 and LSBC2. The former corrects for bias due to cross-sectional heteroscedasticity of errors, time-serial heteroscedasticity and timeserial correlation of errors; and the latter in addition corrects the bias due to the predetermined regressor. We use $\rho=0.3$ in our simulations. The simulation results show that the model exhibits lower size distortion for large $\mathrm{T}$, small $\mathrm{N}$ than for small T large $\mathrm{N}$ and bias is lowest when $\mathrm{R}=1$ in this particular simulation. The results also show that the lagged regressor introduces bias due to predetermined regressor and 


\begin{tabular}{|c|c|c|c|c|c|}
\hline Estimator & $\mathrm{R}$ & $\rho$ & Bias & Std & RMSE \\
\hline \multirow{5}{*}{$\mathrm{T}=56, \mathrm{~N}=10$} & 1 & 0.3033 & -0.0033 & 0.0578 & 0.0579 \\
\hline & 2 & 0.2965 & -0.0035 & 0.0542 & 0.0543 \\
\hline & 3 & 0.2942 & -0.0058 & 0.0627 & 0.0629 \\
\hline & 4 & 0.2904 & -0.0095 & 0.0741 & 0.0747 \\
\hline & 5 & 0.2861 & -0.0139 & 0.0903 & 0.0913 \\
\hline \multirow{5}{*}{$\mathrm{T}=56, \mathrm{~N}=21$} & 1 & 0.2993 & -0.0007 & 0.0338 & 0.0338 \\
\hline & 2 & 0.2963 & -0.0037 & 0.0327 & 0.0330 \\
\hline & 3 & 0.2940 & -0.0060 & 0.0369 & 0.0374 \\
\hline & 4 & 0.2916 & -0.0084 & 0.0415 & 0.0423 \\
\hline & 5 & 0.2884 & -0.0116 & 0.0469 & 0.0484 \\
\hline \multirow{5}{*}{$\mathrm{T}=30, \mathrm{~N}=100$} & 1 & 0.2942 & -0.0058 & 0.0226 & 0.0233 \\
\hline & 2 & 0.2860 & -0.0140 & 0.0227 & 0.0266 \\
\hline & 3 & 0.2733 & -0.0267 & 0.0286 & 0.0391 \\
\hline & 4 & 0.2519 & -0.0481 & 0.0384 & 0.0615 \\
\hline & 5 & 0.2158 & -0.0842 & 0.0511 & 0.0985 \\
\hline \multirow{5}{*}{$\mathrm{T}=100, \mathrm{~N}=100$} & 1 & 0.2993 & -0.0007 & 0.0103 & 0.0103 \\
\hline & 2 & 0.2987 & -0.0013 & 0.0102 & 0.0103 \\
\hline & 3 & 0.2981 & -0.0019 & 0.0106 & 0.0108 \\
\hline & 4 & 0.2975 & -0.0025 & 0.0112 & 0.0114 \\
\hline & 5 & 0.2967 & -0.0033 & 0.0117 & 0.0122 \\
\hline
\end{tabular}

Table 5.5: Bias corrected (LSBC2)least squares estimates for different sample sizes, $\rho=0.3$ 
bias corrected estimators produce better results. The results show that our sample size does not lead to size distortion and bias corrected estimates are more accurate for $\mathrm{R}=1$. In table 5.5 , we consider different values of $\mathrm{T}$ and $\mathrm{N}$. For $\mathrm{T}=56$ and $\mathrm{N}=10$, the model estimates the parameter with little bias. The bias is larger for large $\mathrm{N}$ and small $\mathrm{T}$ as shown in the table for values when $\mathrm{T}=30$ and $\mathrm{N}=100$.

\subsection{Conclusions}

In this paper, the impact of foreign capital inflows on house price movements in 21 advanced countries that use macroprudential policy measures is investigated using a dynamic panel model with interactive fixed effects. It is found that house prices are positively affected by capital inflows but the impact is quantitatively small. Despite the complexities and difficulties of constructing macroprudential policy data, our analysis shows that house prices are affected more by macroprudential policy measures than by OFDI in the domestic real estate sectors of these countries. Our results suggest that Chinese investors are helping in driving the real estate market in the countries where they invest more, but the prices could be controlled by using domestic macroprudential policy measures as the impact of the OFDI is relatively small. 


\section{Chapter 6}

\section{CONCLUSION}

This dissertation studies the role of financial frictions in DSGE models with durable goods and sticky prices, and how key economic variables respond in such an environment to monetary policy shocks. Chapter 1 reconfirms the empirical evidence on the response of monetary and fiscal policy rules using more recent data for the US and Canada. As shown, real GDP and both durable and non-durable consumptions fall in response to the monetary tightening. The decline in durable consumption is higher than decline in non-durable consumption and is about 4 to 5 times larger than the decline non-durables. Real household debt also declines.

In Chapter 2, we show that agency costs due to information asymmetry in lending and credit friction with consumption loan, explains the behaviour of durables in a way that is consistent with empirical evidence when there is moderate level of price stickiness in the durables. Our results also show that credit friction does not make co-movement problem more difficult to solve. A rise in agency cost increases the loan to value ratio which induces a rise in user cost of durables and a small rise in shadow value of durables for borrowers relative to the models without agency cost. The borrowers facing higher user cost reduce investment in durables and the savers facing monitoring cost also reduce durable investment relative to the model with only credit friction. The net effect is a fall in aggregate investment.

In chapter 3, we extended the two sector DSGE sticky price model with durable

and non-durable goods to include both collateral, LTV, and income, PTI, constraints 
on borrowers. The two credit constraints are randomly combined by shocks to the borrowers' labour income and determine jointly the amount of collateralized loans that the borrowers can obtain. We used this model to resolve the well-known comovement problem between durable and non-durable consumption following a monetary contraction, when durable prices are fully flexible.

In this context, an increase in the nominal interest rate increases the threshold level of the labour shock and results in a greater fraction of borrowers with a binding PTI constraint. As a result there is a fall in the relative price of durables and a sharp decline in the amount of collateralized loans to the borrowers, who cut back on their purchases of durables, along with the relatively more expensive non-durables. The lenders decrease their purchases of non-durables but increase their purchases of durables by an amount less than the fall in durable purchases by borrowers. As a consequence, aggregate durable purchases fall and co-move positively with nondurables as in the data. Aggregate output also declines and the nominal interest rate rises consistent with the empirical evidence. Thus the model resolves the co-movement problem in an empirically adequate way, based solely on credit frictions that include PTI limits on borrowers. Our results imply that financial frictions on the demand side of the economy are still important in re-solving the co-movement problem even with flexible durable prices, and complement to a large extend the results from other strands of literature that rely on supply side frictions or non-separable preferences.

The predictions of the model developed in the dissertation square well with the empirical evidence, and thus may help policy makers in arriving at correct decisions regarding the effects of their policies in the durable goods market and the economy as a whole. It adds new insights to the literature by evaluating how general equilibrium models with financial frictions can explain better the empirical evidence regarding 
the reaction of key macroeconomic variables, such as durable and nondurable goods, output, and interest rates to monetary shocks. Also, it sheds light on how different combinations of financial frictions, such as collateral and income constraints affect the asset price of durables and the amount of debt or credit growth in the economy. Further, it helps in studying whether monetary authorities should include indicators of financial vulnerability such as credit growth in their monetary policy rules. 


\section{Appendices}




\section{Appendix A}

\section{SOLVING THE MODEL WITH ADJUSTMENT COSTS TO DURABLES}

In this case, the Lagrangian for the borrowers' problem is

$$
\begin{gathered}
L=\sum_{t=0}^{\infty}\left[\beta ^ { t } \left[\left(\log \left(X_{t}\right)-\frac{\nu N_{t}^{1+\varphi}}{1+\varphi}\right)\right.\right. \\
+\lambda_{t}\left(b_{t}+\frac{W_{t}}{P_{c, t}} N_{t}+\frac{T_{t}}{P_{c, t}}-C_{t}-q_{t} I_{t}-R_{t-1} \frac{b_{t-1}}{\pi_{c, t}}\right) \\
+\lambda_{t} \psi_{t}\left(b_{t}^{p t i} F\left(\bar{e}_{t}\right)+b_{t}^{l t v}\left(1-F\left(\bar{e}_{t}\right)\right)-b_{t}\right) \\
\left.\left.+\lambda_{t} \varrho_{t}\left(\left(1-\frac{\Theta}{2}\left(\frac{I_{t}}{I_{t-1}}-1\right)^{2}\right) I_{t}\right)+(1-\delta) D_{t-1}-D_{t}\right]\right]
\end{gathered}
$$

The optimality conditions are

$$
\begin{gathered}
\frac{\partial L}{\partial N_{t}} \Rightarrow \nu N_{t}^{\varphi}=-U_{n, t}=\lambda_{t} \frac{W_{t}}{P_{c, t}}\left[1+\psi_{t} \frac{\kappa_{2}}{R_{t}-1+\tau} F_{e}\left(\bar{e}_{t}\right)\right] \\
\frac{\partial L}{\partial C_{t}} \Rightarrow U_{c, t}=\lambda_{t} \\
\frac{\partial L}{\partial b_{t}} \Rightarrow \psi_{t}=1-\beta E_{t}\left[\frac{U_{c, t+1}}{U_{c, t}} \frac{R_{t}}{\pi_{c, t+1}}\right]
\end{gathered}
$$




$$
\begin{gathered}
\frac{\partial L}{\partial D_{t}} \Rightarrow \varrho_{t} \lambda_{t}=U_{d, t}+\beta(1-\delta) E_{t} \varrho_{t+1} \lambda_{t+1}+U_{c, t} \psi_{t} q_{t}\left[\frac{(1-\chi)(1-\delta) E_{t}\left(\pi_{d, t+1}\right)}{R_{t}}\left(1-F_{e}\left(\bar{e}_{t}\right)\right)\right] \\
\frac{\partial L}{\partial I_{t}} \Rightarrow U_{c, t} q_{t} \\
=\lambda_{t} \varrho_{t}\left(\left(1-\frac{\Theta}{2}\left(\frac{I_{t}}{I_{t-1}}-1\right)^{2}\right)-\Theta\left(\frac{I_{t}}{I_{t-1}}-1\right) \frac{I_{t}}{I_{t-1}}\right) \\
+\beta E_{t}\left(\lambda_{t+1} \varrho_{t+1} \Theta\left(\frac{I_{t+1}}{I_{t}}-1\right)\left(\left(\begin{array}{c}
I_{t+1} \\
I_{t}
\end{array}\right)\right)^{2}\right)
\end{gathered}
$$

The Lagrangian for the savers' problem is

$$
\begin{gathered}
L=\sum_{t=0}^{\infty}\left[\gamma ^ { t } \left(\log \left(\tilde{X}_{t}\right)-\frac{\nu \tilde{N}_{t}^{1+\varphi}}{1+\varphi}\right.\right. \\
+\tilde{\lambda}_{t}\left(\tilde{b}_{t}+\frac{\tilde{W}_{t}}{P_{c, t}} \tilde{N}_{t}+\frac{\tilde{T}_{t}}{P_{c, t}}+\frac{\tilde{\Gamma}_{c, t}}{1-\omega}+\frac{q_{t} \tilde{\Gamma}_{d, t}}{1-\omega}-\tilde{C}_{t}-q_{t} \tilde{I}_{t}-R_{t-1} \frac{\tilde{b}_{t-1}}{\pi_{c, t}}\right) \\
\left.+\tilde{\varrho}_{t} \tilde{\lambda}_{t}\left((1-\delta) \tilde{D}_{t-1}+\left(1-\frac{\Theta}{2}\left(\frac{\tilde{I}_{t}}{\tilde{I}_{t-1}}-1\right)^{2}\right) \tilde{I}_{t}-\tilde{D}_{t}\right)\right] .
\end{gathered}
$$

The optimality conditions for this optimization problem are

$$
\begin{gathered}
\tilde{U}_{c, t}=\tilde{\lambda}_{t} \\
\frac{-\tilde{U}_{n, t}}{\tilde{\lambda}_{t}}=\frac{\tilde{W}_{t}}{P_{c, t}} \\
\tilde{U}_{c, t}=\gamma E_{t}\left\{\frac{\tilde{U}_{c, t+1}}{\tilde{\pi}_{c, t+1}} R_{t}\right\} \\
\tilde{\varrho}_{t} \tilde{\lambda}_{t}=\tilde{U}_{d, t}+(1-\delta) \gamma E_{t} \tilde{\lambda}_{t+1} \tilde{\varrho}_{t+1} \\
\tilde{U}_{c, t} q_{t}=\tilde{\varrho}_{t} \tilde{\lambda}_{t}\left(\left(1-\frac{\Theta}{2}\left(\frac{\tilde{I}_{t}}{\tilde{I}_{t-1}}-1\right)^{2}\right)-\Theta\left(\frac{\tilde{I}_{t}}{\tilde{I}_{t-1}}-1\right) \frac{\tilde{I}_{t}}{\tilde{I}_{t-1}}\right) \\
+\gamma E_{t}\left(\tilde{\varrho}_{t+1} \tilde{\lambda}_{t} \Theta\left(\frac{\tilde{I}_{t+1}}{\tilde{I}_{t}}-1\right)\left(\left(\begin{array}{c}
\tilde{I}_{t+1} \\
\tilde{I}_{t}
\end{array}\right)\right)^{2}\right) .
\end{gathered}
$$


Appendix B

RESULTS FROM MONTE-CARLO SIMULATIONS

\begin{tabular}{|c|c|c|c|c|c|}
\hline Estimator & $\mathrm{R}$ & $\rho$ & Bias & Std & RMSE \\
\hline LS & $\begin{array}{l}0 \\
1 \\
2 \\
3 \\
4\end{array}$ & $\begin{array}{l}0.6095 \\
0.2815 \\
0.2773 \\
0.2743 \\
0.2709\end{array}$ & $\begin{array}{c}0.3095 \\
-0.0185 \\
-0.0227 \\
-0.0257 \\
-0.0291\end{array}$ & $\begin{array}{l}0.0568 \\
0.0344 \\
0.0337 \\
0.0391 \\
0.0451\end{array}$ & $\begin{array}{l}0.3147 \\
0.0391 \\
0.0406 \\
0.0468 \\
0.0537\end{array}$ \\
\hline LSBC1 & $\begin{array}{l}1 \\
2 \\
3 \\
4 \\
5\end{array}$ & $\begin{array}{l}0.2809 \\
0.2770 \\
0.2740 \\
0.2706 \\
0.2662\end{array}$ & $\begin{array}{l}-0.0191 \\
-0.0230 \\
-0.0260 \\
-0.0294 \\
-0.0338\end{array}$ & $\begin{array}{l}0.0344 \\
0.0339 \\
0.0394 \\
0.0456 \\
0.0529\end{array}$ & $\begin{array}{l}0.0393 \\
0.0409 \\
0.0472 \\
0.0542 \\
0.0628\end{array}$ \\
\hline LSBC2 & $\begin{array}{l}1 \\
2 \\
3 \\
4 \\
5\end{array}$ & $\begin{array}{l}0.2993 \\
0.2963 \\
0.2940 \\
0.2916 \\
0.2884\end{array}$ & $\begin{array}{r}-0.0007 \\
-0.0037 \\
-0.0060 \\
-0.0084 \\
-0.0116\end{array}$ & $\begin{array}{l}0.0338 \\
0.0327 \\
0.0369 \\
0.0415 \\
0.0469\end{array}$ & $\begin{array}{l}0.0338 \\
0.0330 \\
0.0374 \\
0.0423 \\
0.0484\end{array}$ \\
\hline
\end{tabular}

Table B.1: Interactive Effect Estimator, One factor, $\rho=0.3, \mathrm{~N}=21, \mathrm{~N}=56$ 


\begin{tabular}{|c|c|c|c|c|c|}
\hline Estimator & $\mathrm{R}$ & $\rho$ & Bias & Std & RMSE \\
\hline \multirow{5}{*}{ LS } & 0 & 0.6074 & 0.3074 & 0.0451 & 0.3107 \\
\hline & 1 & 0.2587 & -0.0413 & 0.0231 & 0.0473 \\
\hline & 2 & 0.2458 & -0.0542 & 0.0256 & 0.0599 \\
\hline & 3 & 0.2250 & -0.0750 & 0.0365 & 0.0834 \\
\hline & 4 & 0.1900 & -0.1100 & 0.0533 & 0.1222 \\
\hline \multirow{5}{*}{ LSBC1 } & 1 & 0.2588 & -0.0412 & 0.0231 & 0.0472 \\
\hline & 2 & 0.2453 & -0.0547 & 0.0261 & 0.0606 \\
\hline & 3 & 0.2237 & -0.0763 & 0.0375 & 0.0850 \\
\hline & 4 & 0.1876 & -0.1124 & 0.0548 & 0.1250 \\
\hline & 5 & 0.1290 & -0.1710 & 0.0747 & 0.1866 \\
\hline \multirow{5}{*}{ LSBC2 } & 1 & 0.2942 & -0.0058 & 0.0226 & 0.0233 \\
\hline & 2 & 0.2860 & -0.0140 & 0.0227 & 0.0266 \\
\hline & 3 & 0.2733 & -0.0267 & 0.0286 & 0.0391 \\
\hline & 4 & 0.2519 & -0.0481 & 0.0384 & 0.0615 \\
\hline & 5 & 0.2158 & -0.0842 & 0.0511 & 0.0985 \\
\hline
\end{tabular}

Table B.2: Interactive Effect Estimator, One factor, $\rho=0.3, \mathrm{~N}=100, \mathrm{~N}=30$ 117 


\begin{tabular}{|c|c|c|c|c|c|}
\hline Estimator & $\mathrm{R}$ & $\rho$ & Bias & Std & RMSE \\
\hline \multirow{5}{*}{ LS } & 0 & 0.6165 & 0.3165 & 0.0296 & 0.3179 \\
\hline & 1 & 0.2878 & -0.0122 & 0.0103 & 0.0160 \\
\hline & 2 & 0.2869 & -0.0131 & 0.0105 & 0.0168 \\
\hline & 3 & 0.2860 & -0.0140 & 0.0112 & 0.0180 \\
\hline & 4 & 0.2849 & -0.0151 & 0.0121 & 0.0194 \\
\hline \multirow{5}{*}{ LSBC1 } & 1 & 0.2878 & -0.0122 & 0.0103 & 0.0160 \\
\hline & 2 & 0.2869 & -0.0131 & 0.0105 & 0.0168 \\
\hline & 3 & 0.2859 & -0.0141 & 0.0113 & 0.0180 \\
\hline & 4 & 0.2848 & -0.0152 & 0.0122 & 0.0195 \\
\hline & 5 & 0.2837 & -0.0163 & 0.0132 & 0.0210 \\
\hline \multirow{5}{*}{ LSBC2 } & 1 & 0.2993 & -0.0007 & 0.0103 & 0.0103 \\
\hline & 2 & 0.2987 & -0.0013 & 0.0102 & 0.0103 \\
\hline & 3 & 0.2981 & -0.0019 & 0.0106 & 0.0108 \\
\hline & 4 & 0.2975 & -0.0025 & 0.0112 & 0.0114 \\
\hline & 5 & 0.2967 & -0.0033 & 0.0117 & 0.0122 \\
\hline
\end{tabular}

Table B.3: Interactive Effect Estimator, One factor, $\rho=0.3, \mathrm{~N}=100, \mathrm{~N}=100$ 118 
Appendix C

\section{COUNTRIES CONSIDERED}

The countries we considered for the effectiveness of macroprudential policies are Australia, Belgium, Canada, Denmark, Finland, France, Germany, Hong Kong, Ireland,

Israel, Italy, Japan, Korea, New Zealand, Singapore, Spain, Sweden, Switzerland, Thailand UK and US. 


\section{Appendix D}

\section{DATA SOURCES FOR CHAPTER 4}

The macroprudential data used in this paper come from the policy action table from the Bank for International Settlements, cerutti et al. (2015) and we also use information from national sources to update the database to 2016. We crossed-checked our

database against country database by Cerutti et al (2015), Lim etal (2011) and Shim et al (2013). Following Akinci et al (2018), we construct the database for policies that are targeted at the housing market. The sources of the other variables used in our analysis are shown in table D.1. 


\begin{tabular}{cl}
\hline \hline Variables & Source \\
\hline \hline GDP & Annual data from World bank, WDI. The \\
& data is transformed to quarterly frequency \\
& using interpolation method \\
Policy rate & Quarterly data from BIS. \\
OFDI & Annual data National Bureau of Statistics, \\
& China. Transformed to quarterly data using \\
& interpolation method \\
Bank Crisis & Indicates Systemic Banking Crisis per \\
& Laeven and Fabian Valencia (2013), updated \\
& to 2016 using national data \\
& Quarterly data from BIS supplemented by \\
House Price & national data
\end{tabular}

Table D.1: Macroeconomic Variables 


\section{REFERENCES}

[1] Akinci, O., Olmstead-Rumsey, 2018. How effective are macroprudential policies? An empirical investigation. Journal of Financial Intermediation 33, 33-57.

[2] Arellano, M. and Bond, S., 1991. "Some tests of specification for panel data: Monte Carlo evidence and an application to employment equations". Review of Economic Studies, 58, 277-297.

[3] Bai, J., 2009. Panel data models with interactive fixed effects. Econometrica, 77, 1229-1279.

[4] Blundell, R. and Bond, S., 2000. "GMM estimation with persistent panel data: an application to production functions." Econometric Reviews, 19(3), 321-340.

[5] Barsky, R.B., C.L. House, and M.S. Kimball, 2003, "Do flexible durable goods prices undermine sticky price models", National Bureau of Economic Research Working Paper 9832.

[6] Barsky, R.B, C.L. House, and M.S. Kimball, 2007, "Sticky price models and durable goods", American Economic Review 97, 984-998.

[7] Bernanke, B., M. Gertler, and S. Gilchrist. 1999. "The Financial Accelerator in a Quantitative Business Cycle Framework." In Handbook of Macroeconomics .Vol. 1, ed. J. Taylor and M. Woodford. Amsterdam: North-Holland.

[8] Bernanke, B. S., and M. L. Gertler 1995, "Inside the Black Box: The Credit Channel of Monetary Policy Transmission". Journal of Economic Perspectives, 9, 27-48. 
[9] Bouakez, H., Cardia, E. and Ruge-Murcia, J., 2011, "Durable goods, intersectoral linkages and monetary policy". Journal of Economic Dynamics and Control 35(5), 730-745

[10] Calza, A., Monacelli, T. and Stracca, L., 2013. "Housing Finance and Monetary Policy." Journal of the European Economic Association, 11, 101-122.

[11] Canova, F. and Pappa, P., 2007. Price Differentials in Monetary Unions: The Role of Fiscal Shocks. Economic Journal, 117, 2007, 713-737.

[12] Carlstrom, C. T. and Fuerst, T. S. 2010. Nominal rigidities, residential investment, and adjustment costs. Macroeconomic Dynamics, 14:136 - 148.

[13] Cerutti, E., et al.,2017. The use and effectiveness of macroprudential policies: New evidence. J. Financial Stability, 28, 203-224

[14] Chow, H.K., Lim, G. C., Xie, T., 2017. "Macroprudential policies in global cities amid rising Chinese outbound direct investments". School of Economics, Singapore Management University, Singapore working paper

[15] Christiano, L., Eichenbaum, M.,Evans,1999. In: Taylor, J.B., Woddford, M(Eds.), Handbook of Monetary Economics. Elsevier, Amsterdam,pp.65-148.

[16] Christiano, L. J., M. Eichenbaum, and C. L. Evans 2005. "Nominal Rigidities and the Dynamic Effects of a Shock to Monetary Policy," Journal of Political Economy, 113:1, 1-45

[17] Claessens, S., Ghosh, S., Mihet, R., 2013. "Macroprudential policies to mitigate financial system vulnerabilities". J. Int. Money Financ. 39, 153-185. 
[18] Corbae, D. and E. Quintin 2013. "Leverage and the Foreclosure Crisis," Tech. rep., National Bureau of Economic Research.

[19] Craig, R.S., Hua, C., 2011. "Determinants of Property Prices in Hong Kong SAR: Implications for Policy". IMF Working Papers 11/277. International Monetary Fund .

[20] DellAriccia, G., Igan, D., Laeven, L., Tong, H., 2012. "Policies for Macrofinancial Stability: How to Deal with Credit Booms. IMF Staff Discussion Note 12/06. International Monetary

[21] Erceg, C. J., D. W. Henderson, and A. T. Levin ,2006. Optimal monetary policy with durable consumption goods, Journal of Monetary Economics, 53(7), 13411359.

[22] Fisher, Irving. "The Debt-Deflation Theory of Great Depressions." Econometrica, 1933,1(4), pp. 337-57.

[23] Forlati, C., and L. Lambertini, 2011. "Risky Mortgages in a DSGE Model". International Journal of Central Banking, Vol. 7(1), pp. 285-336.

[24] Greenwald D. 2016, "The Mortgage Credit Channel of Macroeconomic Transmission". MIT working paper.

[25] D. Holtz-Eakin, W. Newey, H.S. Rosen, 1988. "Estimating vector autoregressions with panel data", Econometrica, 6 (1988), pp. 1371-1395

[26] Iacoviello, M. 2005. "House Prices, Borrowing Constraints and Monetary Policy in the Business Cycle," American Economic Review, 95(3), 739-764. 
[27] Iacoviello, M. and Neri, S. 2010. "Housing Market Spillovers: Evidence From an Estimated DSGE Model". American Economic Journal: Macroeconomics, 2, $125-164$.

[28] Igan, D., Kang, H., 2011. "Do loan-to-value and debt-to-income limits work? Evidence from Korea". IMF Working paper 11/297.

[29] Justiniano,A.,Primicerib, G., and Tambalottie, A. 2015. "Household leveraging and deleveraging", Review of Economic Dynamics 18, 3-20

[30] Juwai 2017,"Chinese global property investment report"

[31] Kim, K. and Katayama, M., 2013. "Non-separability and sectoral co-movement in a sticky price model," Journal of Economic Dynamics and Control, Elsevier, vol. 37(9), pages 1715-1735.

[32] Kim, D. and OKa, T. 2014. " Divorce Law Reforms and Divorce Rates in the U.S.: An Interactive Fixed Effects Approach". Journal of Applied Econometrics 29(2), 1099-1255

[33] Kwan C. H, Lim, G. and Xie, T. 2017. "Macroprudential policies in global cities amid rising Chinese outbound direct investments"

[34] Liao, S. and Chen, B. 2014 "Capital, Credit Constraints and the Comovement between Consumer Durables and Non-durables", Journal of Economic Dynamics \& Control 39, 127-139

[35] Lim, C. H., Costa, A., Columba, F., Kongsamut, P., Otani, A., Saiyid, M., Wezel, T., Wu, X., 2011. "Macroprudential Policy: What Instruments and How 
to Use Them? Lessons from Country Experiences". IMF Working Papers 11/238, International Monetary Fund.

[36] Lu, X. and Su, L. 2016. "Shrinkage estimation of dynamic panel data models with interactive fixed effects". Journal of Econometrics 1902016 148-175

[37] Mendoza, E. , 2010, "Sudden Stops, Financial Crises, and Leverage", American Economic Review 100, 1941-1966

[38] Mian, A. and Sufi, A. 2011, "House Prices, Home Equity-Based Borrowing, and the U.S. Household Leverage Crisis , American Economic Review, 101: 21322156.

[39] Monacelli T., 2009, "New Keynesian models, durable goods, and collateral constraints"

[40] Moon, H., Weidner, M., 2015. Linear regression for panel with unknown number of factors as interactive fixed effects. Econometrica 83, 1543-1579.

[41] Moon, H., Weidner, M., 2017. "Dynamic linear panel regression models with interactive fixed effects". Econometric Theory

[42] Moore, J. and Kiyotaki, N. 1997. "Credit Cycles", Journal of Political Economy $105,211-248$.

[43] Notarpietro, A.,and Siviero, S., 2015. "Optimal Monetary Policy Rules and House Prices: The Role of Financial Frictions", Journal of Money, Credit and Banking, Supplement to Vol. 47, No. 1 (March-April 2015)

[44] Shim, I., Bogdanova, B., Shek,J., Subelyte,A., 2103. "Database for policy actions on housing markets". BIS Quarterly Review, September 2013 . 
[45] Sterk, V., (2010), Credit frictions and the co-movement between durable and non-durable consumption, Journal of Monetary Economics 57, 217-225.

[46] Ohanian, L., Stockman, A. and Killian, L., 1995, The Effects of Real and Monetary Shocks in a Business Cycle Model with Some Sticky Prices. Journal of Money, Credit and Banking, 27 (4)

[47] Sudo, N., (2012), Sectoral co-movement, monetary-policy shock, and inputoutput structure, Journal of Money, Credit and Banking 44, 1225-1244.

[48] Tillmann, P. 2013. Capital inflows and asset prices: Evidence from emerging Asia. Journal of Banking and Finance 37(3), 717-729.

[49] Townsend, M 1979 "Optimal contracts and competitive markets with costly state verification". Journal of Economic theory 21(2), 266-293.

[50] Vandenbussche, Vogel and Detragiache, 2015. Macro-prudential Policies and Housing Prices - A New Database and Empirical Evidence for Central, Eastern and South-Eastern Europe, Journal of Money, Credit and Banking 